\title{
WestVirginiaUniversity
}

THE RESEARCH REPOSITORY @ WVU

Graduate Theses, Dissertations, and Problem Reports

2003

\section{In-situ, near real-time acquisition of particle movement in rotating drum coating equipment}

\author{
Sandeepa Sandadi \\ West Virginia University
}

Follow this and additional works at: https://researchrepository.wvu.edu/etd

\section{Recommended Citation}

Sandadi, Sandeepa, "In-situ, near real-time acquisition of particle movement in rotating drum coating equipment" (2003). Graduate Theses, Dissertations, and Problem Reports. 1897.

https://researchrepository.wvu.edu/etd/1897

This Thesis is protected by copyright and/or related rights. It has been brought to you by the The Research Repository @ WVU with permission from the rights-holder(s). You are free to use this Thesis in any way that is permitted by the copyright and related rights legislation that applies to your use. For other uses you must obtain permission from the rights-holder(s) directly, unless additional rights are indicated by a Creative Commons license in the record and/ or on the work itself. This Thesis has been accepted for inclusion in WVU Graduate Theses, Dissertations, and Problem Reports collection by an authorized administrator of The Research Repository @ WVU. For more information, please contact researchrepository@mail.wvu.edu. 


\title{
In-Situ, Near Real-Time Acquisition of Particle Movement in Rotating Drum Coating Equipment
}

\section{Sandeepa Sandadi}

\author{
Thesis Submitted to the \\ College of Engineering and Mineral Resources \\ at West Virginia University \\ in partial fulfillment of the requirements \\ for the degree of \\ Master of Science \\ in \\ Chemical Engineering \\ Richard Turton, Ph.D., Chair \\ Eugene V. Cilento, Ph.D. \\ Paula Jo Meyer Stout, Ph.D. \\ John W. Zondlo, Ph.D. \\ Department of Chemical Engineering \\ Morgantown, West Virginia \\ 2003
}

Keywords: Particle Coating, Rotating Drum Coaters, Video Imaging, Particle Tracking Technique, Particle Movement, Coating Uniformity 


\section{Abstract \\ In-Situ, Near Real-Time Acquisition of Particle Movement in Rotating Drum Coating Equipment \\ Sandeepa Sandadi}

The uniformity of coating applied to large particles and tablets in rotating-drum coating devices is of significant interest to the Pharmaceutical Industry, especially when the coating contains active material or provides a sustained release barrier for drug transport in a functional coat. As tablets move around the coating drum, they periodically spend time at the surface of the avalanching layer and pass through the spray zone. During this time they receive amounts of coating solution proportional to both the time spent in the spray zone and the area exposed to the spray. The purpose of this research was to quantify parameters that characterize the movement of tablets through the spray region. The three parameters of greatest interest are (1) Circulation time $\left(\tau_{\text {circ }}\right)$, defined as the time between successive particle sightings at the surface of the bed (2) Surface exposure time $\left(\tau_{\text {surface }}\right)$, defined as the time that a particle spends at the surface of the bed within the spray zone during each pass (3) Surface area of the tablet projected toward the spray source (nozzle) during each pass through the spray zone $\left(A_{t a b}\right)$.

In order to measure these parameters, a digital imaging system was developed and implemented to analyze images of the surface of the tumbling tablet bed. A single white tracer particle was introduced into a bed of black tablets. The tracer particle location and movement at the surface of the bed were analyzed using machine-vision software at a framing rate of $25 \mathrm{~Hz}$. Data for $\tau_{\text {circ }}$ and $\tau_{\text {surface }}$ were compared on a qualitative level with previous studies, and similar decreasing trends have been observed in both sets of data with increasing drum speeds, drum loadings, and tablet size. $A_{t a b}$ and surface velocities $\left(V_{y}\right)$ were also estimated for the movement of tablets through the spray zone in the 
rotating drum. This study proves that machine vision software and digital imaging can be applied successfully to the acquisition of tablet movement on the surface of moving beds in rotating drum coating equipment. The independent variables drum speed, drum loading, and tablet size showed significant effects $(\mathrm{p}<0.05$ ANOVA) on the dependent parameters, $\tau_{\text {circ }}, \tau_{\text {surface }}, A_{\text {tab }}$ and $V_{y}$. However baffles were not significant for the circulation times, but influenced the other parameters. Linear regression models were calculated for the dependent parameters assuming linear effects of all the independent variables. 


\section{Acknowledgements}

I wish to express my sincere gratitude to my research advisor Dr. Richard Turton for his guidance and encouragement during the course of this work. It has indeed been a great pleasure and honor to work with a gifted researcher and wonderful person like him. I am grateful to the members of my advisory committee, Dr. Eugene V. Cilento, Dr. John W. Zondlo, and Dr. Paula Jo Stout for their useful comments and suggestions. I would like to thank all the faculty and graduate students in the Department of Chemical Engineering for their help. My sincere thanks to James Hall for building the equipment and helping me troubleshoot problems during my work. I would also like to thank Linda Rogers and Bonita Helmick for handling all the paper work and being great friends.

I am grateful to Scott Montgomery, Coreco Imaging, Bedford, MA and Michael Kokkinos, Micro Disc, Inc., Yardley, PA for their initial help with Sherlock software and CCD camera. Glenn Redelman and Raymond Rosenberger, Mylan Pharmaceuticals, Morgantown, WV, deserve a special mention for making the black tablets necessary for this work. I wish to thank Schering-Plough Research Institute, Merck and Co, and National Science Foundation for their financial support for this project. I thank my entire family especially my parents, Hema Sandadi and Jagadeshwar Reddy Sandadi, and brother Sirish Sandadi for their unconditional love and support. I would also like to make a special mention of my grandfather Ramachandra Reddy Sandadi, whose encouraging words inspire me, everyday of my life. I finally thank God almighty and express my most sincere gratitude to all my friends for their support and patience during my research at WVU. 
I dedicate this thesis to my parents, Hema Sandadi and

Jagadeshwar Reddy Sandadi. 


\section{Table of Contents}

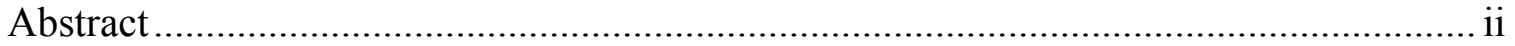

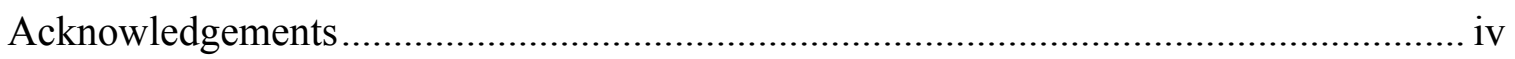

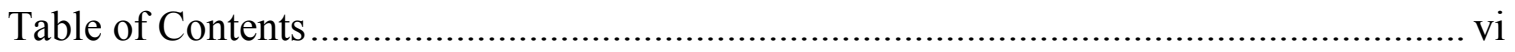

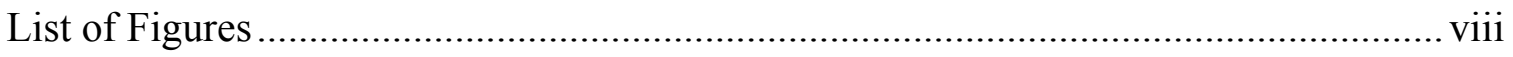

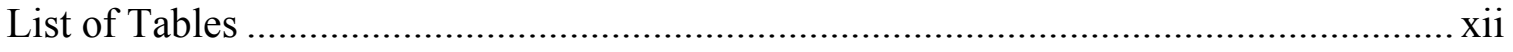

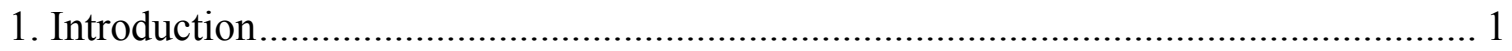

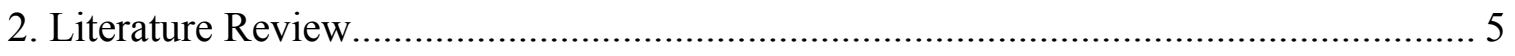

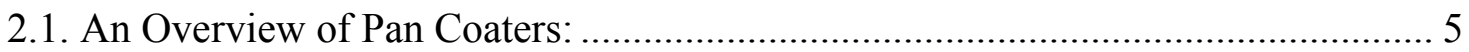

2.2. Techniques Used To Study Particle Motion within a Particulate Bed...................... 9

2.3 Dynamics of Mixing in Rotating Drums: ........................................................ 12

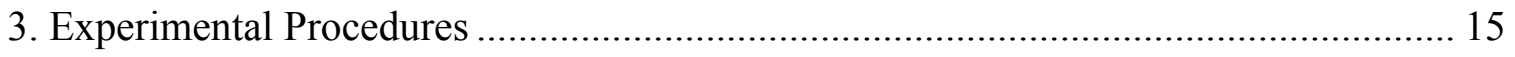

3.1 Set-up of Rotating Drum and Video Imaging Equipment ...................................... 15

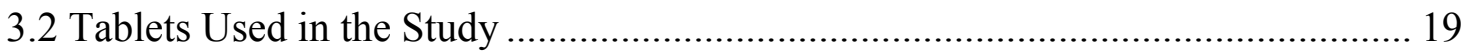

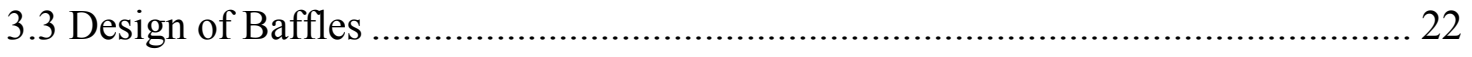

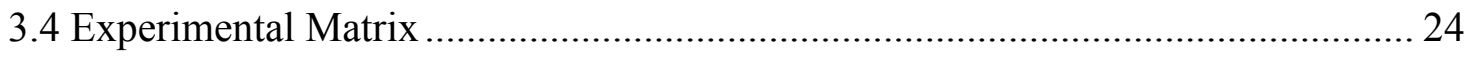

4. Calibration and Validation of Imaging System ………………............................... 26

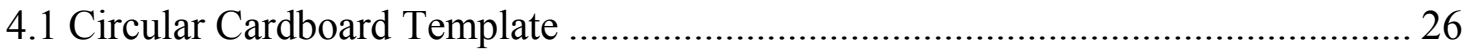

4.2 Two-Camera Set-up for Verification of Imaging System....................................... 30

4.3 Tablet Identification and Calculation of Parameters ………................................. 36

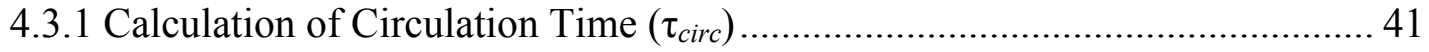

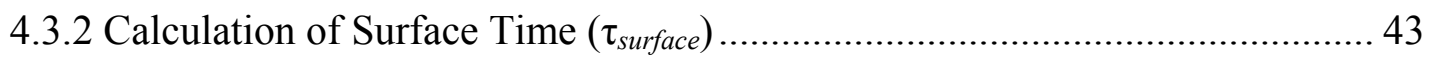

4.3.3 Calculation of Projected Surface Area $\left(A_{t a b}\right)$................................................ 43 


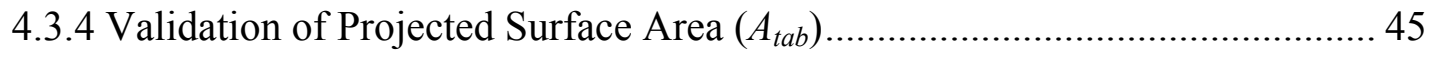

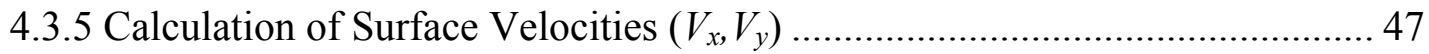

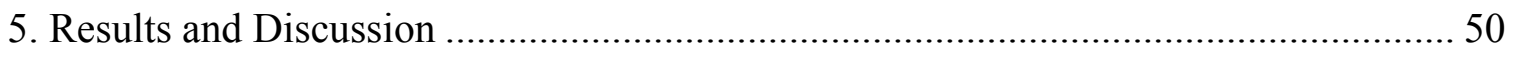

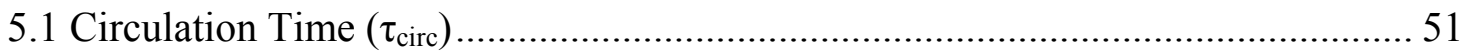

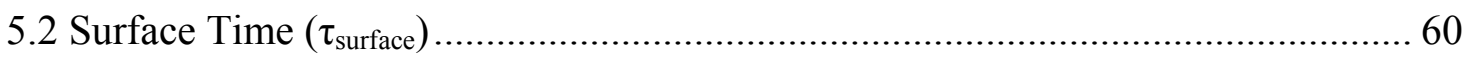

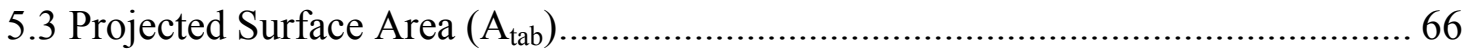

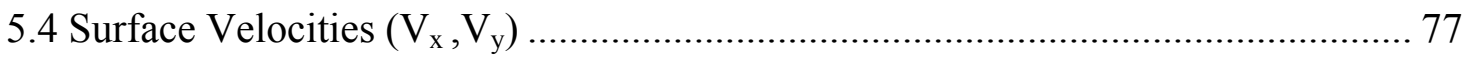

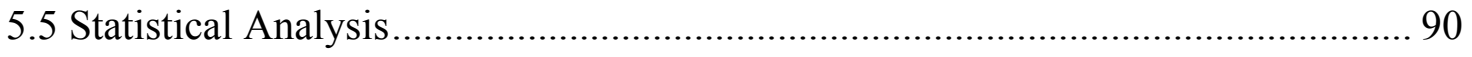

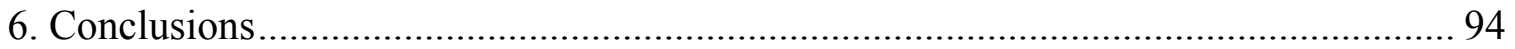

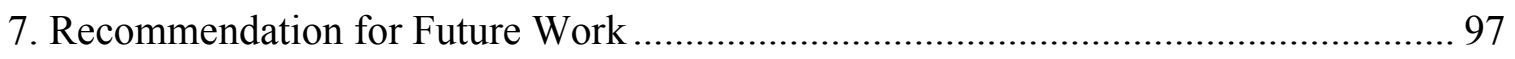

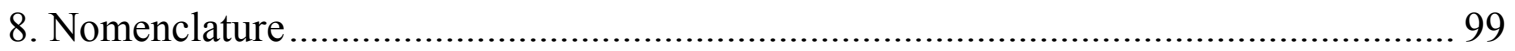

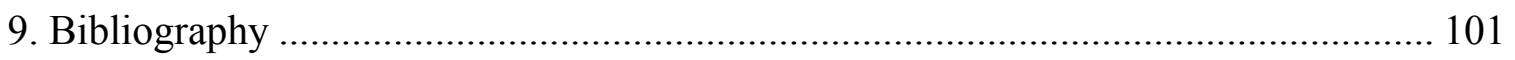

Appendix I: Comparison of Distributions of Surface Areas......................................... 104

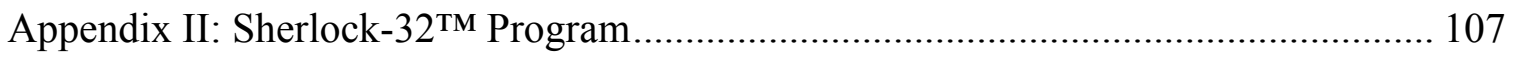

Appendix III: Calculation of Parameters .................................................................. 116

Appendix IV: Calculation of Velocity .................................................................... 120

Appendix V: Method of Calculation of Statistical Parameters....................................... 124

Appendix VI: Statistical Analysis Results .................................................................. 127

Appendix VII: Effect of Process Variables on Tablet Bed Surface Angle...................... 133

Appendix VIII: Comparison of Tablet Weights ………………................................... 134 


\section{List of Figures}

Figure 1.1: Illustration of processes taking place in drum coating equipment ................. 2

Figure 2.1: Schematic diagram of a Pellegrini coating pan (Porter, 1985)...................... 6

Figure 2.2: Schematic diagram of a 48-inch Accela-Cota (Porter, 1985) ....................... 7

Figure 2.3: Schematic diagram of the Hi-coater (Porter, 1985) .................................... 8

Figure 2.4: Movement of tablets in a $30 \mathrm{~cm}$ diameter rotating drum, showing the avalanching layer 14

Figure 3.1: Arrangement of experimental apparatus, (A) side view (B) end view.......... 16

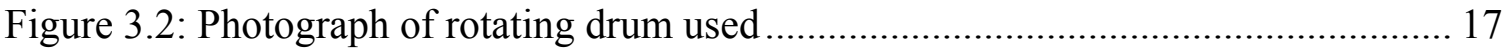

Figure 3.3: Set-up of Camera and Linear Positioner ................................................... 18

Figure 3.4: Photograph of tablets used in the study ................................................... 19

Figure 3.5: Design of Baffles Used........................................................................ 22

Figure 3.6: Photographs of design of baffles (a) side view (b) baffle placed in the drum 23

Figure 3.7: Schematic Representation of Drum Loading ............................................ 25

Figure 4.1: Set-up of the circular cardboard template on the side of the rotating drum ... 27

Figure 4.2: Schematic representation of the tracer particle movement through the ROI on

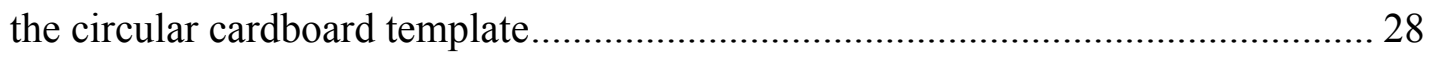

Figure 4.3: Results of validation experiments, Curve 1 - circulation time (s), Curve 2 total projected area during the tablet sighting (normalized units), and Curve 3 mean occurrence time in the ROI (s).

Figure 4.4: Two-camera set-up for verification of the imaging system

Figure 4.5: Distributions of circulation time $\left(\tau_{\text {circ }}\right)$ using VCR set-up, and Sherlock and Streampix software 
Figure 4.6: Identification of the tracer tablet by Sherlock software based on the gradient of pixel values in a frame 37

Figure 4.7: Digitized images of tablet movement through ROI 39

Figure 4.8: Calculation of circulation time 42

Figure 4.9: Calculation of surface time. 43

Figure 4.10: Calculation of projected surface area 44

Figure 4.11: Images of tracer tablets used for validation (a) full white tablet, (b) two sides white, (c) white ring on the side. 46

Figure 4.12: Movement of tracer tablet in ROI 48

Figure 5.1: A portion of raw data. 50

Figure 5.2: Change in average circulation time $\left(\tau_{\text {circ }}\right)$ as a function of drum rotation rate, for unbaffled system with $1 / 8$ drum loading. 54

Figure 5.3: Change in average circulation time $\left(\tau_{\text {circ }}\right)$ as a function of drum rotation rate, for unbaffled system with $1 / 4$ drum loading. 55

Figure 5.4: Comparison of average circulation time $\left(\tau_{\text {circ }}\right)$ as a function of drum rotation rate, for baffled and unbaffled systems, with $1 / 8$ drum loading

Figure 5.5: Distribution of circulation time $\left(\tau_{\text {circ }}\right)$ for $7.9 \mathrm{~mm}$ tablets, $1 / 8$ drum loading, 9 rpm drum speed. 58

Figure 5.6: Distribution of circulation time $\left(\tau_{\text {circ }}\right)$ for $10.4 \mathrm{~mm}$ tablets, $1 / 4$ drum loading, 9 rpm drum speed. 59

Figure 5.7: Change in average surface time $\left(\tau_{\text {surface }}\right)$ as a function of drum rotation rate, for unbaffled system with $1 / 8$ drum loading. 
Figure 5.8: Change in average surface time $\left(\tau_{\text {surface }}\right)$ as a function of drum rotation rate, for unbaffled system with $1 / 4$ drum loading.

Figure 5.9: Change in average surface time $\left(\tau_{\text {surface }}\right)$ as a function of drum rotation rate, for baffled and unbaffled systems, with $1 / 8$ drum loading 65

Figure 5.10: Change in average $A_{t a b}$ as a function of drum rotation rate for unbaffled system with $1 / 8$ drum loading. 68

Figure 5.11: Change in average $A_{t a b}$ as a function of drum rotation rate for unbaffled system with $1 / 4$ drum loading.

Figure 5.12: Change in normalized surface area $\left(A_{t a b} / D^{2}\right)$ as a function of drum rotation rate for unbaffled system

Figure 5.13: Comparison of average $A_{t a b}$ as a function of drum rotation rate for baffled and unbaffled systems, 1/8 drum loading

Figure 5.14: Comparison of average $A_{t a b}$ as a function of drum rotation rate for baffled and unbaffled systems, 1/4 drum loading

Figure 5.15: Distribution of total projected surface area per pass for $7.9 \mathrm{~mm}$ tablets, $1 / 8$ drum loading, 9 rpm drum speed

Figure 5.16: Distribution of total projected surface area per pass for $7.9 \mathrm{~mm}$ tablets, $1 / 4$ drum loading, 9 rpm drum speed 75

Figure 5.17: Comparison of normalized surface area $\left(A_{t a b} / D^{2}\right)$ as a function of drum rotation rate for baffled system 76

Figure 5.18: Distribution of $V_{x}$ for $7.9 \mathrm{~mm}$ tablets, 1/8 drum loading, 9rpm drum speed, unbaffled system 
Figure 5.19: Distribution of $V_{y}$ for $7.9 \mathrm{~mm}$ tablets, $1 / 8$ drum loading, 9 rpm drum speed, unbaffled system

Figure 5.20: Change in average surface velocity $\left(V_{x}\right)$ as a function of drum rotation rate for baffled and unbaffled systems with $1 / 8$ drum loading 84

Figure 5.21: Change in average surface velocity $\left(V_{y}\right)$ as a function of drum rotation rate for unbaffled system 85

Figure 5.22: Movement of tracer particle through ROI …………………..................... 86

Figure 5.23: Comparison of experimental and predicted $\tau_{\text {circ }}$ values............................... 92

Figure 5.24: Comparison of experimental and predicted $\tau_{\text {sufface }}$ values ............................ 92

Figure 5.25: Comparison of experimental and predicted $A_{t a b}$ values .............................. 93

Figure 5.26: Comparison of experimental and predicted $V_{y}$ values............................... 93

Figure A.1: Comparison of distributions of projected surface area $\left(A_{t a b}\right)$ for validation of surface area (6rpm drum speed) 105

Figure A.2: Comparison of distributions of projected surface area $\left(A_{t a b}\right)$ for validation of surface area (9rpm drum speed) 106

Figure A.3: Sample visual basic program used for calculation of parameters 116

Figure A.4: Sample visual basic program to calculate surface velocity 120 


\section{List of Tables}

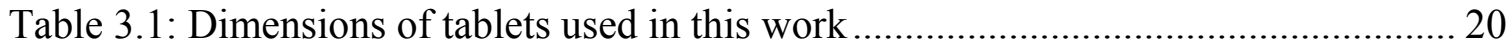

Table 3.2: Dimensions of white placebo tablets used for calibration experiments .......... 21

Table 3.3: Experimental matrix used in factorial design ......................................... 25

Table 4.1: Comparison of circulation time $\left(\tau_{\text {circ }}\right)$ for validation of the imaging system... 32

Table 4.2: Results of t-test for the three systems used for validation (two-sample

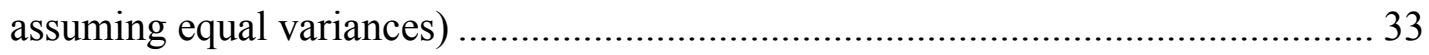

Table 4.3: Raw Data for $7.9 \mathrm{~mm}$ tablets, $1 / 8$ drum loading and 9rpm drum speed......... 40

Table 4.4: Projected surface area values for $7.9 \mathrm{~mm}$ tablets and $1 / 8$ drum fill .............. 47

Table 5.1: Mean circulation time $\left(\tau_{\text {circ }}\right)$ data for unbaffled system ................................5 53

Table 5.2: Mean circulation time $\left(\tau_{\text {circ }}\right)$ data for baffled system ................................. 56

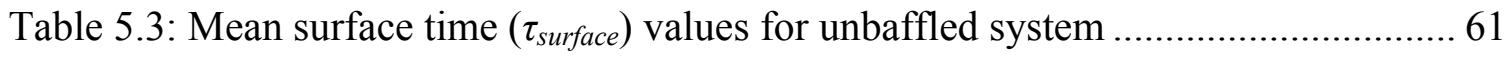

Table 5.4: Mean surface time $\left(\tau_{\text {surface }}\right)$ data for baffled system ..................................... 64

Table 5.5: Mean projected surface area $\left(A_{t a b}\right)$ data for unbaffled system ....................... 67

Table 5.6: Mean projected surface area $\left(A_{t a b}\right)$ data for baffled system .......................... 71

Table 5.7: Mean surface velocities for unbaffled system ......................................... 78

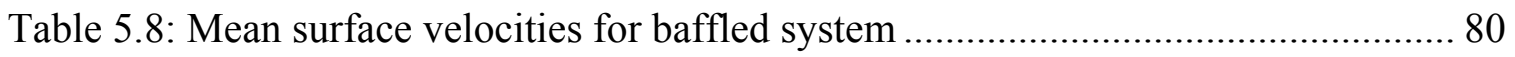

Table 5.9: Exposure Fraction $\left(f_{\text {exp }}\right)$ for unbaffled system ...................................... 88

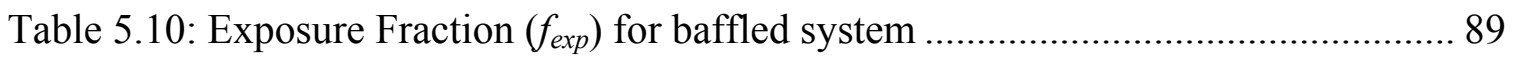

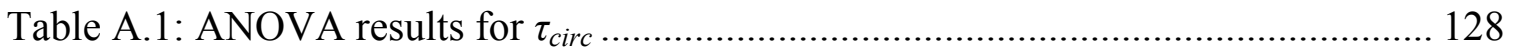

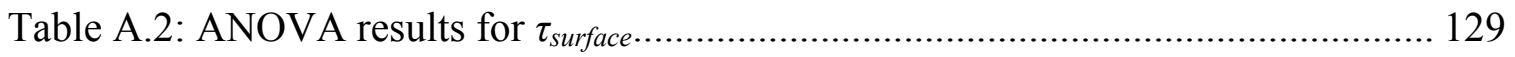

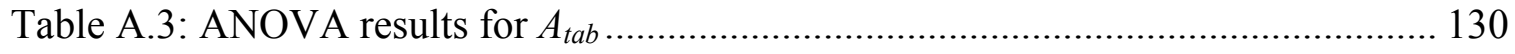

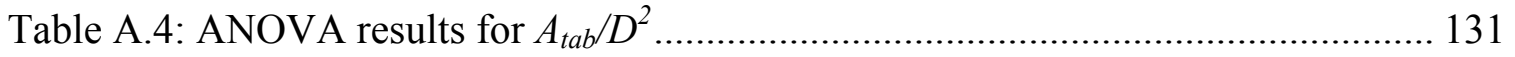


Table A.5: ANOVA results for $V_{y}$

Table A.6: Effect of process variables on the angle formed at the surface of tablet bed 133

Table A.7: Comparison of tablet weights for $6.3 \mathrm{~mm}$ tablets.

Table A.8: Comparison of tablet weights for $7.9 \mathrm{~mm}$ tablets..... 136

Table A.9: Comparison of tablet weights for $10.4 \mathrm{~mm}$ tablets ..................................... 137 


\section{Introduction}

In the Pharmaceutical Industry, during the course of producing a batch of products, an inventory of solid material, often containing hundreds of thousands of dollars of active ingredients or drugs, is subjected to one or more coating processes. The reasons for using these coatings in product formulation range from the aesthetic, which include improving the cosmetic appearance of the product, masking unpleasant tastes, to a desire to control the bioavailability of the drug, like controlling drug release, and maximizing drug stability. Oral drugs are usually given in three different forms, namely syrup, capsules, and tablets. In the case of a capsule, the drug is in the form of small particles that may be individually coated and housed in a capsule of gelatin or similar material. The coating of these small particles is often carried out in fluidized beds and usually validated by end-of-batch testing. However, tablets are not usually coated in fluidized beds due to the mechanical damage that occurs in such devices. Tablet coating usually occurs in rotating drum devices. The uniformity of coating applied to large particles and tablets in rotating-drum coating devices is of significant interest to the Pharmaceutical Industry. This is especially true when the coating is comprised of a sustained release formulation or contains active ingredients in a functional coat.

A typical coating set-up is illustrated in Figure 1.1. As tablets pass through the spray zone, they receive amounts of coating solution proportional to the time spent in the spray zone and the area exposed to the spray. As tablets continue to circulate in the equipment, additional coating is received every time the tablet "sees" the spray. The amount of coating received by a given tablet can be determined if one knows the number of times that the tablet "sees" the spray, the time that the tablet spends in the spray zone, 
and the surface area exposed each time coating is deposited. This model of the coating process is based on concepts from renewal theory that have been developed for batch coating of particulates by Mann and co-workers (1975). In order to predict the uniformity of coating obtained in coating drums, it is necessary to estimate the movement of tablets (particulates) within the drum. Specifically, information about the distribution of the circulation time, $\tau_{\text {circ }}$, defined here as the time between successive particle sightings at the surface of the bed, and the exposure time, $\tau_{\text {surface }}$, defined as the time that a particle spends within the spray zone during each pass, must be known. In addition, the surface area of the tablet projected toward the spray source (nozzle), during each pass through the spray zone, $A_{\text {tab }}$, must be known.

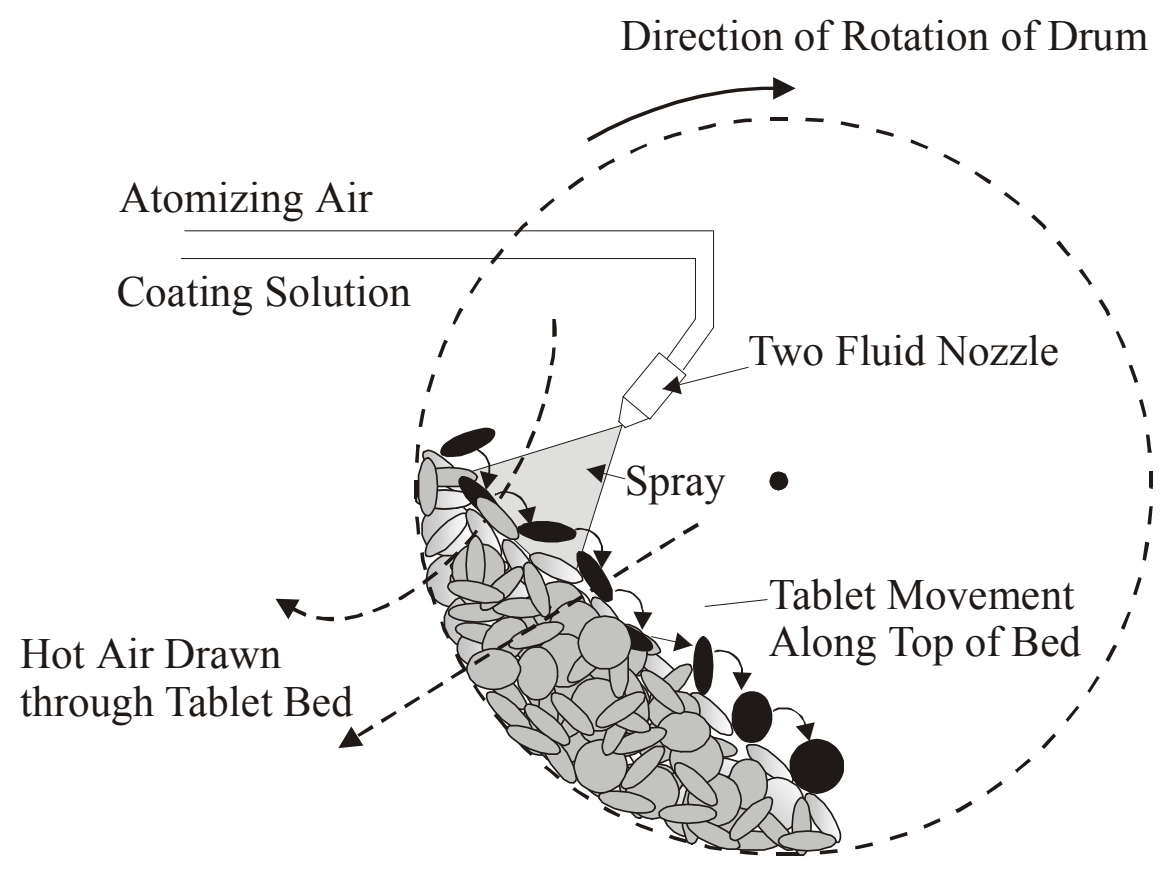

Figure 1.1: Illustration of processes taking place in drum coating equipment 
Poor tablet movement in the bed of a tablet coater can lead to differences in coating thickness from tablet-to-tablet within the coated batch, which can result in detectable coating variation between tablets, bridging of the intagliations or embossed marks on the film coated tablet (Rowe \& Forse, 1980), and variability in the drug release rate, where the film is used as a diffusion barrier. Since every time that the tablet "sees" the spray there is an increase in the variation of product quality, the need for continuous monitoring and control of such processes is necessary. Experiments have been carried out to study the effect of the normal process variables on the movement of tablets in a sidevented perforated drum coater using photometric analysis (Leaver et al., 1985). Until recently it has been impossible to monitor and control particulate coating processes in real time. However, with the advent of video imaging, fast processors, and sophisticated software for imaging, and using machine vision, this task has become tractable (Kennedy and Niebergall, 1997). Thus a vision system capable of detecting and interpreting the change in coating characteristics can be applied to monitor coating processes. Although real-time or near real-time imaging of different processes is now possible using fast imaging boards, high resolution CCD cameras and Machine Vision software, this technology has yet to be applied to investigating the movement of solids in rotating drum coating devices.

The objective of this research is to investigate the dependence of the movement of particles on the process variables i.e. drum speed, drum loading and the presence/absence of mixing elements, using a two-dimensional rotating drum and particle tracing techniques. The technique involves tracking the movement of a single tracer tablet in a bed of tablets in a horizontal rotating drum coater, using sophisticated imaging and 
Machine Vision software (Coreco Imaging, Bedford, MA). The results from this research may enable effective optimization of the process parameters in a coating operation. Thus the purpose of this research is to quantify the three parameters $\tau_{\text {circ }}, \tau_{\text {surface }}$, and $A_{\text {tab }}$ using digital imaging and machine-vision software for a variety of key operating parameters; drum speed, drum loading, tablet size, baffles and liquid spray. The Machine Vision software captures and analyzes frames in real-time for the presence of the tracer tablet. The data obtained are then analyzed off-line. 


\section{Literature Review}

Coating is an old process and has been utilized for centuries. The equipment used in coating operations can be classified into three general categories: pans, perforated pans, and fluid bed equipment. These systems are used to contain the materials being coated and provide an environment for the coating to dry, and also provide a means to ensure that an equal amount of coating material is applied evenly to each particle (Porter, 1985).

\subsection{An Overview of Pan Coaters:}

The coating pan was invented approximately 140 years ago (Mehta, 1997) and a great many products are still being coated in round pans. Primarily used for sugar coating, this system uses drying air blown onto the surface of the tumbling bed; exhaust air is withdrawn by a manifold situated at the outer perimeter of the pan opening. These pans have several disadvantages, which include poor drying efficiency and dependence on the skills of the operator. To overcome these disadvantages, the perforated pan (Figure1.1) was developed (Mehta, 1997). In this device, air is drawn through the bed as opposed to air being supplied to the bed surface only. There are several variations in these systems, with the intention to maximize the drying capability of the machine at high spray rates (Mehta, 1997). Although considerable experimentation has taken place with the geometric design of conventional equipment, a significant change came with the introduction of the Pellegrini coating pan (Figure2.1), which is somewhat angular and rotates on a horizontal axis (Mehta, 1997). 


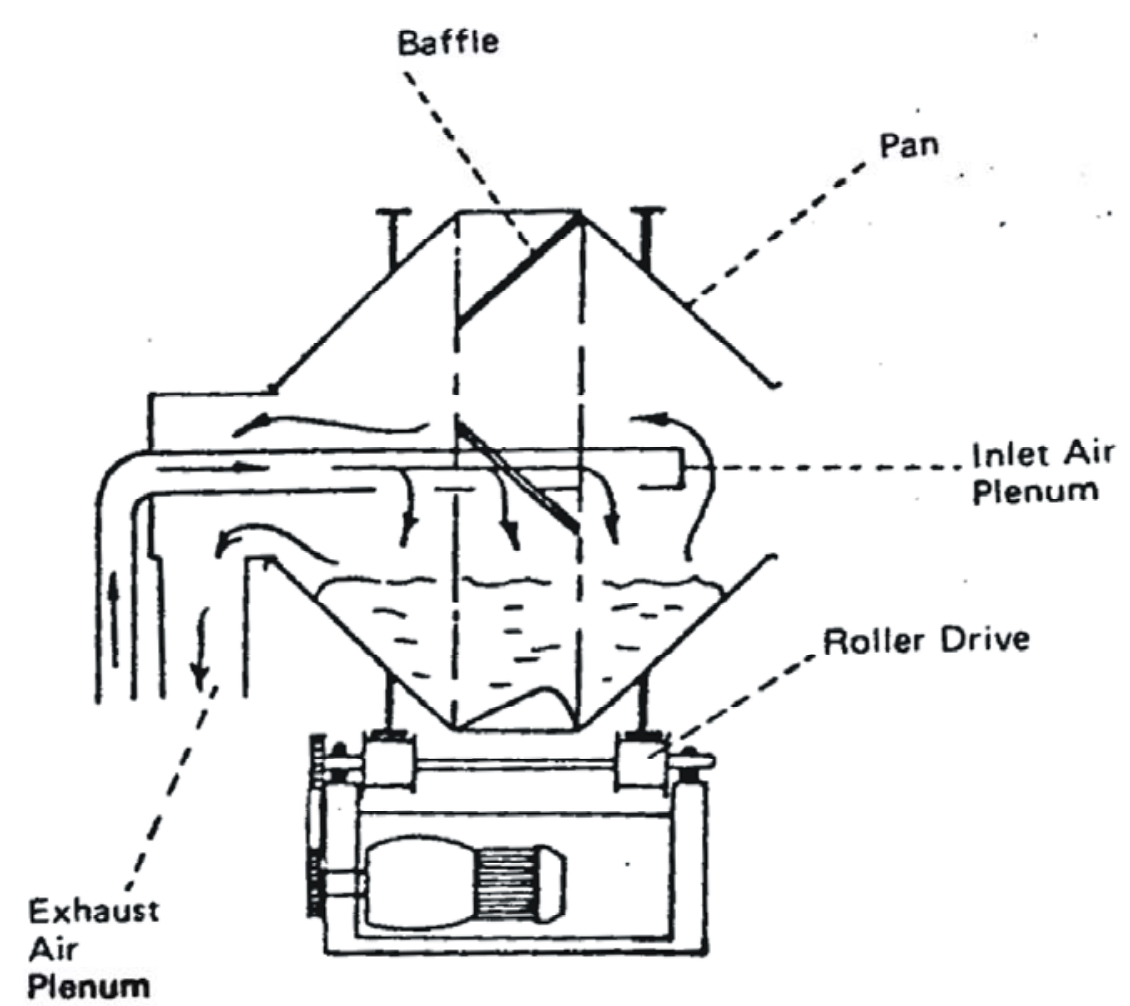

Figure 2.1: Schematic diagram of a Pellegrini coating pan (Porter, 1985)

A major contribution to film-coating processing technology was made by the introduction of the Accela-Cota (Figure2.2), an invention of Eli Lilly \& Co, which is also an angular pan rotating on a horizontal axis. One variant of the Accela-Cota that also uses a perforated pan design is the Hi-Coater (Figure2.3), which contains four perforated panels linked to air ducts that continuously make contact with a stationary exhaust plenum as the pan rotates (Porter, 1985). However, these rotating devices have had some inherent problems such as lengthy processing time, the need for skilled operator supervision and high energy of operation. 


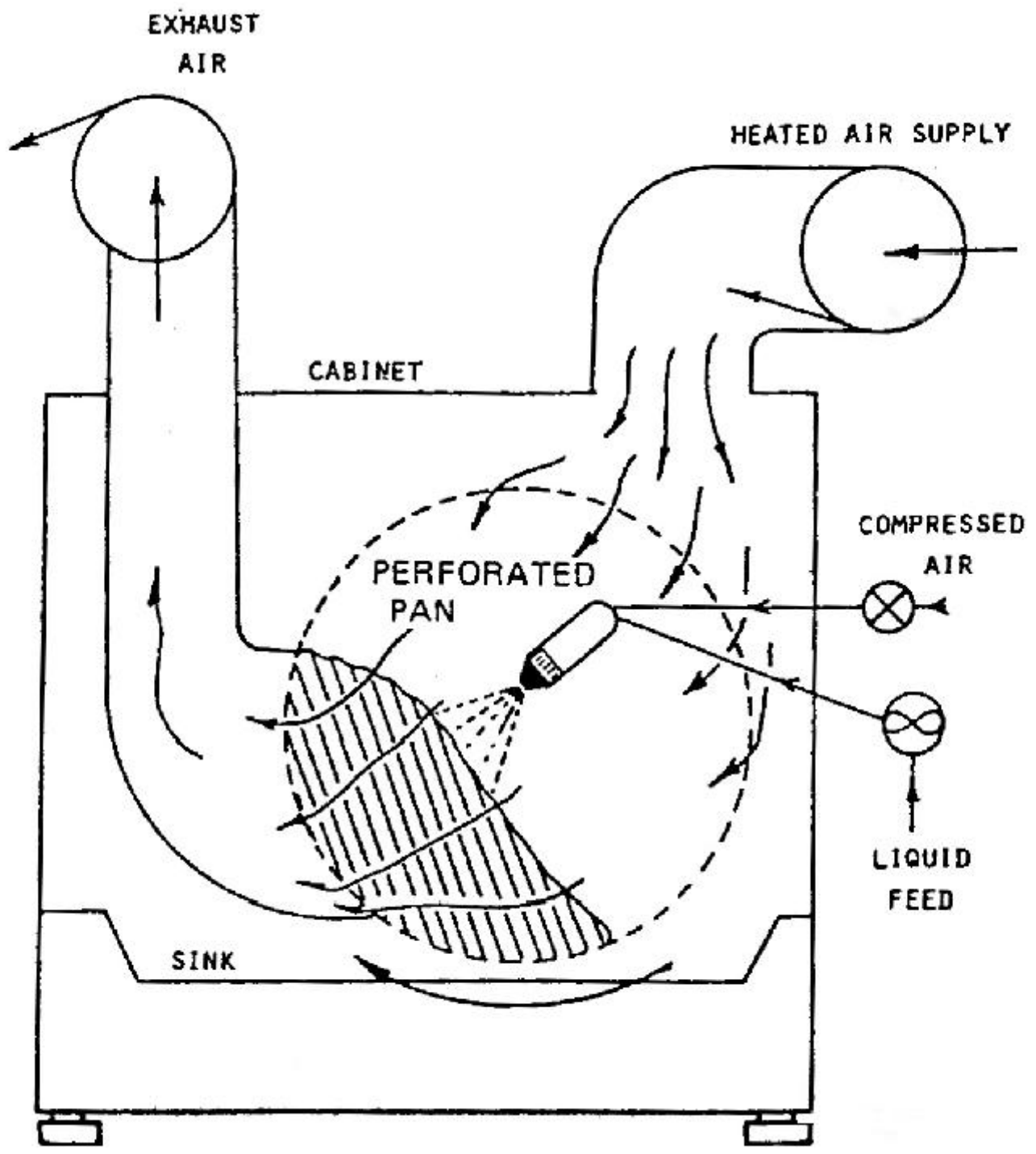

Figure 2.2: Schematic diagram of a 48-inch Accela-Cota (Porter, 1985) 


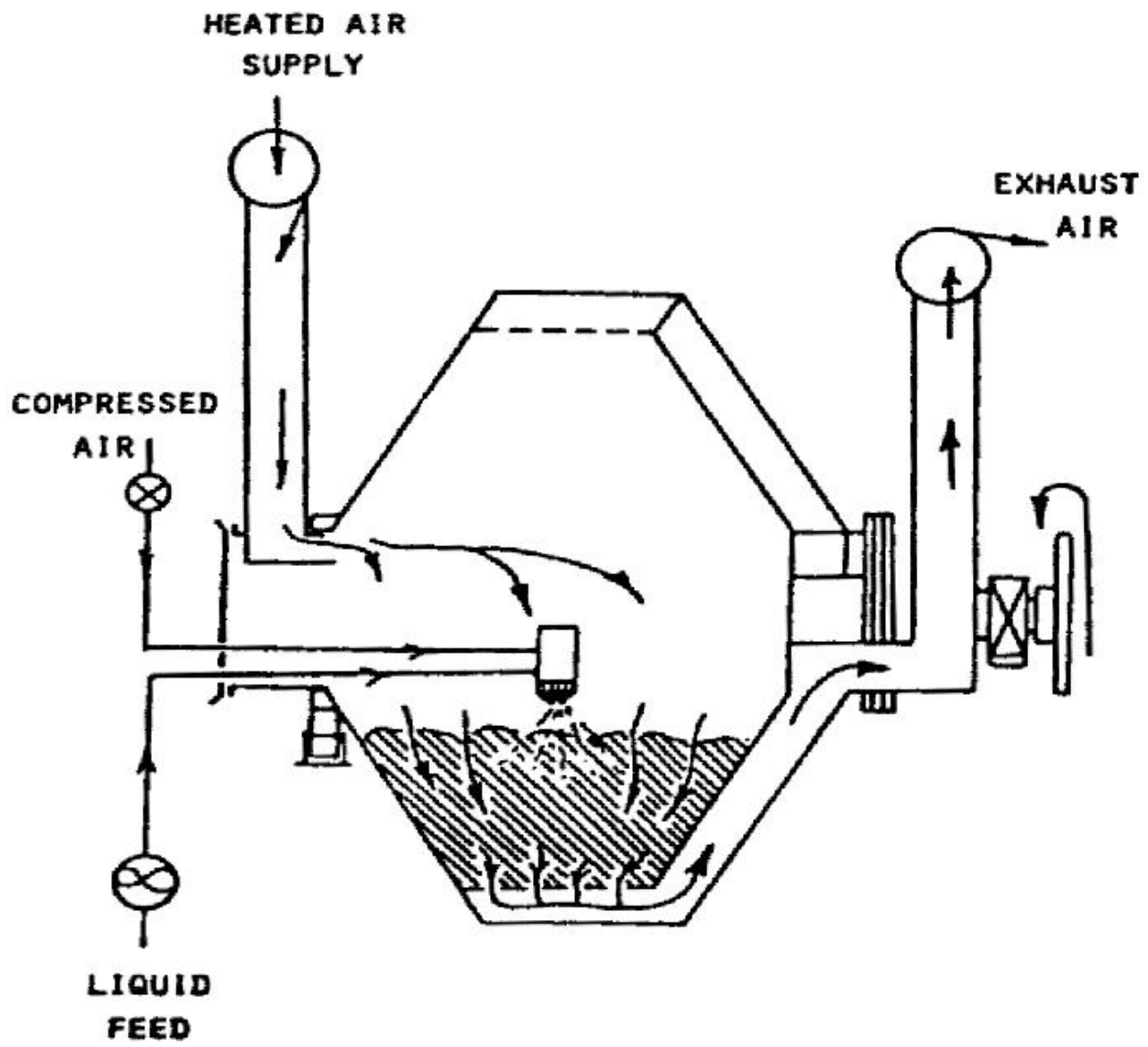

Figure 2.3: Schematic diagram of the Hi-coater (Porter, 1985)

Moreover, there is considerable variation in product quality because of the inherent dead zones in the pan coaters. Thus newer processes were developed including compression coating machines, and fluidized and spouted bed coaters. The earliest fluidbed coating equipment was based on the Wurster design. But limitations of fluid-bed equipment in tablet coating occur as a result of the harsh treatment that the tablets receive, causing greater potential for tablet damage due to attrition and abrasion. In the case of small tablets, the equipment used for coating does not make much difference, however for large tablets a rotating drum coater is preferred, since more air would be required to fluidize larger particles and the higher velocities cause much higher attrition 
in a fluidized-bed coater. However the fluidized beds have shorter processing times and low product variability. With the perforated pans, though the coating process is simple and the tablets are subjected to lower mechanical stress, there is greater product variability and longer processing times. Shelukar et al. (2000) conducted experiments to determine the variation in product coating uniformity in the Wurster column, based on the two factors: the coating-per-pass distribution and the circulation-time distribution. Experimental techniques were developed to quantify this variation. Some previous studies on coating variability using the perforated pans are discussed in Section 2.2.

\subsection{Techniques Used To Study Particle Motion within a Particulate Bed}

The main technique involved in this work is the measurement of the times at which the tracer tablet appears on the surface of the tablet bed in the rotating drum (tablet appearance data). Previous work on the measurement of tablet appearance times has involved photographic and manual-counting techniques to obtain a limited amount of data from a bed of tablets containing a number of different colored tracer tablets (Prater et al., 1980). The need for specialized photographic equipment and the time needed to abstract data from replayed film makes this technique unsuitable for more than a cursory assessment of tablet movement. However, such techniques can provide useful information on the direction and orientation of the tablets as they move through the spray region.

Another technique was developed by Sibbett and Oliver (1984), for studying particle movement in fluidized beds, which was also used in photometric analysis of the movement of tablets in a side-vented perforated drum by Leaver et al. (1985). This technique involved measuring the duration of light emission from a single luminous 
tracer tablet made of zinc sulfide in a bed of iron oxide coated tablets using a photo multiplier tube mounted to scan the same area as a spray gun and focused on the surface of the bed. Data were recorded over a 15-20 minute period for different tablet sizes, loadings, and drum speeds. Circulation and surface times were calculated for the conditions used in the experiments. Although signal intensity was also recorded, no projected surface area data were presented. This technique also allowed the study of the uniformity of tablet appearances by means of circulation profiles. It was found that, while both the surface and circulation times decreased with increasing drum speed and loading, there was irregularity of tablet appearance especially at low drum speeds and in the absence of baffles. It was also observed that baffles have an effect on the surface times of the tablet, with considerably higher surface times recorded in an unbaffled system due to the absence of induced turbulence within the bed.

Movement of tablets in a coating drum has also been obtained via computer simulation (Yamane et al., 1995) using DEM (discrete element method). These simulations were made using spherical particles. Although no quantitative comparisons could be made between the simulations and experimental data, qualitative results were in agreement. Heinamaki et al. (1997) conducted studies on a side-vented pan coater for the optimization of the aqueous film coating of tablets using a fractional factorial design. The coating process was optimized using response surface methodology (central composite design). The major parameters affecting the film coating process efficiency were identified as the rotation speed of the pan and the inlet air temperature. It was also observed that the pneumatic spraying pressure and the position of the spray gun did not affect the coating process. 
Rodriguez et al. (1996) studied the mass and energy balance during aqueous film coating to optimize the qualitative and quantitative yield of the process. The equipment used in this study had a Pellegrini solid-wall pan and a proprietary heating ventilation unit that considerably improved the heat-exchange efficiency. The main independent variables considered were the ventilation airflow rate, temperature, film-coating fluid spraying rate, and coating pan rotation speed. Core temperature, outlet air temperature, and relative humidity were considered as dependent variables. The quantitative relationships between the dependent and independent variables in the pan-coating process were studied under pseudo-steady-state conditions. The influence of tablet shape and pan speed on the intra-tablet film coating uniformity have been studied using four different tablet shapes in a Hi-Coater by Wilson and Crossman (1997). The coating was found to be thicker on the face than on the edges or ends of each of the tablets. It was observed that the more spherical the geometry of the tablets, the more uniform the coating would be. Also increasing the rotational speed improved the coating uniformity in all the cases.

Kennedy and Niebergall (1997) made a preliminary assessment of an image analysis method for the evaluation of pharmaceutical coatings, using nonpareils previously hot-melt coated with a red water soluble dye incorporated into polyethylene glycol. Digital images of batch samples were acquired and transferred to a PC for evaluation by image analysis software. This technique provided both qualitative and quantitative measures for coating uniformity, a qualitative measure for coating thickness, and maintained a high degree of precision. However, a potential disadvantage to the method is the apparent dependence on the existence of a colorant in the coating of interest. When using a colorant as a temporary indicator, the formulator must assume that 
the removal of the colorant after optimization, will not significantly impact the coating or process.

Parker et al. (1997) conducted similar studies, using positron emission particle tracking to track the motion of a single radioactively labeled tracer particle within a bed of similar particles in a partially filled horizontal rotating drum. They determined the axial dispersion coefficient for each experiment and found it to be proportional to the frequency of particle circulation around the bed. They concluded that the axial dispersion coefficient strongly depended on the particle size, but was independent of the drum diameter.

Saadevandi and Turton (1998) used computer based video imaging techniques to measure the axial and radial components of particle velocity and voidage profiles in the draft-tube region of a semi-circular spouted fluid bed coating device. Studies were conducted by Cheng and Turton (2000), to study the effect of process variables on the coating mass distribution on nu-pareil particles coated in a Wurster process, using a magnetic tracer particle to track the movement of solids in the fluidized bed. The current work is an extension of the analysis done by Leaver et al. (1985), but using video imaging techniques. The purpose of this research is to investigate the effect of normal process variables like drum speed, drum loading etc, on the movement of tablets in a horizontal rotating drum coater, in real time.

\subsection{Dynamics of Mixing in Rotating Drums:}

When granular materials are placed in rotating drums different flow characteristics are observed. The mixing of granular materials is a complex process determined by both the kinematics of the mean flow and local diffusive and segregation 
fluxes arising from random motions of particles and from differences in the properties of the particles being mixed. Mixing and segregation are two facets of the same physical process, the underlying mechanisms being diffusion, shearing or convection. Khakhar et al. (1997 a) conducted studies on the mixing of granular materials in a rotating cylinder, with the objective of understanding and highlighting the role of flow on the dynamics of the process. The analysis was restricted to low speeds of rotation, when the free surface of the granular solids is nearly flat, and when particles are identical so that segregation is unimportant. The dynamics of the mixing process were studied by using tracer particles and allowing particle diffusion in the cascading layer. The operating conditions at which the mixing rates were maximum were determined and thus optimized.

Studies were also conducted by Khakhar et al. (1997 b) to analyze the radial segregation of granular mixtures in rotating cylinders and a constitutive model for the segregation flux in cascading layers was proposed and validated by particle dynamics and Monte Carlo simulations for steady flow down an inclined plane. It was found that in the case of slow mixing, the intensity of segregation monotonically decreases to an equilibrium value. However for fast mixing, an optimal mixing time exists at which best mixing is obtained. It has also been reported by Dury and Ristow (1999) that segregation of solids of different sizes and densities occurs in the rotating drums. This work shows that a core of dense particles can be created in a bed of less dense particles and the segregation may be beneficial to the circulation of tablets. Figure 2.4 shows the avalanching layer of tablets in a $30 \mathrm{~cm}$ diameter, rotating drum (a test unit similar to the equipment used in this study). 


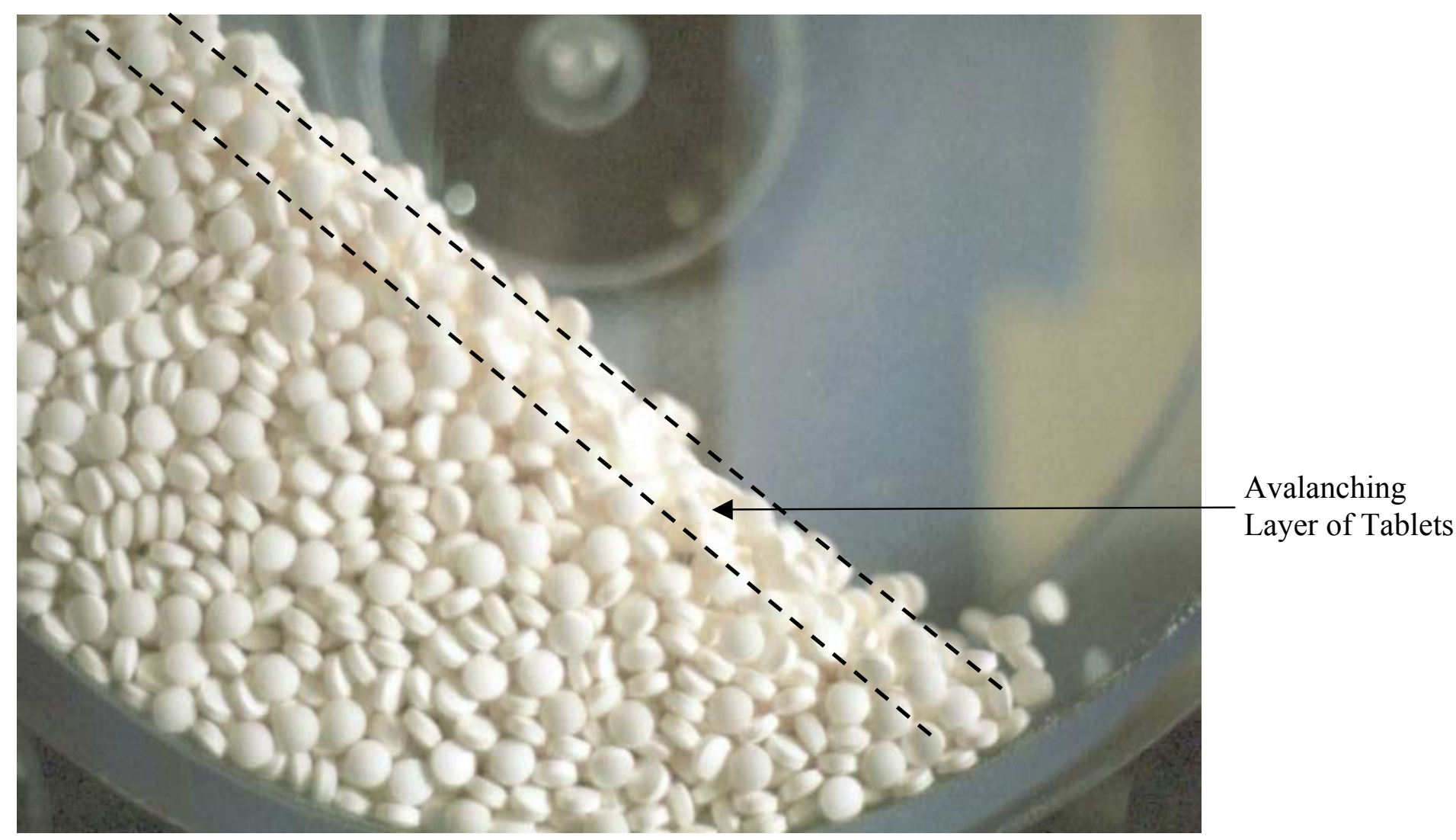

Figure 2.4: Movement of tablets in a $30 \mathrm{~cm}$ diameter rotating drum, showing the avalanching layer 


\section{Experimental Procedures}

\subsection{Set-up of Rotating Drum and Video Imaging Equipment}

The rotating drum equipment used in this research is illustrated in Figure 3.1. Many of the mechanical details are omitted from the Figure but are discussed below. The drum consists of two transparent Plexiglas ${ }^{\circledR}$ discs (AIN Plastics, Inc., Norfolk, VA), 60 $\mathrm{cm} \mathrm{OD}$ and $57.5 \mathrm{~cm} \mathrm{ID,} \mathrm{which} \mathrm{are} \mathrm{separated} \mathrm{by} \mathrm{a} 10 \mathrm{~cm}$ perforated aluminum strip. The discs are secured to the strip using setscrews drilled through the Plexiglas discs (not shown). The drum is rotated about its axis using a 1/30 hp stepper motor (Dayton model no. 42537A) controlled by a feedback speed controller (Dart Controls, Inc. model no. MD10P, Zionsville, IN), with a digital display showing the rate of rotation. Drum speed can be adjusted continuously from 1 to $30 \mathrm{rpm}$. The drum is supported on a metal frame and four rubber rollers (two at the bottom and two on the side) support the movement of the drum. Figure 3.2 is a photograph of the rotating drum with the camera focused over the tablet bed.

The imaging of the surface of the cascading bed of tablets, and specifically the recognition of a black tracer tablet, was carried out using a Pulnix ${ }^{\mathrm{TM}} 1020-25$ area scan

CCD (charged coupled device) camera (Micro Disc, Inc., Yardley, PA) equipped with a $12.5 \mathrm{~mm}$ macro lens (Navitar model no. DO-1213, Image Labs International, Bozeman, MT). This camera takes $1 \mathrm{~kb} \times 1 \mathrm{~kb}$ images at a framing rate of $25 \mathrm{~Hz}$ and was connected to a PC-DIG-L PCI LVDS digital frame grabber board (Micro Disc, Inc., Yardley, PA). 


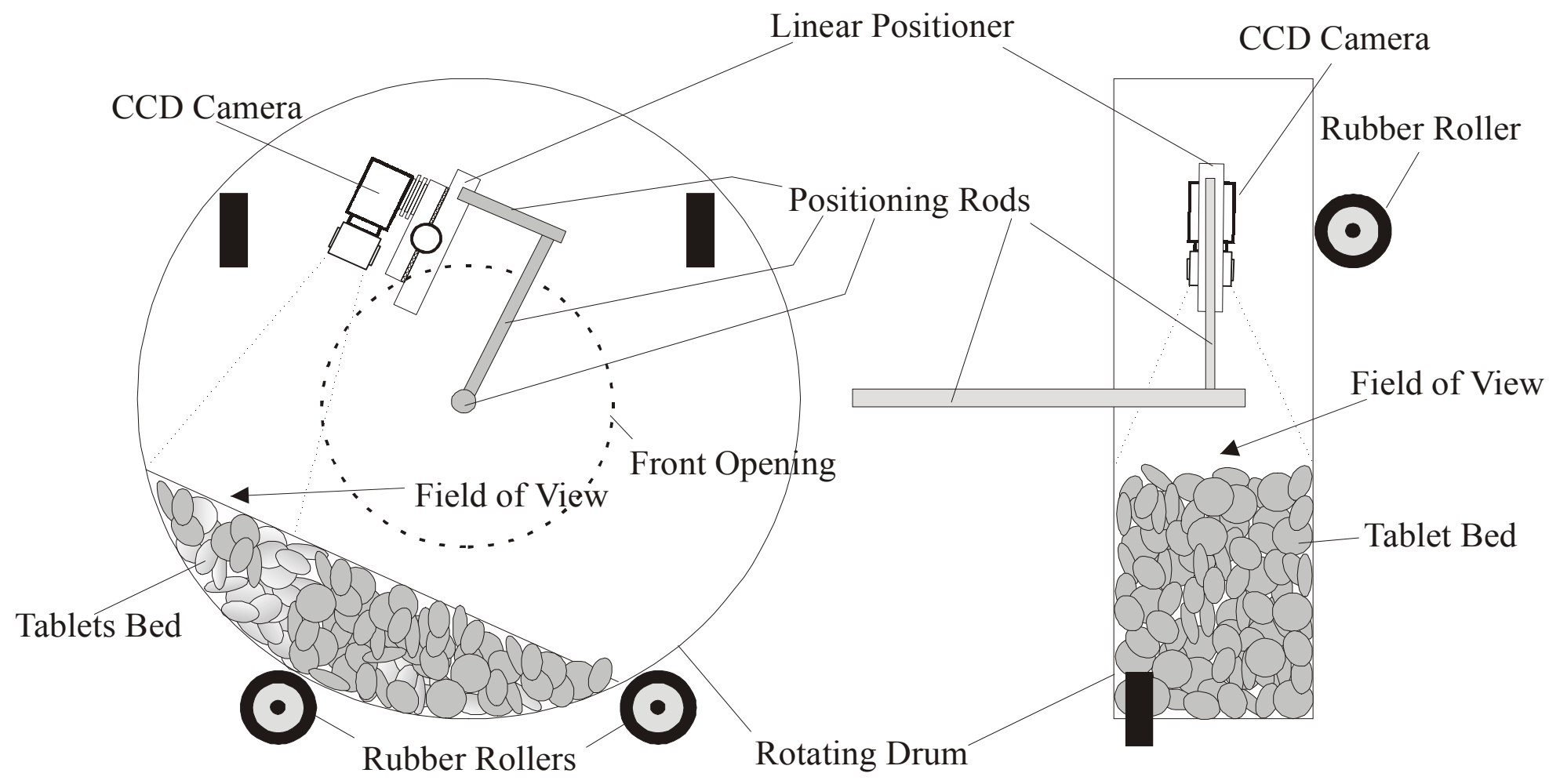

Figure 3.1: Arrangement of experimental apparatus, (A) side view (B) end view 


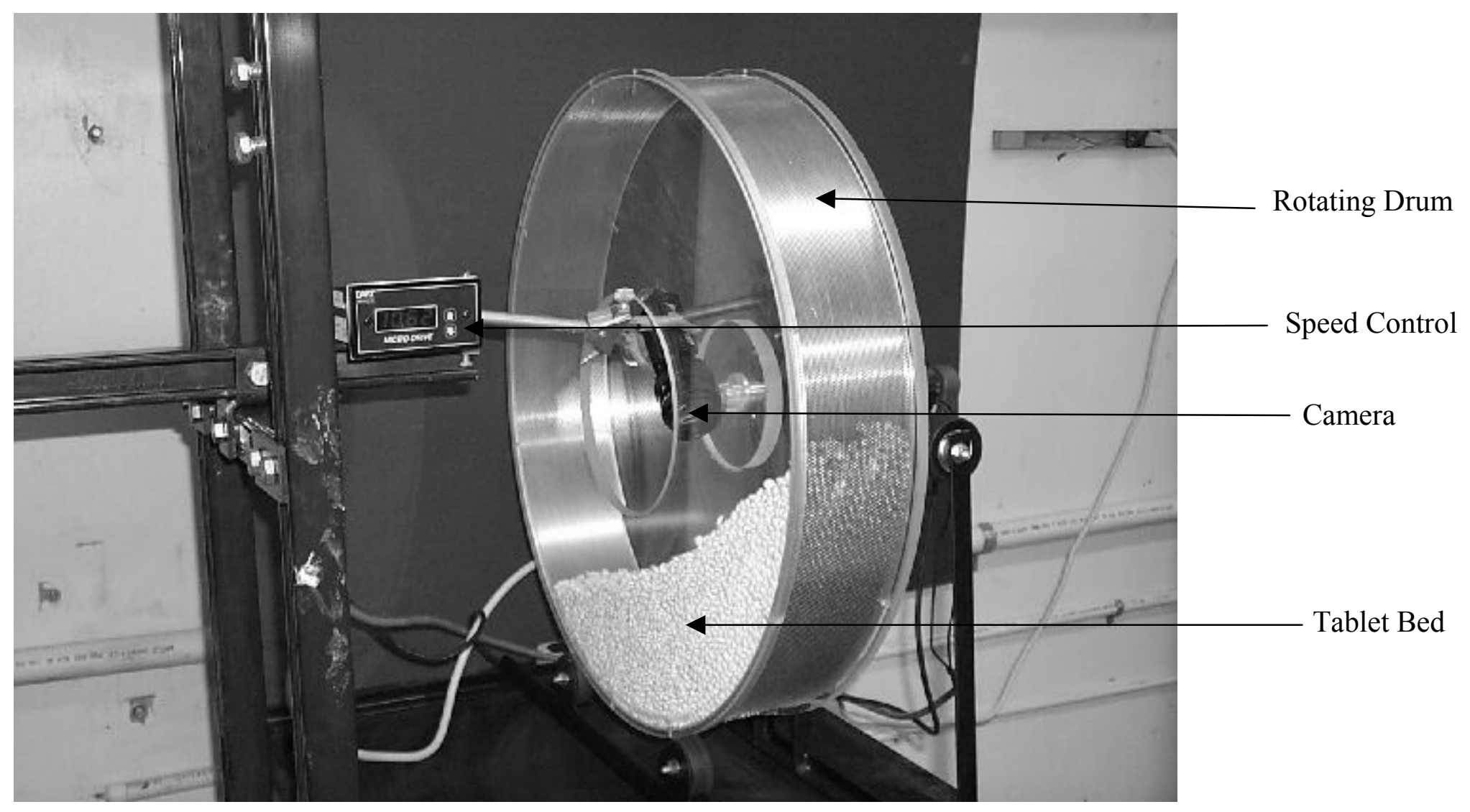

Figure 3.2: Photograph of rotating drum used 
The camera was connected to an $800 \mathrm{MHz}$ PC using the Windows ${ }^{\mathrm{TM}} \mathrm{NT}$ operating system that uses Sherlock ${ }^{\mathrm{TM}}$ 32, machine-vision software (Coreco Imaging, Bedford, MA) to analyse the images. A flexible fibre-optic light guide that fits onto the end of the lens provides light inside the drum. The fibre-optic light source is made by Cuda Instruments (model no. I-150, Jacksonville, FL). The camera was mounted via an aluminum heat sink onto a linear positioner that allows fine tuning of the working distance of the camera. The positioner was connected to a positioning rod that has threesections. The position of each section can be adjusted to locate the camera at the desired position relative to the tablet bed. The front section of the drum has an opening $(20 \mathrm{~cm}$ in diameter) in it to allow the horizontal section of the positioning rod to be secured to a mounting bracket that lies outside the drum. Figure 3.3 shows the camera and the linear positioner.

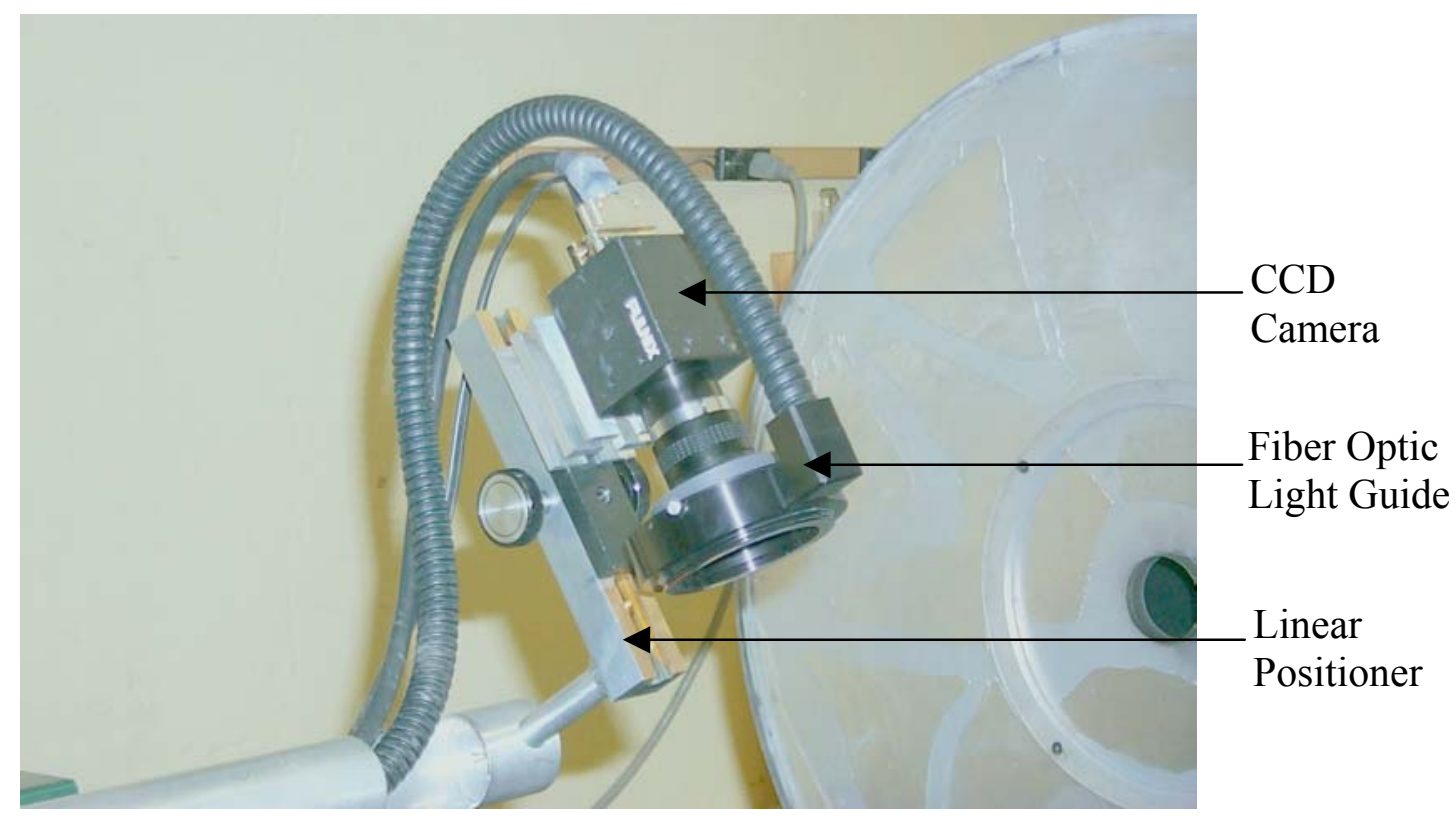

Figure 3.3: Set-up of Camera and Linear Positioner 


\subsection{Tablets Used in the Study}

The different tablets used in the current research are shown schematically along with their dimensions in Table 3.1. These tablets are placebo units supplied by Mylan Pharmaceuticals Inc. (Morgantown, WV). The tablets were first coated to a $4 \%$ theoretical weight gain using Black Opadry ${ }^{\circledR}$ (Colorcon, West Point, PA) and then coated to a $0.25 \%$ theoretical weight gain using Clear Opadry ${ }^{\circledR}$ (Colorcon, West Point, PA). In each experiment a single white tracer tablet was introduced into the rotating bed of tablets. The tracer tablets were produced by coating the placebo tablets to $4.25 \%$ theoretical weight gain using Clear Opadry®. The resulting images obtained from the CCD camera, using the appropriate lighting level with the black tablets, were easily distinguished from both the white tablets and shadows within the bed. Figure 3.4 shows the white tracer tablet with the black tablets used.

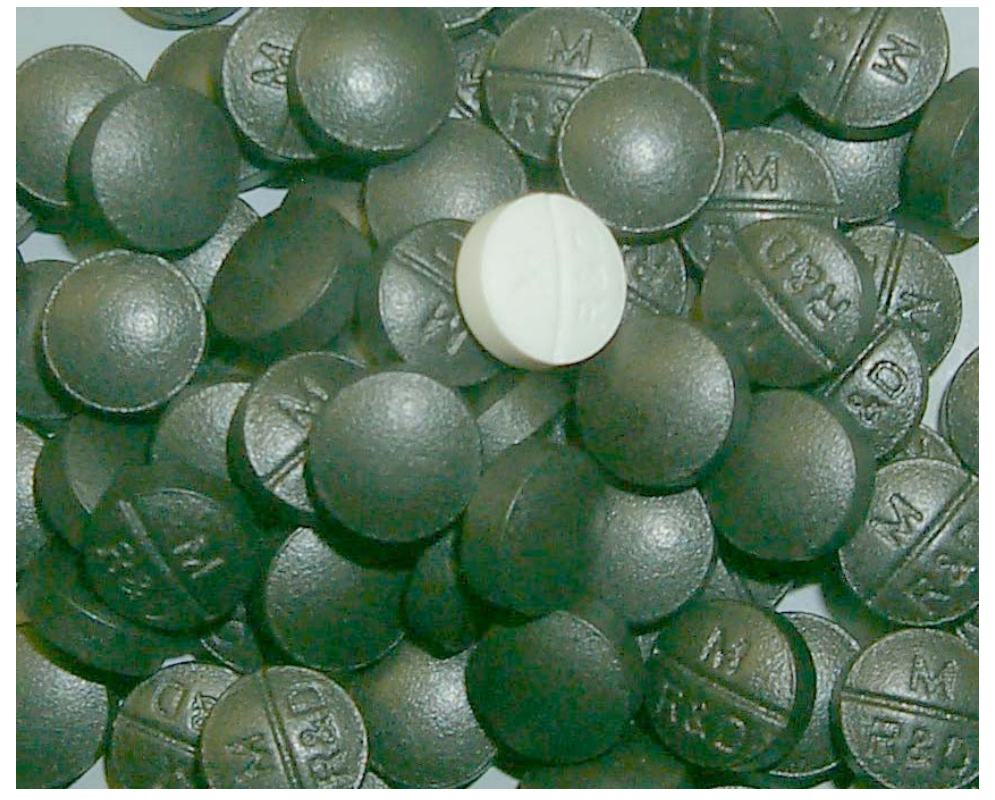

Figure 3.4: Photograph of tablets used in the study 


\begin{tabular}{|c|c|c|c|c|c|c|c|c|c|}
\hline \multirow{2}{*}{$\begin{array}{c}\text { Nominal } \\
\text { Size }\end{array}$} & \multirow{2}{*}{ Shape } & \multicolumn{2}{|c|}{$\mathrm{d}(\mathrm{mm})$} & \multicolumn{2}{|c|}{$\mathrm{t}(\mathrm{mm})$} & \multicolumn{2}{|c|}{$\mathrm{h}(\mathrm{mm})$} & \multicolumn{2}{|c|}{ Weight (mg) } \\
\hline & & $\begin{array}{c}\text { Uncoated } \\
\text { Tablets }\end{array}$ & $\begin{array}{l}\text { Coated } \\
\text { Tablets }\end{array}$ & $\begin{array}{c}\text { Uncoated } \\
\text { Tablets }\end{array}$ & $\begin{array}{l}\text { Coated } \\
\text { Tablets }\end{array}$ & $\begin{array}{c}\text { Uncoated } \\
\text { Tablets }\end{array}$ & $\begin{array}{l}\text { Coated } \\
\text { Tablets }\end{array}$ & $\begin{array}{c}\text { Uncoated } \\
\text { Tablets }\end{array}$ & $\begin{array}{l}\text { Coated } \\
\text { Tablets }\end{array}$ \\
\hline $1 / 4$ inch & $\mathrm{d}$ & 6.2 & 6.3 & 3.1 & 3.2 & 1.8 & 1.8 & 100.0 & 104.3 \\
\hline $5 / 16$ inch & & 7.8 & 7.9 & 3.8 & 3.9 & 2.5 & 2.5 & 200.0 & 208.5 \\
\hline $13 / 32$ inch & & 10.3 & 10.4 & 5.0 & 5.1 & 3.1 & 3.1 & 500.0 & 521.3 \\
\hline
\end{tabular}

Table 3.1: Dimensions of tablets used in this work 
The tablets used for the calibration and initial experiments were placebo units supplied by Merck and Co., Inc (West Point, PA). The black tracer tablets used in this case were produced by spray-painting placebo tablets with flat, black, oil-based paint. The tablets produced had a matt finish that did not reflect much light in order to distinguish from the non-painted tablets and the shadows within the bed. The reason for switching to the black tablets and white tracer tablet will be discussed in further chapters. Table 3.2 shows the dimensions of the white placebo tablets used for the preliminary experiments. The weights of the tablets used in the study were compared with the tracer tablets, which have been included as Appendix VIII.

\begin{tabular}{|c|c|}
\hline Nominal Size & $8 \mathrm{~mm}$ \\
\hline Shape & 205.0 \\
\hline Weight $(\mathrm{mg})$ & 8.0 \\
\hline $\mathrm{d}(\mathrm{mm})$ & 4.3 \\
\hline $\mathrm{t}(\mathrm{mm})$ & 2.4 \\
\hline $\mathrm{h}(\mathrm{mm})$ & \\
\hline
\end{tabular}

Table 3.2: Dimensions of white placebo tablets used for calibration experiments 


\subsection{Design of Baffles}

Inherent dead zones are formed in the coating pan, at the center of the tablet bed, leading to non-uniform tablet appearances at the surface of the tablet bed. Baffles may promote uniform mixing and eliminate the formation of these dead zones in the tablet bed, thus improving the tablet circulation and coating uniformity. The baffles used in the rotating drum were made of copper and were placed at an angle of $45^{\circ}$ in the drum in a plough arrangement. Figure 3.5 shows a schematic representation of the placement of the baffles in the drum and their dimensions. Photographs of the baffles used and arrangement inside the rotating drum are illustrated in Figure 3.6. The design of baffles in the industrial scale coating devices was considered. The design and dimensions of the baffles were scaled to the equipment used in this study.

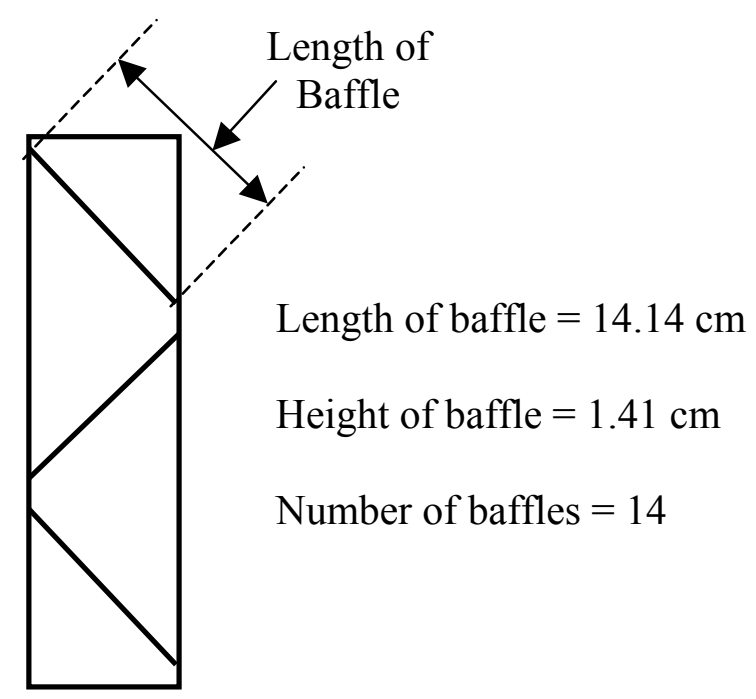

Figure 3.5: Design of Baffles Used 

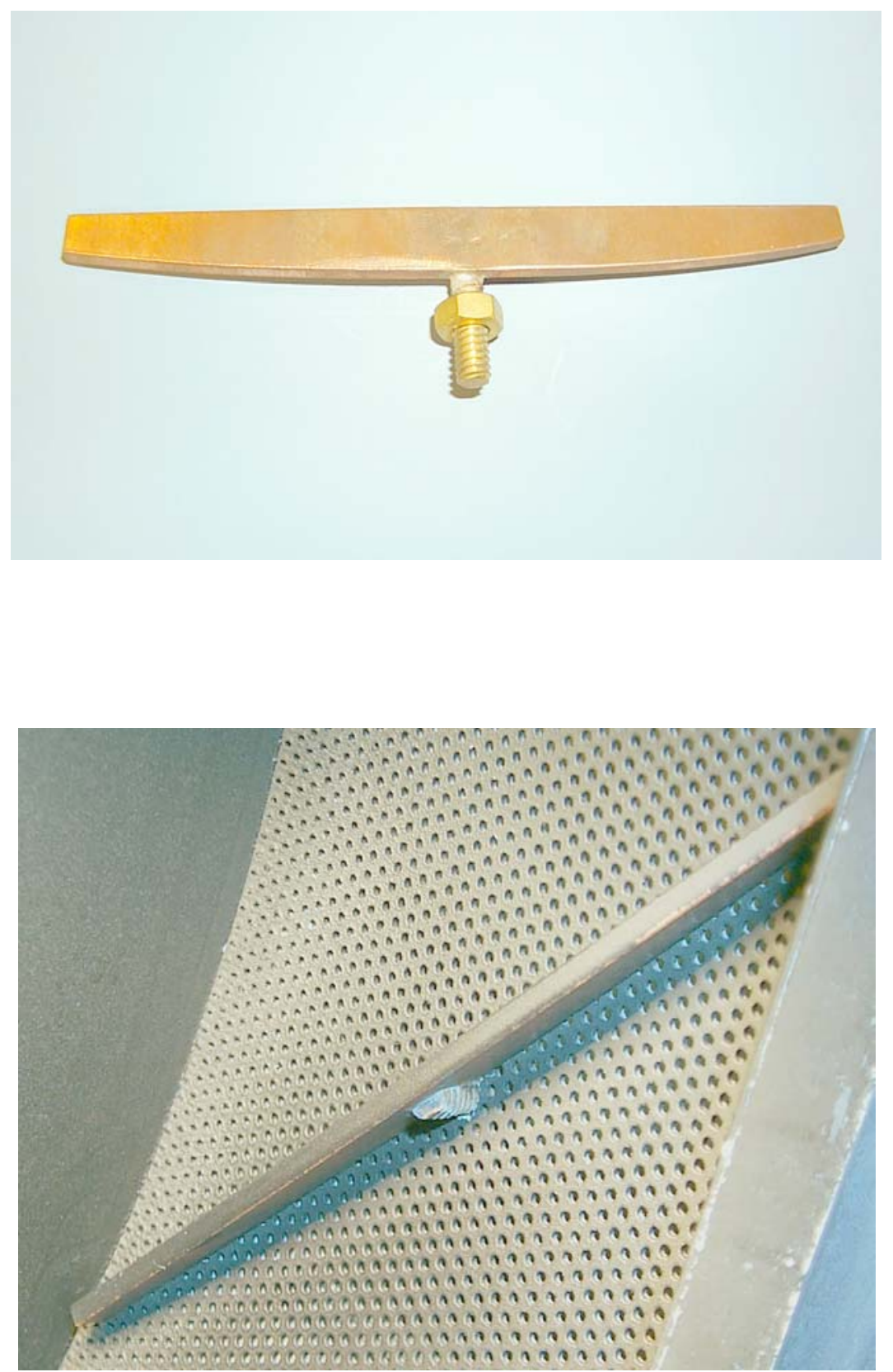

Figure 3.6: Photographs of design of baffles (a) side view (b) baffle placed in the drum 


\subsection{Experimental Matrix}

The experimental matrix for this project was designed to obtain data for the most important operating variables that were determined to be: drum speed, tablet size, bed loading, and baffles (Table 3.3). The three variables, drum speed, drum loading, and size of tablets were used in a full factorial design and, therefore, were investigated thoroughly. Baffles were not a part of the full factorial design. The number of levels and tests for these variables were changed to understand better the interactions and effects of each variable on the circulation rate and surface occurrence time of the tracer tablet in the bed.

The experiments were conducted in a random manner under identical conditions in order to minimize any effects of linear changes in the variables. For replications, the extreme points of the response surface were repeated. The number of tracer tablet sightings in the region of interest (ROI) on the surface of the tablet bed, over a period of 30 minutes, was observed to be in the range 1500-2000. The data obtained for this period of time can be considered statistically significant. Hence the run-time for each of the experiments conducted was 30 minutes. Drum Loading in Table 3.3 is defined in terms of the fractional fill level (f), which is the ratio of the height of the tablets in the bed (H) to the inner diameter of the drum (D) ( $\mathrm{f}=\mathrm{H} / \mathrm{D}$, shown in Figure 3.7). Two different fill levels of the drum were investigated during the course of this research which were the optimal loadings used in the industrial scale equipment. The drum fill is equivalent to the mass of tablets, which is also shown in Table 3.3. For the drum speeds, the optimal speeds used in the industry for different sizes of coating pans were considered and scaled to the rotating drum equipment used in this study. 


\begin{tabular}{|c|c|c|c|}
\hline Variable & Level 1 & Level 2 & Level 3 \\
\hline Drum Loading (H/D) & 1/8 fill $(1.4 \mathrm{~kg})$ & $1 / 4$ fill $(3.2 \mathrm{~kg})$ & - \\
\hline Tablet Size $(\mathrm{mm})$ & 6.3 & 7.9 & 10.4 \\
\hline Rotation Rate $(\mathrm{rpm})$ & 6 & 9 & 12 \\
\hline Baffles & No & Yes & - \\
\hline
\end{tabular}

Table 3.3: Experimental matrix used in factorial design

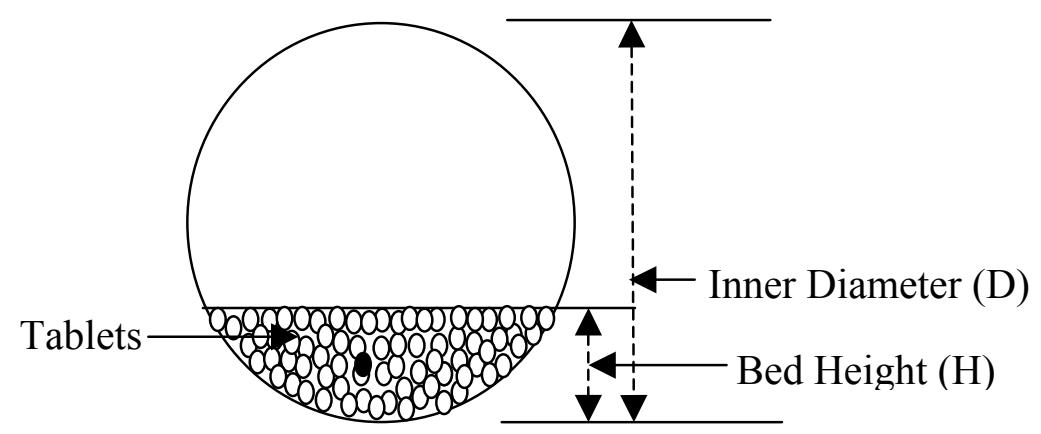

Figure 3.7: Schematic Representation of Drum Loading 


\section{Calibration and Validation of Imaging System}

In order to test the imaging equipment, and in particular the machine-vision software, a series of calibration and verification tests were carried out. These tests included the use of a circular cardboard template, a two-camera set-up and a series of experiments to validate the projected surface area of the tracer tablet calculated by the software. The results shown in this section also include standard deviation and $95 \%$ confidence interval values, the calculations of which have been explained in Appendix VI.

\subsection{Circular Cardboard Template}

A circular cardboard template, $60 \mathrm{~cm}$ in diameter, was attached to the side of the drum. Tablets were glued to this template and a single black tracer tablet was also glued to the surface of the template as shown in Figure 4.1. The camera was focused on an area of the template through which the tracer tablet would pass when the drum was rotated. The drum was rotated at different speeds while the video imaging system and software were set to capture and analyze images of the tablets. Since the drum was rotated at known speeds and the tablet was located at a known radius, the speed and occurrence time of the tablet in the region of interest (ROI) could be calculated and compared to the data from the imaging system. A schematic representation of the path of the tracer particle through the region of interest is illustrated in Figure 4.2. From Figure 4.3, which shows the raw data, it is clear that the software gives very repeatable measurements of all the variables. 


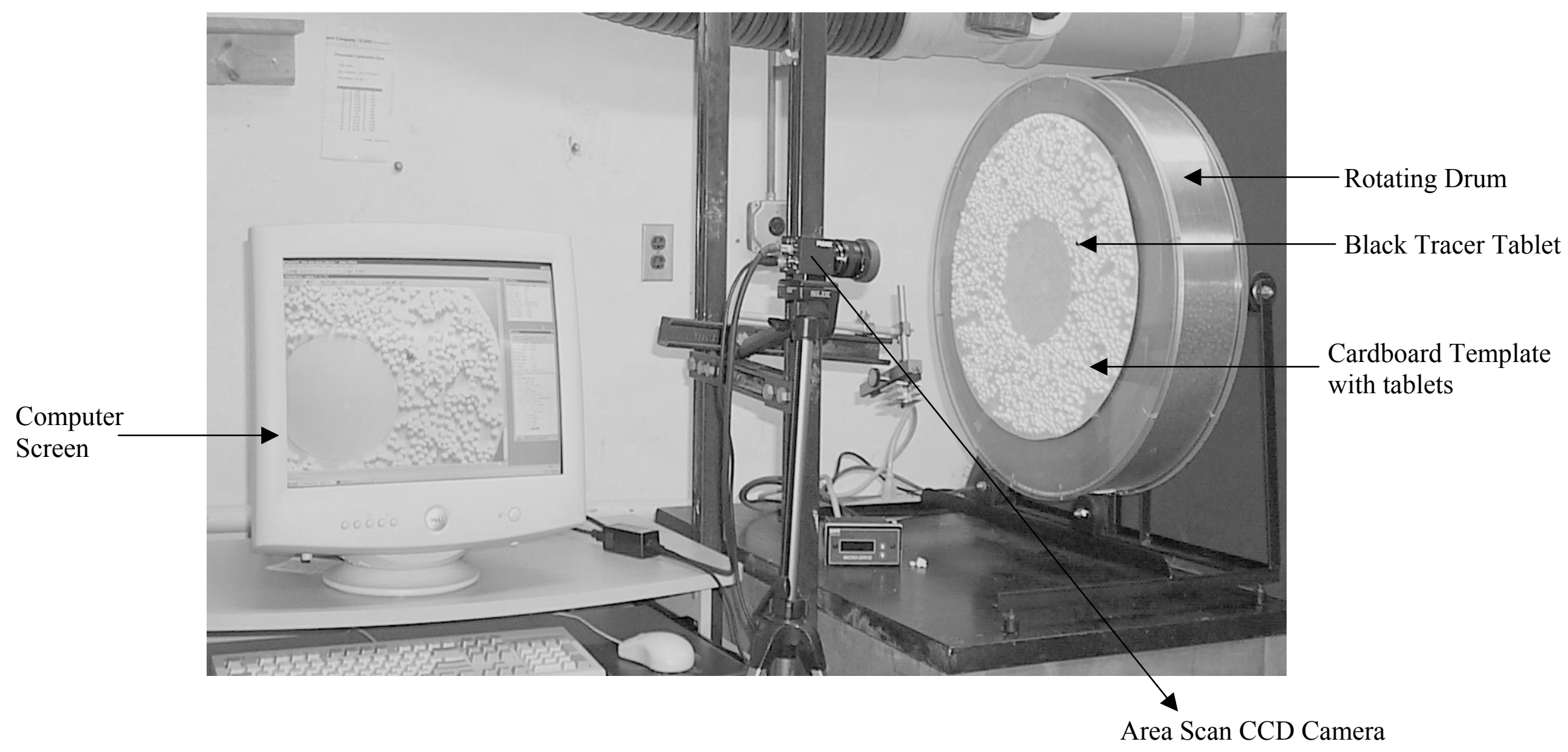

Figure 4.1: Set-up of the circular cardboard template on the side of the rotating drum 


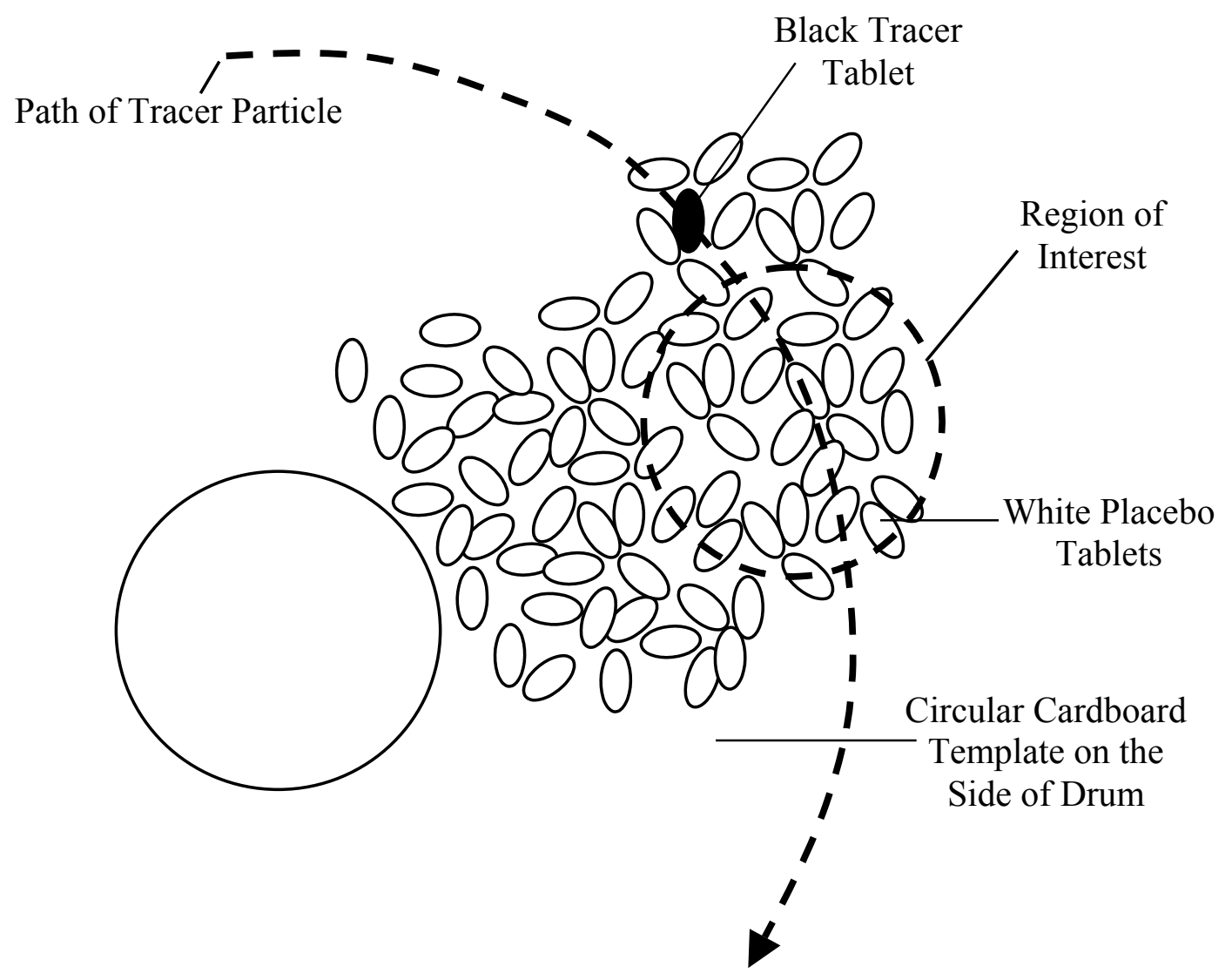

Figure 4.2: Schematic representation of the tracer particle movement through the ROI on the circular cardboard template

The mean circulation rate (Curve 1) was measured as $7.86 \pm 0.04 \mathrm{~s}$ and the time of occurrence of the tracer within the ROI (Curve 3) was measured to be $1.59 \pm 0.02 \mathrm{~s}$. These data compare with independently calculated values of 7.8 and $1.5 \mathrm{~s}$, respectively. The average projected area of the tracer in the ROI (Curve 2) was also measured and was equal to $3.86 \pm 0.09$ in normalized units. 


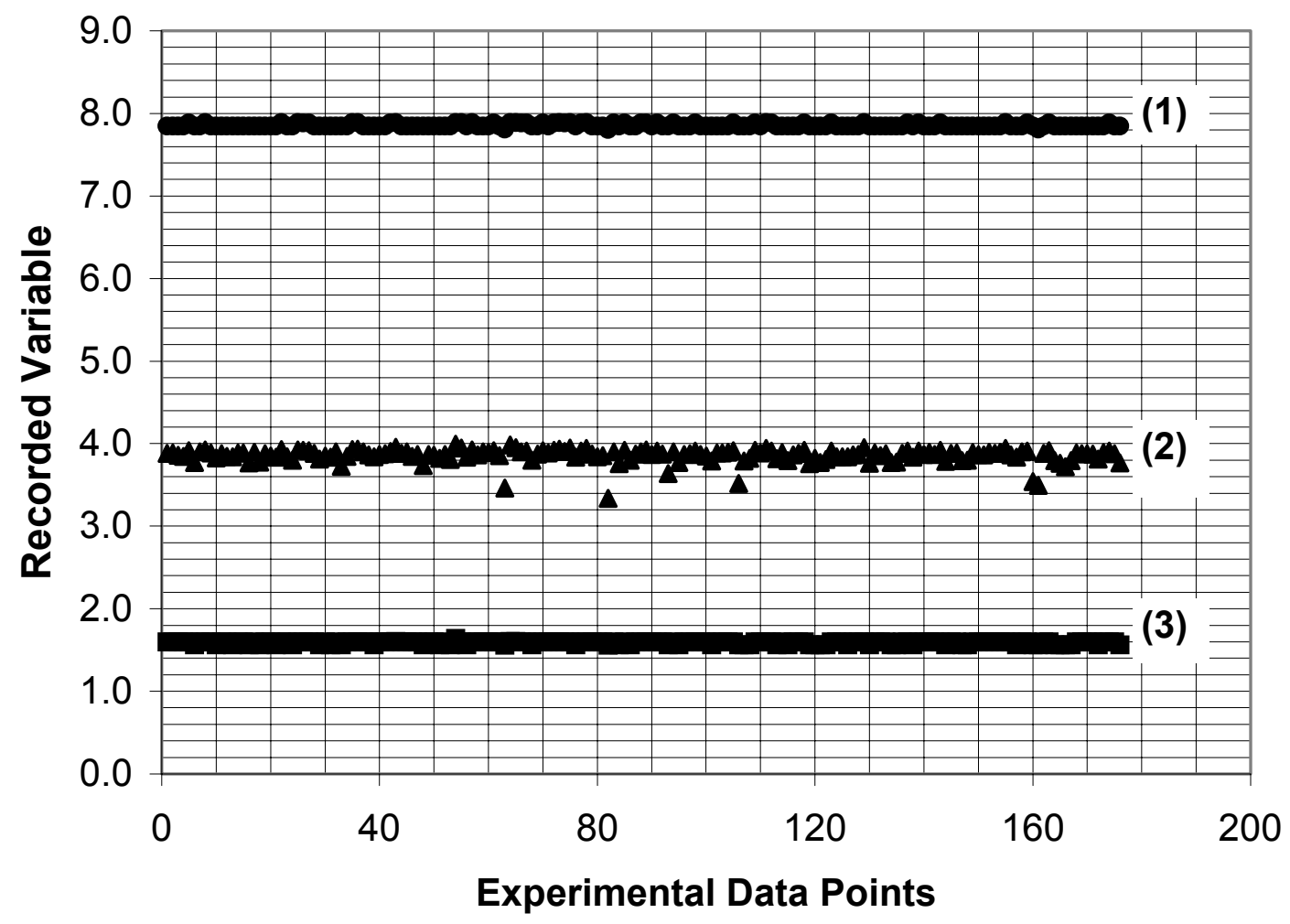

Figure 4.3: Results of validation experiments, Curve 1 - circulation time (s), Curve 2 - total projected area during the tablet sighting (normalized units), and Curve 3 - mean occurrence time in the ROI (s). 


\subsection{Two-Camera Set-up for Verification of Imaging System}

An experiment was performed to compare the number and timing of sightings of a single tracer tablet that occurred in a small rotating drum (approx. $30 \mathrm{~cm}$ in diameter) using both the imaging software and data recorded using a VCR (shown in Figure 4.4). Data were obtained from both systems for a period of approximately 1 hour and compared. The occurrences of the tracer particle observed from the video tape were in very close agreement both in number of sightings of the tracer tablet and the timings of those sightings with the data from the imaging system and machine-vision software. The error in the number of sightings was less than $7 \%$. All of these errors were due to the edge effects caused by shadows of the tablets that passed across the surface of the bed next to the walls of the drum. The ROI for the imaging system was set to be just inside the walls of drum and consequently the imaging system did not identify tablets next to the wall. Based on these experiments the white tablets-black tracer system was replaced by the black tablets-white tracer system in the subsequent experiments. The inside of the drum was also painted black with a matt-finish spray paint in order to minimize errors in the identification of the tracer tablet.

A series of experiments was conducted using a Pulnix TM-7CN (Pulnix America, Inc., Sunnyvale, CA) camera connected to Streampix software (Noesis, France). The camera used in this case had a framing rate of 30 frames/sec and the software captured frames every $0.033 \mathrm{sec}$. These frames were then manually analysed offline for the presence of the white tracer tablet. The above experiments were repeated using the black tablets-white tracer system and data was analyzed separately using Sherlock software, Streampix software, and the TV-VCR set-up. 


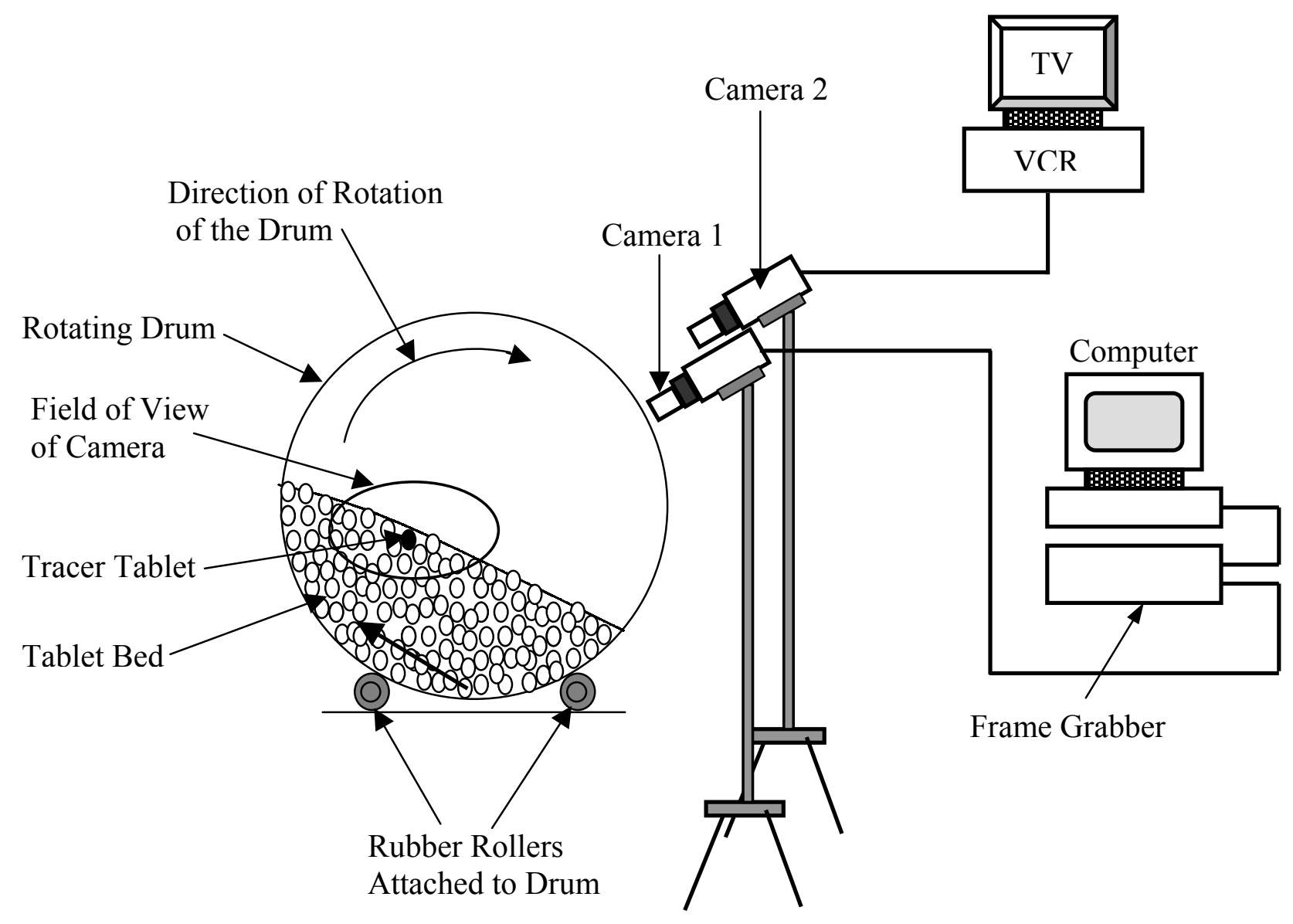

Figure 4.4: Two-camera set-up for verification of the imaging system 
The circulation time of the tracer tablets is defined as the time between successive sightings of the tracer tablet in the ROI. The method of calculation of circulation times will be discussed in Section 4.3.1. The circulation times for the tracer tablets were then calculated in each case and a comparison of results obtained with the three systems is given in Table 4.1.

\begin{tabular}{|c|c|c|c|c|}
\hline Description & $\begin{array}{c}\text { Mean Circulation } \\
\text { Time (s) }\end{array}$ & $\begin{array}{c}\text { Number of } \\
\text { Data Points }\end{array}$ & $\begin{array}{c}\text { Standard } \\
\text { Deviation (s) }\end{array}$ & $\begin{array}{c}\text { 95\% Confidence } \\
\text { Interval (s) }\end{array}$ \\
\hline VCR Set-up & 5.90 & 101 & 5.44 & \pm 1.07 \\
\hline Sherlock & 4.32 & 139 & 4.13 & \pm 0.69 \\
\hline Streampix & 5.28 & 111 & 4.55 & \pm 0.86 \\
\hline
\end{tabular}

Table 4.1: Comparison of circulation time $\left(\tau_{c i r c}\right)$ for validation of the imaging system

The table shows the mean and standard deviation values along with the $95 \%$ confidence interval values for the circulation time of the tracer tablets through the ROI in the rotating drum at $6 \mathrm{rpm}$ drum speed. The results shown in the table above were obtained for three different sets of experiments using the three systems under similar conditions. Standard two-sample t-tests assuming equal variances were conducted for the data shown in Table 4.1. The results obtained from the t-tests comparing the results using VCR set-up and the Streampix software with Sherlock software are given in Table 4.2. The table shows the value of the t-statistic calculated from the data, which is compared 
with the critical value of $t$ ( $t$-critical) assuming a $95 \%$ confidence interval. The method of calculation of the t-statistic is discussed in Appendix V.

\begin{tabular}{|c|c|c|}
\hline Description & Sherlock-VCR Set-up & Sherlock-Streampix \\
\hline $\begin{array}{c}\text { Hypothesized Mean } \\
\text { Difference }\end{array}$ & 0 & 0 \\
\hline Degrees of freedom & 238 & 248 \\
\hline t-statistic & 2.48 & 1.75 \\
\hline $\mathrm{P}(\mathrm{T} \leq \mathrm{t})$ two-tail & 0.01 & 0.08 \\
\hline $\mathrm{t}$-critical two-tail & 1.96 & 1.96 \\
\hline Summary & means are statistically & means are statistically \\
\hline
\end{tabular}

Table 4.2: Results of t-test for the three systems used for validation (two-sample assuming equal variances)

According to the results of the t-test shown in Table 4.2, there are significant differences in the $\tau_{\text {circ }}$ values recorded using the Sherlock software and VCR Set-up. This variation can be attributed to the fact that the framing rate of the camera and systems used, and the method of analysis of data obtained, in each case were different. The camera used with the VCR and Streampix set-up had a framing rate of 30 frames/sec, whereas the area scan camera used with the Sherlock set-up operated at $25 \mathrm{frames} / \mathrm{sec}$. In 
addition, when the VCR tape was operated frame by frame, the framing rate was much lower. This results in longer circulation times when the tablet is assumed to be not on the surface of the ROI, but is identified by the software. When the surface times $\left(\tau_{\text {surface }}\right)$ for both sets of data were correlated, the values of $\tau_{\text {surface }}$ were much lower with the VCR setup when compared with the Sherlock software. Hence some tablet appearances may not have been identified with the VCR set-up, but recorded when operated using Sherlock system. However there were no significant differences observed between the Streampix and Sherlock software results using the t-test. The results obtained using the Streampix software are the most accurate among the three systems used, since all the data is available frame by frame ( 30 frames/s). The above results validated the imaging system using Sherlock software and further experiments were conducted. Figure 4.5 shows the comparison of the distribution of circulation times using the three different systems discussed above. 


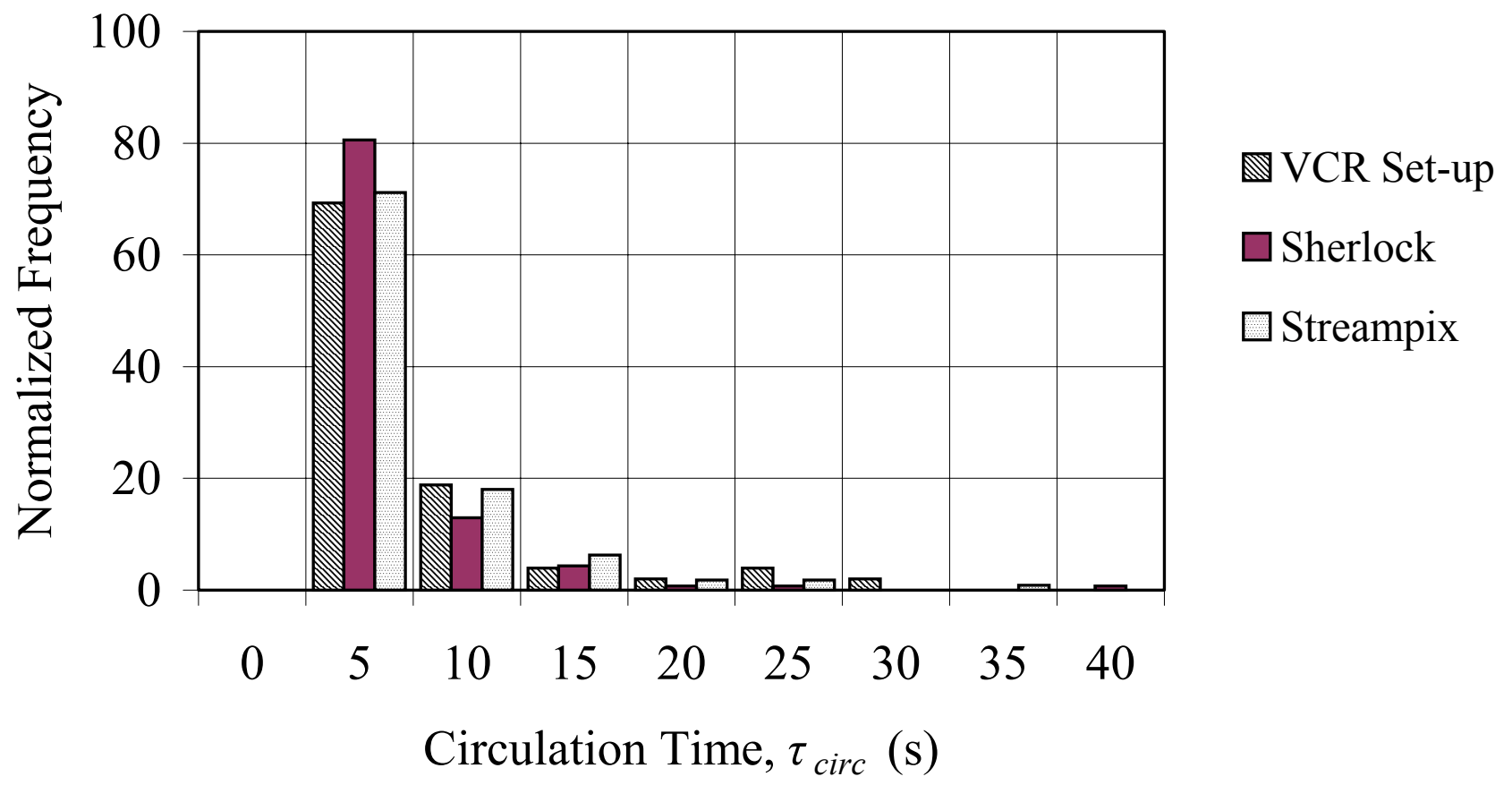

Figure 4.5: Distributions of circulation time $\left(\tau_{c i r c}\right)$ using VCR set-up, and Sherlock and Streampix software 


\subsection{Tablet Identification and Calculation of Parameters}

The CCD camera was mounted inside the rotating drum in approximately the same position as the spray gun would normally be fitted in a pan coater and was adjusted to scan an area covering the normal spray zone during a coating operation. The experimental set-up has been discussed in detail in Section 3.1. The tracer tablet is identified using Machine Vision Software. The frame grabber board captures a frame or field from the CCD camera at a given time. Each frame is then reduced to a maximum of $1 \mathrm{~kb} \times 1 \mathrm{~kb}$ array of pixel values which range from $0-255$ (0-black and 255-white). The image is thresholded and the background pixels are set to 0 . The Sherlock ${ }^{\mathrm{TM}}$ software uses edge-detection algorithms, based on the gradients of pixel values, to identify the location of the "blobs" in the array. The algorithm tries to find islands of one or more bright pixels (related by touching any of the eight neighbors in a $3 \times 3$ region) and thus estimates the center, area and the other parameters of the object. Figure 4.6 shows a pictorial representation of the pixel values in a frame and identification of the tracer tablet by Sherlock software. The figure also shows the centroid position of the "blob", marked by the software. 


\begin{tabular}{|c|c|c|c|c|c|c|c|c|c|c|c|c|c|}
\hline 0 & 1 & 3 & 0 & 1 & 3 & 1 & 2 & 4 & 1 & 2 & 4 & 0 & 1 \\
\hline 1 & 2 & 4 & 1 & 2 & 4 & 2 & 0 & 1 & 2 & 0 & 1 & 1 & 2 \\
\hline 2 & 0 & 1 & 2 & 0 & 1 & 1 & 0 & 2 & 1 & 0 & 2 & 2 & 0 \\
\hline 1 & 0 & 2 & 1 & 0 & 2 & 1 & 2 & 4 & 1 & 2 & 4 & 1 & 0 \\
\hline 3 & 0 & 1 & 0 & 1 & 3 & 2 & 0 & 1 & 2 & 0 & 1 & 0 & 1 \\
\hline 4 & 0 & 2 & 1 & 2 & 4 & 1 & 0 & 2 & 1 & 0 & 2 & 1 & 2 \\
\hline 3 & 0 & 1 & 2 & $\therefore 0$ & $-\bar{T}$ & 145 & 165 & 720 & 7 & 4 & 1 & 2 & 0 \\
\hline 4 & 1 & 0 & 1 & Q & 72 & 197 & 199 & 199 & 94 & 1 & 2 & 1 & 0 \\
\hline 1 & 2 & 1 & 0 & 32 & 203 & 200 & 200 & 203 & 180 & 31 & 1 & 0 & 1 \\
\hline 2 & 1 & 2 & 1 & 77 & 197 & 199 & 199 & 197 & 199 & 102 & 1 & 1 & 2 \\
\hline 1 & 0 & 1 & 0 & 102 & 177 & 194 & 200 & 177 & 194 & 143 & 2 & 2 & 0 \\
\hline 2 & 1 & 4 & 1 & 143 & 199 & 201 & 203 & 199 & 201 & 163 & 1 & 1 & 0 \\
\hline 1 & 3 & 1 & 2 & 163 & 197 & 197 & 203 & 197 & 197 & 183 & 2 & 0 & 1 \\
\hline 2 & 4 & 2 & 1 & 188 & 188 & 200 & 197 & 188 & 200 & $15 t$ & 1 & 1 & 2 \\
\hline 0 & 1 & 1 & 0 & 54 & 197 & 199 & 177 & 194 & 199 & 102 & 2 & 2 & 0 \\
\hline 0 & 2 & 2 & 1 & 92 & 187 & 200 & 199 & 201 & , 198 & 88 & 1 & 1 & 0 \\
\hline 1 & 3 & 2 & 3 & 57 & 201 & 201 & 197 & 197 & 200 & 32 & 0 & 1 & 0 \\
\hline 2 & 4 & 1 & 4 & $\lambda$ & 124 & 204 & 188 & 200 & 120 & $\therefore 0$ & 2 & 1 & 0 \\
\hline 0 & 1 & 2 & 1 & $<-2$ & -4 & -73 & 130 & 90 & --1 & -19 & 1 & 0 & 1 \\
\hline 4 & 1 & 3 & 2 & 1 & 1 & 2 & 0 & 1 & 0 & 0 & 2 & 1 & 2 \\
\hline 1 & 2 & 4 & 1 & 0 & 2 & 1 & 0 & 2 & 1 & 0 & 1 & 2 & 0 \\
\hline 2 & 1 & 1 & 2 & 1 & 4 & 1 & 0 & 1 & 2 & 1 & 0 & 1 & 0 \\
\hline 4 & 1 & 2 & 0 & 2 & 1 & 0 & 2 & 1 & 0 & 0 & 2 & 1 & 0 \\
\hline 0 & 2 & 1 & 0 & 1 & 0 & 0 & 1 & 0 & 0 & 0 & 1 & 0 & 1 \\
\hline 0 & 1 & 0 & 1 & 2 & 1 & 0 & 2 & 1 & 0 & 0 & 2 & 1 & 2 \\
\hline 0 & 2 & 1 & 2 & 1 & 2 & 0 & 1 & 2 & 0 & 0 & 1 & 2 & 0 \\
\hline 0 & 1 & 2 & 0 & 0 & 1 & 1 & 0 & 1 & 1 & 1 & 0 & 1 & 0 \\
\hline
\end{tabular}

Figure 4.6: Identification of the tracer tablet by Sherlock software based on the gradient of pixel values in a frame 
The software is programmed to identify and record the area, location of the centroid and the number of blobs in the region of interest. The total processing time for the above is about $20-30 \mathrm{~ms}$ and the new frame or field is then grabbed $40 \mathrm{~ms}$ after the previous frame. The image acquisition and analysis is accomplished in near real-time (40ms) by this set-up. Figure 4.7 shows the digitized images of tablet movement through the region of interest. These images depict the movement of the tracer tablet as it passes through the region of interest. The change in the orientation of the tablet on the surface, projected towards the camera is easily seen in Figure 4.6. Table 4.2 also shows a portion of raw data for $7.9 \mathrm{~mm}(5 / 16 \mathrm{inch})$ tablets with $1 / 8$ drum loading and 9 rpm pan speed.

As evident from Table 4.2, the software gives values for the number of "blobs" or tracer tablet identified. This value was either 0 or 1, 0 for no tracer tablet in ROI on the surface, and 1 for the presence of a tracer tablet on the surface. The software identified the presence or absence of a single tracer tablet, i.e., the software never identified the presence of more than one tracer tablet. In addition, when the experiment was repeated without the tracer tablet in the drum, the software did not register any tracer tablet sightings. This fact further confirms the ability of the software to distinguish accurately between a white tablet and the black placebo tablets. The time at which the tracer tablet is in view in the ROI is saved as millisecond time. This time is recorded from the computer clock at the instant the tracer particle is identified by the software. The circulation and surface times are calculated from this time given by the software as discussed in Sections 4.3.1 and 4.3.2. 

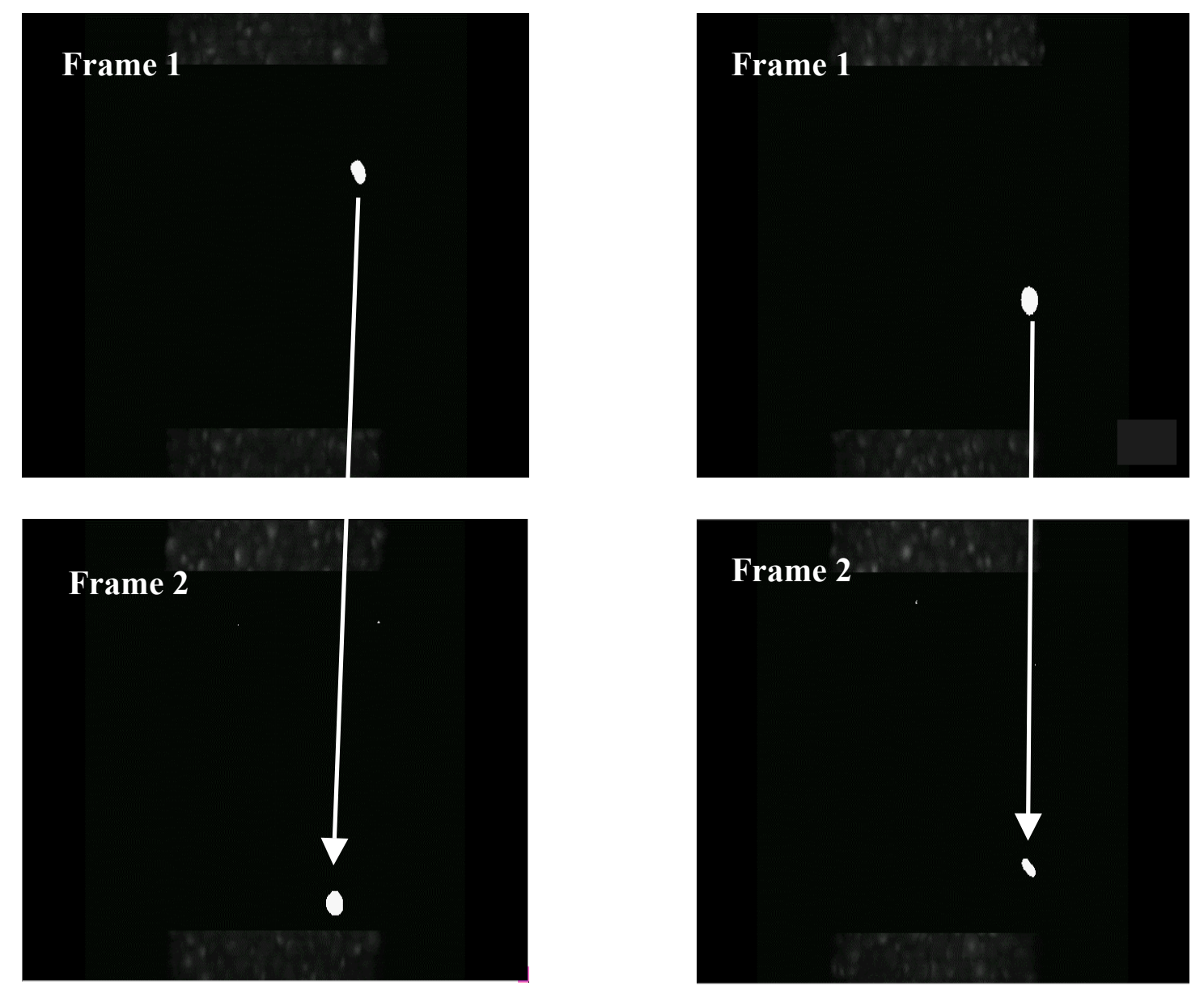

Figure 4.7: Digitized images of tablet movement through ROI 


\begin{tabular}{|c|c|c|c|c|c|c|c|}
\hline \#Blobs & Height (pixel) & Width (pixel) & Area (pixel) & Centroid x & Centroid y & Occupation Ratio (\%) & Clock Time \\
(ms)
\end{tabular}

Table 4.3: Raw Data for $7.9 \mathrm{~mm}$ tablets, $1 / 8$ drum loading and 9rpm drum speed 
In Section 4.3.3, the method of calculation of surface area by the software is explained. The software marks the smallest imaginary box around the tracer tablet it identifies and gives the dimensions of the box as height and width in pixel values. Based on the average pixel values in the imaginary box, it gives an occupation ratio for the tracer tablet in the box. Occupation ratio is the percentage of the bounding box that contains the connected pixels. A square "blob" for example, will have an occupation ratio of 100, while a thin line "blob" may have an occupation ratio of less than 10.

The center of the box is identified as the centroid position of the "blob" with respect to the ROI, and estimated as $x$ and $y$ values, which gives the location of the tracer tablet in the ROI. These centroid $x$ and $y$ values were used to calculate the surface velocity of the tablets both parallel and perpendicular to the direction of flow as detailed in Section 4.3.4. Data is stored by Sherlock software as a text file and Microsoft Visual Basic and Excel are used to sort and analyze the data further. The Sherlock and Visual Basic programs used have been included as Appendices II, III and IV.

\subsubsection{Calculation of Circulation Time $\left(\tau_{\text {circ }}\right)$}

Circulation time, $\tau_{\text {circ }}$, is defined as the time between successive sightings of the tracer tablet in the ROI that is longer than some cut-off time. The cut-off time was set at $500 \mathrm{~ms}$, which is longer than any period of successive tablet sightings on the bed surface but smaller than the minimum time needed for the tablet to pass through and subsequently re-enter the ROI. The choice of cut-off time was somewhat arbitrary but the results did not change for cut-off times in the range of $300 \mathrm{~ms}-600 \mathrm{~ms}$. This is relevant to coating operations since, it is postulated, that only when the tablet can "see" the nozzle will it receive coating material. The value of $\tau_{\text {circ }}$ obtained in the current work 
represents the time for the tablet to make complete circuits through the top surface of the bed. The average value of $\tau_{\text {circ }}$ obtained from this work is not equal to the "cycle time" as defined by Mann (1972), since in this work the tablet may circulate without being detected at the surface of the tablet bed. Figure 4.8 shows a schematic representation for the calculation of circulation time.

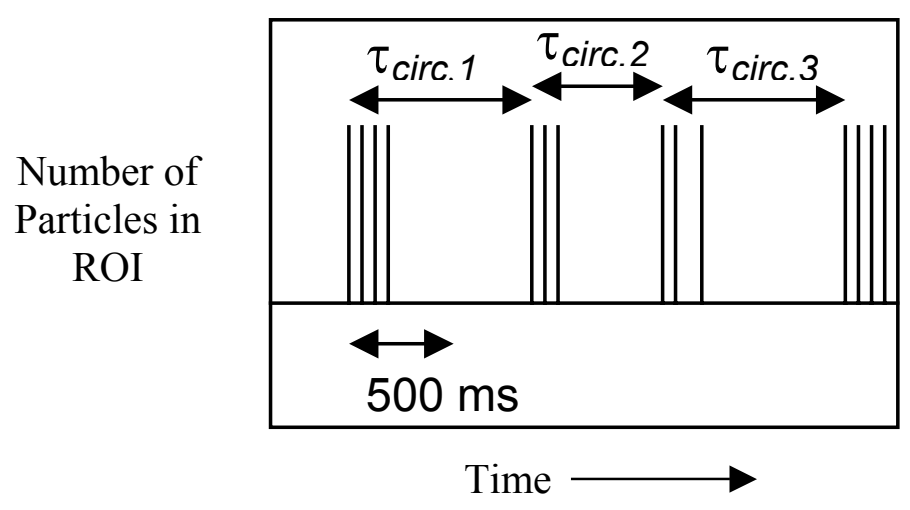

Figure 4.8: Calculation of circulation time

As explained in Section 4.3, the time of appearance of the tracer tablet in the ROI is saved as millisecond time $(t)$. The value of $\tau_{\text {circ }}$ is calculated as the difference in the time when the tracer tablet first appears on the surface and the time recorded for the previous first appearance of the tablet in the ROI (Figure 4.8). A Microsoft Visual Basic program was developed to perform these calculations and has been included as Appendix III. For example, the program scans the raw data file for the first appearance of the tablet and records this time as $t_{1}$. The time for the next appearance is recorded as $t_{n}$ and the difference between these two times is calculated $\left(\Delta t=t_{l}-t_{n}\right)$. If the value of $\Delta t \geq 500 \mathrm{~ms}$, this time is saved as $\tau_{\text {circ, },}$; else the program scans further for the next appearance of the tablet and records the time as $t_{n+I}$ and computes the value of $\Delta t$. The same procedure is repeated for all the data. The program also records the number of successive frames that 
the tracer tablet is in view per pass, as $n$. This value is used to calculate the surface times and the average projected surface areas.

\subsubsection{Calculation of Surface Time ( $\left.\tau_{\text {surface }}\right)$}

Surface Time $\left(\tau_{\text {surface }}\right)$ defined as the time that a particle spends on the surface within the spray zone during each pass is calculated by multiplying the number of frames that the tracer particle is visible in the ROI on the surface $(n)$ with the time for processing each frame, which is illustrated in Figure 4.9. The surface time is thus a multiple of the time for each frame $([n][40] \mathrm{ms})$.

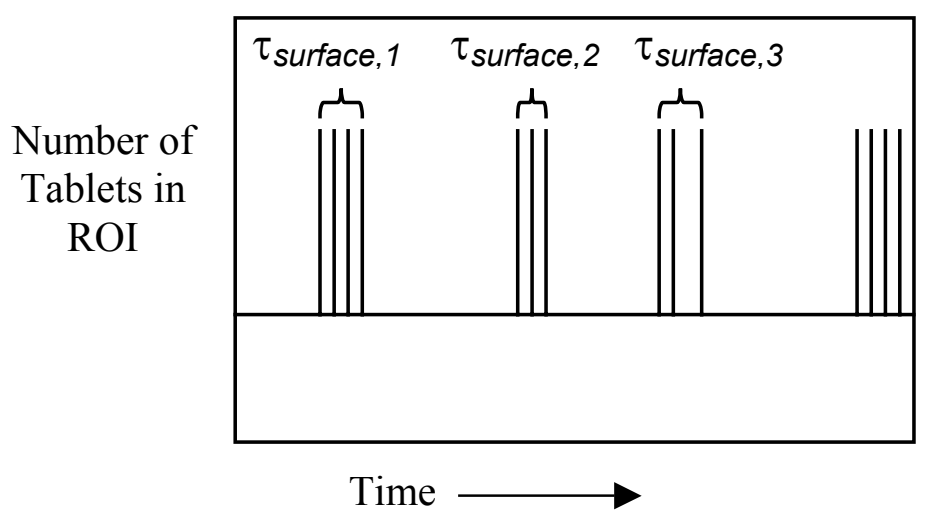

Figure 4.9: Calculation of surface time

\subsubsection{Calculation of Projected Surface Area $\left(A_{t a b}\right)$}

The surface area of the tablet projected towards the spray source (nozzle), during each pass through the spray zone or ROI, is defined as $A_{t a b}$. Every time that the software identifies the white tracer tablet within the ROI, it draws the smallest imaginary box that completely encapsulates the projected image of the tablet. Using the average pixel value within the box, and the known pixel values for the tracer tablet and other placebo tablets, 
the software calculates an occupation ratio. The projected tablet area, $A_{t a b}$, can then be estimated from the relationship shown in Figure 4.10.

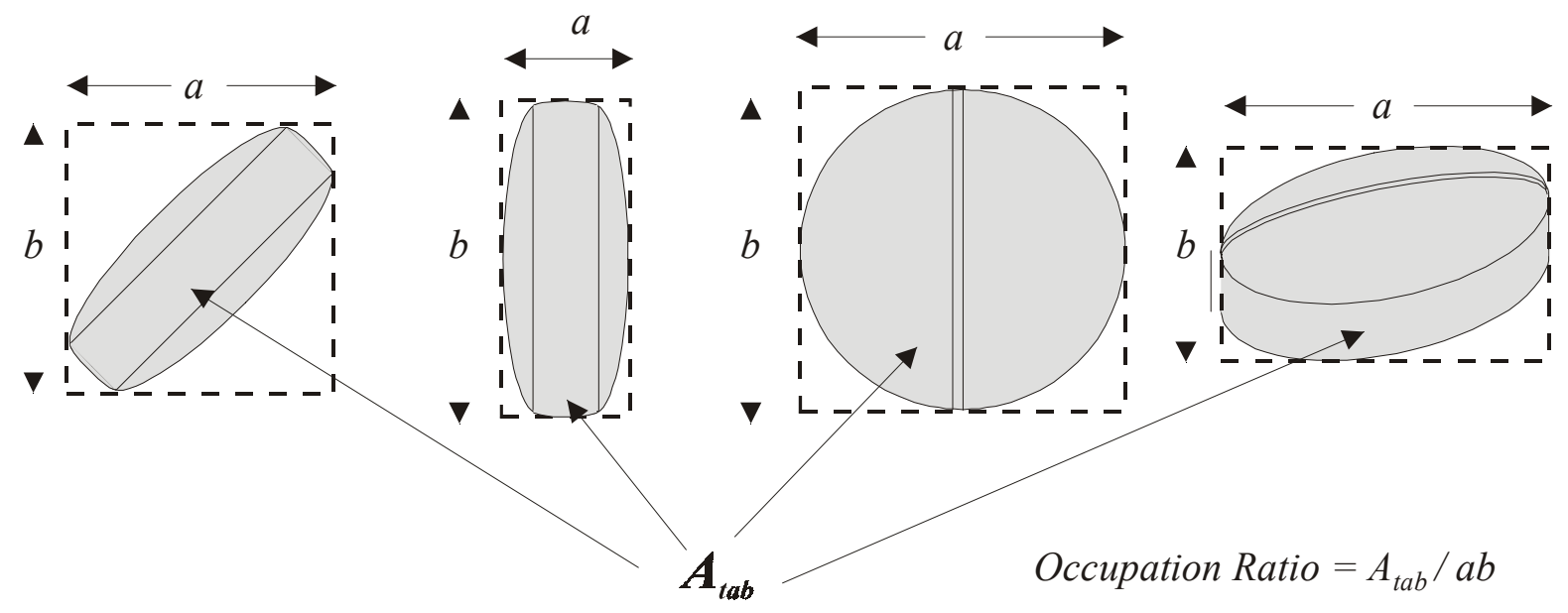

Figure 4.10: Calculation of projected surface area

The projected surface area of the tablet that is visible on the surface in the ROI for $n$ frames can be calculated from the equation, $A_{t a b}=\sum\left(A_{t a b, i}\right) / \mathrm{n}$. The projected area is estimated by the software in pixel values and hence has to be calibrated and converted to SI units. The raw data file (Table 4.2) is scanned for the maximum area, assuming that during the run-time of the experiment there is at least one instance when the largest face of the tablet is completely visible on the surface and maximum surface area of the tracer tablet is exposed towards the camera. The actual projected surface area of the tablet $\left(A_{\text {actual }}\right)$ is calculated knowing the dimensions in SI units. The area factor is calculated as the ratio of $A_{\text {actual }}$ and $A_{\max }\left(\right.$ Area Factor $\left.=A_{\text {actual }} / A_{\max }\right)$. This area factor is then used to multiply the areas saved by the software in pixel values to obtain the $A_{t a b}$ values in SI units. This procedure is repeated for each experiment conducted, thus the relative distance between the tablet bed height and the camera changes with drum speed, drum 
loading, etc. and the values of $A_{\max }$ may be different depending on the experimental conditions used. The values of the area factor will also be different for each experiment.

\subsubsection{Validation of Projected Surface Area $\left(A_{t a b}\right)$}

As discussed above, Sherlock software estimates the projected surface area. In order to validate the values of the surface area given by the software a series of experiments was conducted using different tracer tablets, the images of which are shown in the Figure 4.11. The principle used was that the sum of surface areas estimated by the software using the tracer tablets with two sides painted white (Tablet $b$ ) and white ring on the side of the tablet (Tablet $c$ ) should be equal to the surface area obtained using the full white tracer tablet (Tablet a). Experiments were conducted using the three different tracer tablets shown in Figure 4.11 at two different drum speeds of 6 and 9 rpm using the 7.9 $\mathrm{mm}(5 / 16$ inch) tablets with $1 / 8$ drum loading. The projected surface areas estimated by the software for each of the tracer tablets are shown in Table 4.3 along with standard deviation and $95 \%$ confidence interval values. At both the drum speeds, the sum of the surface areas for tablets $b$ and $c$ are not equal to the area obtained with the full white tablet (a). However the $95 \%$ confidence intervals about means for tablet $a$, and tablets $b$ and $c$ together overlap. The distributions for the projected surface areas using each of the tracer tablets at different drum speeds have been included as Appendix I.

From the above calibration and validation experiments, it was concluded that the software gives repeatable and accurate measurements for all the parameters. Experiments could hence be conducted by changing the different variables according to the experimental matrix. 

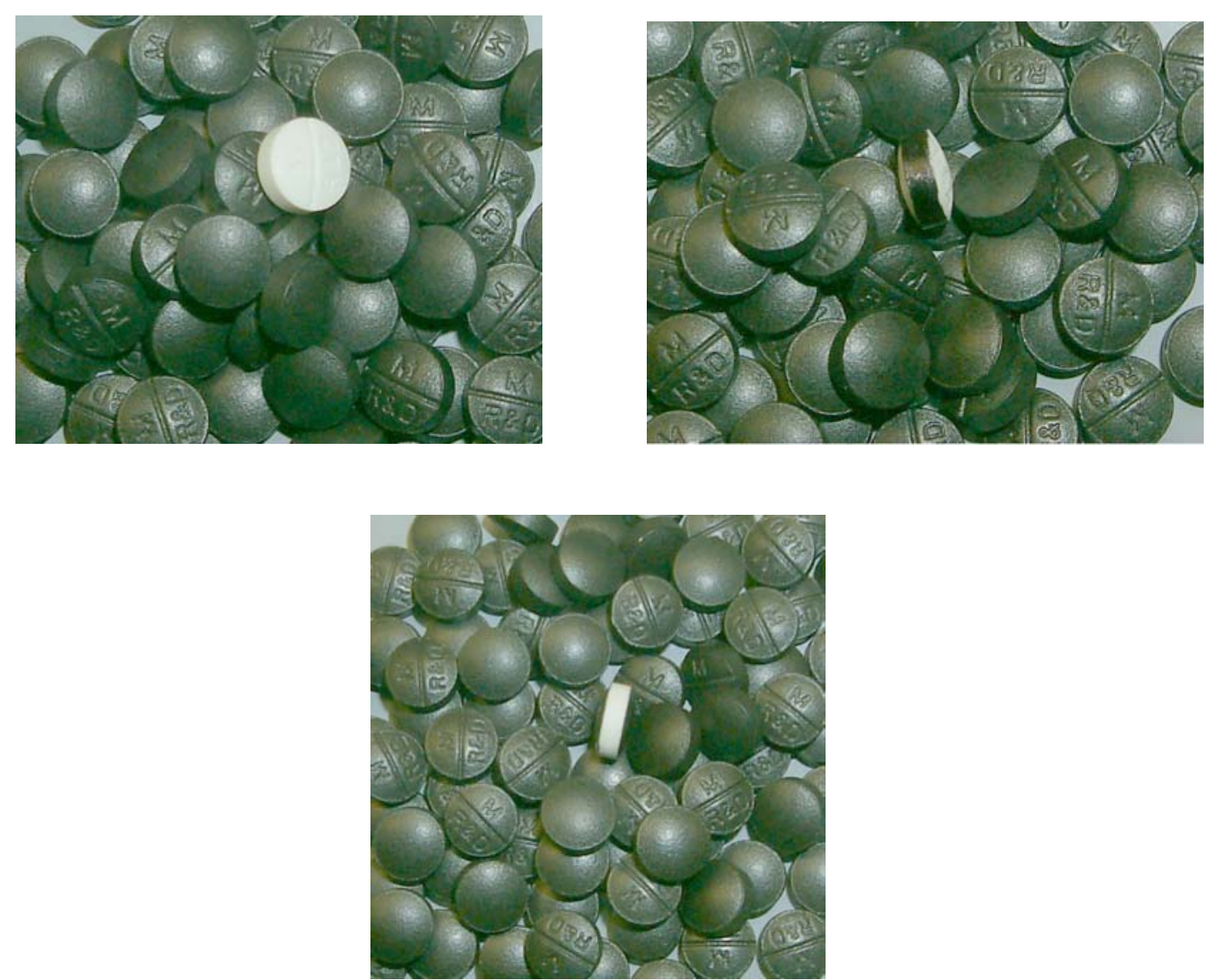

Figure 4.11: Images of tracer tablets used for validation (a) full white tablet, (b) two sides white, (c) white ring on the side 


\begin{tabular}{|c|c|c|c|c|}
\hline Tablet & $\begin{array}{c}\text { Drum Speed } \\
(\mathrm{rpm})\end{array}$ & $\begin{array}{c}\text { Average Area } \\
\left(\mathrm{mm}^{2}\right)\end{array}$ & $\begin{array}{c}\text { Standard } \\
\text { Deviation }\left(\mathrm{mm}^{2}\right)\end{array}$ & $\begin{array}{c}\text { 95\% Confidence } \\
\text { Interval }\left(\mathrm{mm}^{2}\right)\end{array}$ \\
\hline \multirow{2}{*}{ White Ring } & 6 & $\longrightarrow 25.3$ & 21.5 & \pm 2.5 \\
\cline { 2 - 5 } & 9 & 23.9 & 18.4 & \pm 2.2 \\
\hline \multirow{2}{*}{$\begin{array}{c}\text { Two Sides } \\
\text { White }\end{array}$} & 6 & $\longrightarrow 61.0$ & 61.6 & \pm 6.3 \\
\cline { 2 - 5 } & 9 & 60.0 & 53.1 & \pm 5.2 \\
\hline \multirow{2}{*}{ Full White } & 6 & $\longrightarrow 89.0$ & 76.8 & \pm 7.9 \\
\cline { 2 - 5 } & 9 & 77.4 & 69.6 & \pm 6.4 \\
\hline
\end{tabular}

Table 4.4: Projected surface area values for $7.9 \mathrm{~mm}$ tablets and 1/8 drum fill

\subsubsection{Calculation of Surface Velocities $\left(V_{x}, V_{y}\right)$}

The Sherlock software also gives the centroid position of the tracer that it identifies as explained in Section 4.3 (Figure 4.12), with respect to the ROI as $x$ and $y$ values, which gives the location of the tracer tablet in the ROI. These centroid $x$ and $y$ values were used to calculate the surface velocity of the tablets both parallel and perpendicular to the direction of flow, which will be discussed in this section. The figure below shows the path of a tracer tablet through the ROI and the centroid positions $(x, y)$ at different time points.

The values of centroid positions are given by the software in pixel units and hence have to be converted into SI units using a conversion factor in order to estimate the surface velocities as detailed in Section 4.3.3. The diameter of the tablet in pixels $\left(d_{\text {pixel }}\right)$ is calculated from $A_{\max }$. The actual diameter of the tablet is known in SI units $\left(d_{\text {actual }}\right)$ and the velocity conversion factor is calculated as the ratio of $d_{\text {actual }}$ and $d_{\text {pixel }}$ (Velocity factor $\left.=d_{\text {actual }} / d_{\text {pixel }}\right)$. 


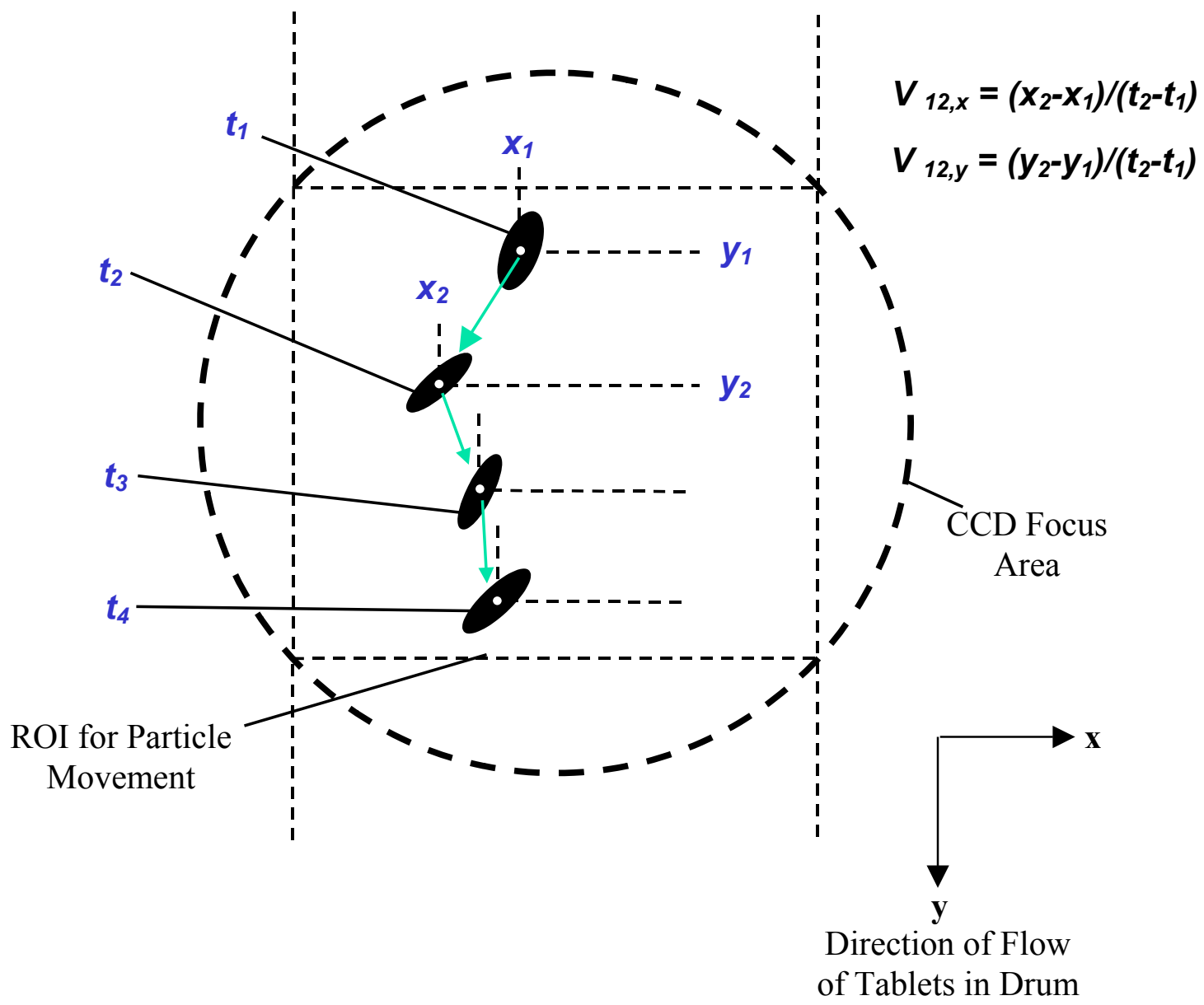

Figure 4.12: Movement of tracer tablet in ROI

This factor is multiplied with the centroid position values $(x, y)$ in pixels to obtain the different positions of the tablets in the ROI in SI units. In addition, the times at which the tracer particle appears on the surface $(t)$ are already known. The velocity parallel to the flow of tablets in the y-direction $\left(V_{y}\right)$, is calculated as $\Delta y / \Delta t$. Similarly the velocity of tablets perpendicular to the flow in the $x$-direction $\left(V_{x}\right)$ is calculated as $\Delta x / \Delta t$. The values of $V_{x}$ and $V_{y}$ are thus obtained in SI units. A programming sequence was developed using Microsoft Visual Basic (Appendix IV) for the calculations discussed above. The values of $V_{x}$ should have an average around zero, which means that there is 
no net axial movement of the tablets in the present set-up i.e. the tablets move back and forth in the x-direction, but on average there is no net movement perpendicular to the flow. 


\section{Results and Discussion}

Experiments were conducted according to the experimental matrix discussed in Section 3.4, each for a period of 30 minutes. The results for each of the parameters will be discussed in this section. Figure 5.1 shows a portion of typical raw data obtained for the tablets at a particular drum speed and drum loading. This figure is a pictorial representation of the surface time, where the thickness of the lines is proportional to the number of consecutive sightings on the surface in the ROI. For the results discussed in this chapter, the statistical analysis is detailed in Section 5.5. The results also include standard deviation and $95 \%$ confidence interval values, the definitions and calculations of which have been explained in Appendix VI.

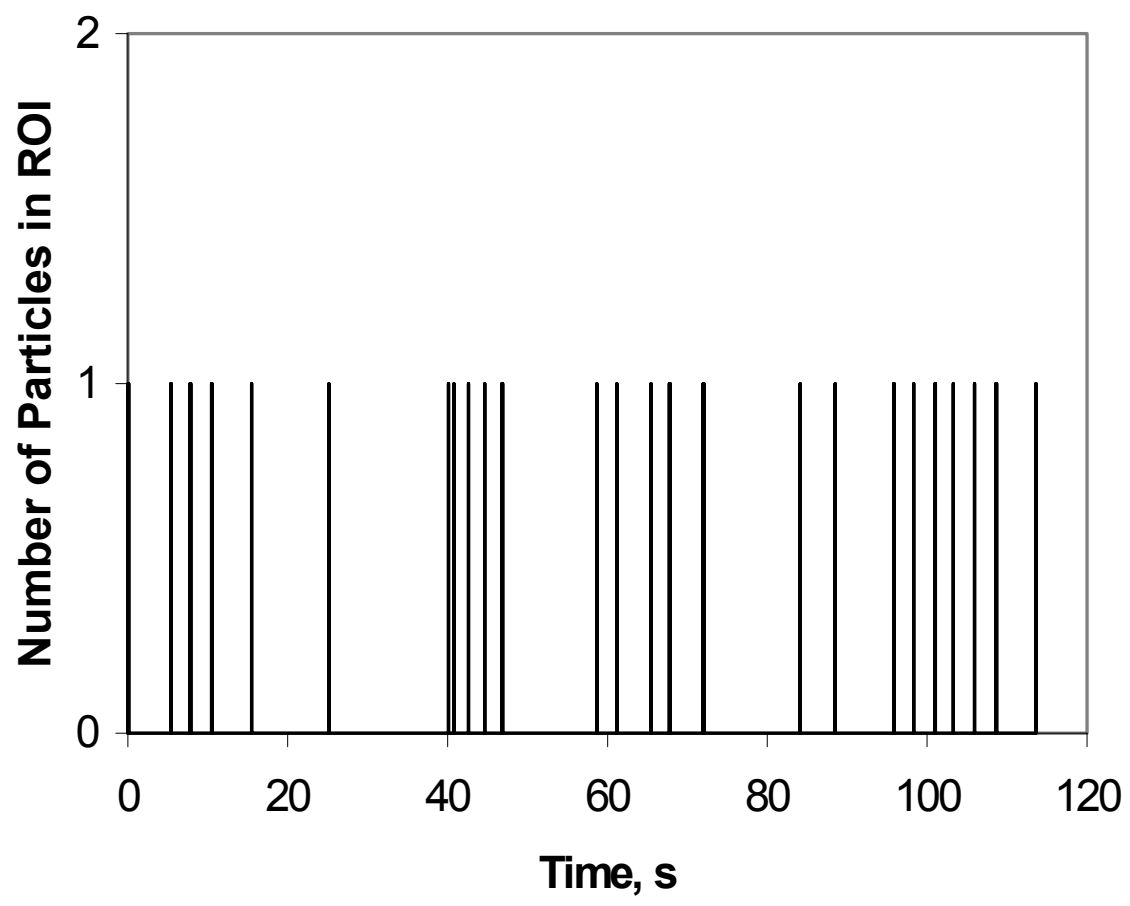

Figure 5.1: A portion of raw data 


\subsection{Circulation Time $\left(\tau_{\text {circ }}\right)$}

As discussed in Section 4.3.1, $\tau_{\text {circ }}$ is defined as the time between successive sightings of the tracer tablet in the ROI. The mean values for circulation times are given in Table 5.1 along with the standard deviation and 95\% confidence interval values for the different tablet sizes, pan speeds and pan loadings. Figures 5.2 and 5.3 show the mean and standard deviations of the distributions of circulation time for both $1 / 8$ and $1 / 4$ drum loadings as functions of drum rotation rate. There is a general decrease in the average circulation time as the drum speed increases. The larger tablets have lower $\tau_{\text {circ }}$ values, which implies that the larger tablets move faster than the smaller tablets through the tablet bed. The higher average circulation times for the smaller tablets also indicate that there may be slip between the tablets and the drum wall, making them circulate slower.

Inherent dead zones are formed in the coating pan, at the center of the tablet bed, leading to non-uniform tablet appearances at the surface of the tablet bed. Baffles may promote uniform mixing and eliminate the formation of these dead zones in the tablet bed, thus improving the tablet circulation and coating uniformity. Table 5.2 gives the values obtained for mean $\tau_{\text {circ }}$ using baffles in the rotating drum, with the standard deviation and $95 \%$ confidence interval values. The results obtained for the distributions of circulation time for $1 / 8$ drum loading have been compared for both the systems with no baffles and with baffles in Figure 5.4. However with the use of baffles, there should be an improvement in the distribution of $\tau_{\text {circ }}$. Figures 5.5 and 5.6 show the circulation time distributions for the two systems with $7.9 \mathrm{~mm}$ (5/16inch) tablets, 9rpm drum speed, and 1/8 fill and 1/4 fill respectively. 
Drum loading has an effect on the circulation time, with higher $\tau_{\text {circ }}$ values observed in the case of higher drum loading. This is due to the fact that the tablets have to circulate through a larger bed and hence take more time to reappear on the surface. Also in the case of higher drum loadings, dead zones may form in the center region of the bed where the tablets get entrapped, thus leading to greater standard deviations in the circulation times for an experiment. This high variation causing large standard deviations is defined as uneven circulation time distribution, which can primarily be held responsible for the uneven exposure that leads to variation in the coat thickness between different tablets in the pan coater. 


\begin{tabular}{|c|c|c|c|c|c|}
\hline $\begin{array}{c}\text { Tablet Size } \\
(\mathrm{mm}) \\
\end{array}$ & $\begin{array}{c}\text { Drum } \\
\text { Loading (fill) } \\
\end{array}$ & $\begin{array}{c}\text { Drum Speed } \\
(\mathrm{RPM}) \\
\end{array}$ & Mean $\tau_{\text {circ }}(\mathrm{s})$ & \begin{tabular}{|c|} 
Standard Deviation \\
$(\mathrm{s})$
\end{tabular} & $\begin{array}{c} \pm 95 \% \text { Confidence } \\
\text { Interval (s) } \\
\end{array}$ \\
\hline 6.3 & $1 / 8$ & 6 & 9.16 & 11.96 & 1.69 \\
\hline 6.3 & $1 / 8$ & 6 & 9.64 & 11.18 & 1.64 \\
\hline 6.3 & $1 / 8$ & 9 & 8.46 & 10.70 & 1.45 \\
\hline 6.3 & $1 / 8$ & 12 & 5.98 & 7.57 & 0.87 \\
\hline 6.3 & $1 / 8$ & 12 & 6.14 & 7.59 & 0.87 \\
\hline 6.3 & $1 / 4$ & 6 & 12.97 & 17.57 & 2.97 \\
\hline 6.3 & $1 / 4$ & 6 & 12.64 & 14.24 & 2.36 \\
\hline 6.3 & $1 / 4$ & 9 & 11.44 & 13.30 & 2.13 \\
\hline 6.3 & $1 / 4$ & 12 & 8.96 & 10.18 & 1.42 \\
\hline 6.3 & $1 / 4$ & 12 & 7.10 & 7.53 & 0.94 \\
\hline 7.9 & $1 / 8$ & 6 & 6.53 & 7.00 & 0.83 \\
\hline 7.9 & $1 / 8$ & 9 & 6.06 & 7.51 & 0.86 \\
\hline 7.9 & $1 / 8$ & 12 & 4.94 & 6.17 & 0.64 \\
\hline 7.9 & $1 / 4$ & 6 & 12.06 & 15.44 & 2.52 \\
\hline 7.9 & $1 / 4$ & 9 & 10.96 & 12.64 & 1.97 \\
\hline 7.9 & $1 / 4$ & 12 & 8.53 & 12.09 & 1.64 \\
\hline 10.4 & $1 / 8$ & 6 & 5.86 & 5.68 & 0.64 \\
\hline 10.4 & $1 / 8$ & 6 & 6.17 & 5.93 & 0.68 \\
\hline 10.4 & $1 / 8$ & 9 & 4.47 & 5.10 & 0.50 \\
\hline 10.4 & $1 / 8$ & 12 & 3.85 & 4.89 & 0.45 \\
\hline 10.4 & $1 / 8$ & 12 & 4.00 & 4.63 & 0.43 \\
\hline 10.4 & $1 / 4$ & 6 & 10.52 & 11.99 & 1.83 \\
\hline 10.4 & $1 / 4$ & 6 & 9.79 & 11.85 & 1.73 \\
\hline 10.4 & $1 / 4$ & 9 & 7.05 & 9.44 & 1.17 \\
\hline 10.4 & $1 / 4$ & 12 & 3.54 & 3.41 & 0.30 \\
\hline 10.4 & $1 / 4$ & 12 & 2.90 & 2.59 & 0.20 \\
\hline
\end{tabular}

Table 5.1: Mean circulation time $\left(\tau_{\text {circ }}\right)$ data for unbaffled system 


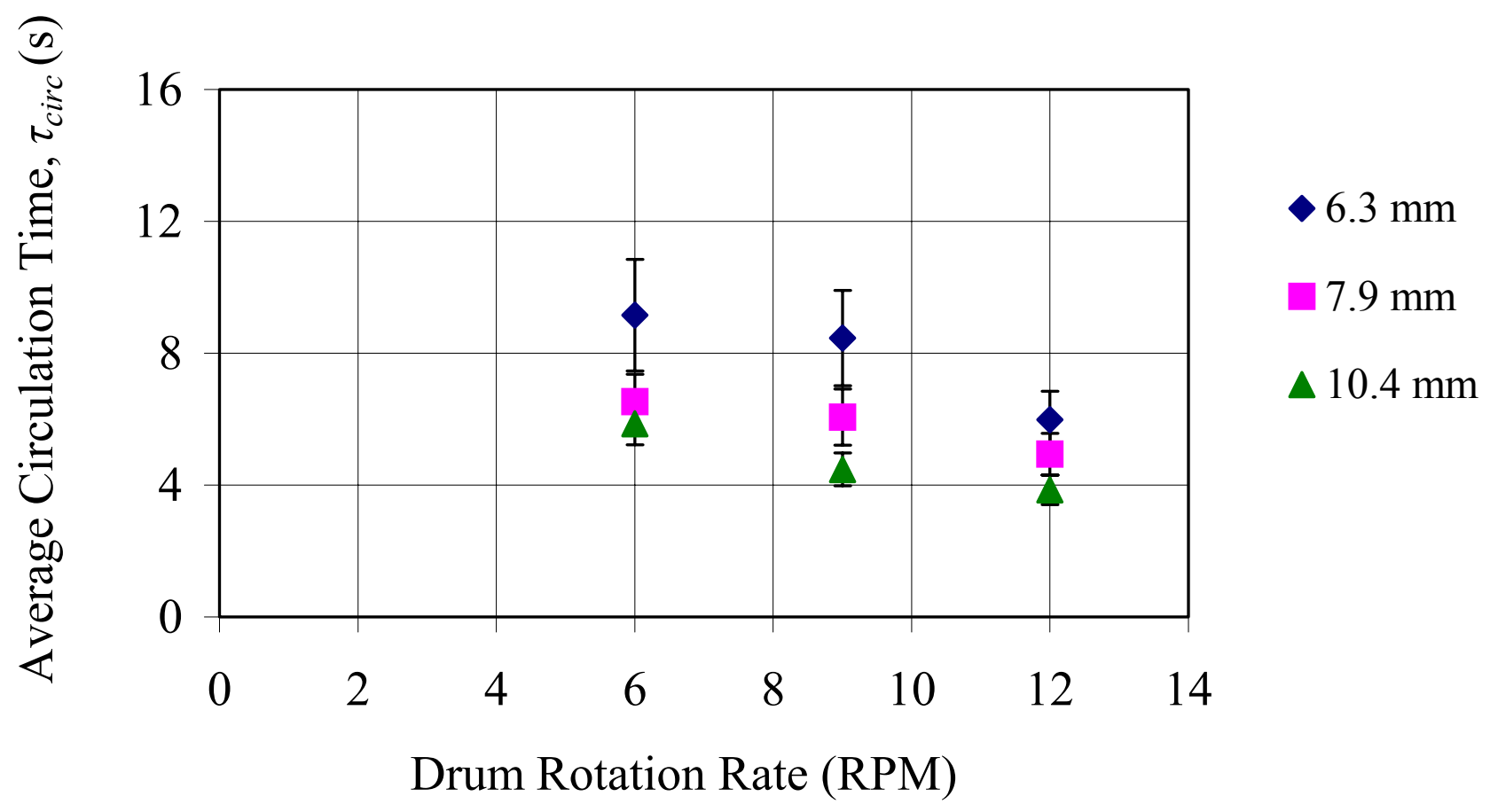

Figure 5.2: Change in average circulation time $\left(\tau_{\text {circ }}\right)$ as a function of drum rotation rate, for unbaffled system with $1 / 8$ drum loading 


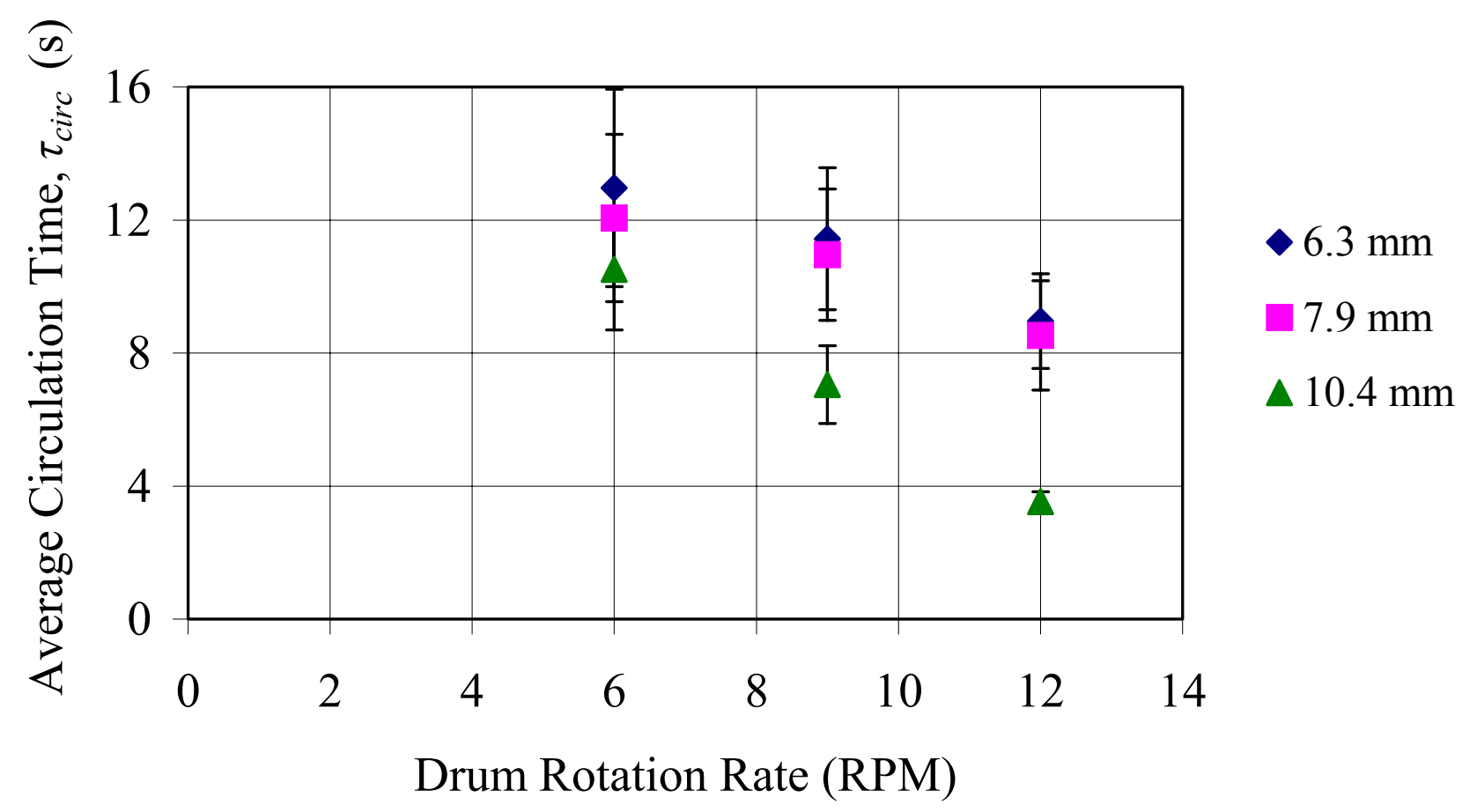

Figure 5.3: Change in average circulation time $\left(\tau_{\text {circ }}\right)$ as a function of drum rotation rate, for unbaffled system with $1 / 4$ drum loading 


\begin{tabular}{|c|c|c|c|c|c|}
\hline $\begin{array}{c}\text { Tablet } \\
\text { Size }(\mathrm{mm})\end{array}$ & $\begin{array}{c}\text { Drum } \\
\text { Loading (fill) }\end{array}$ & $\begin{array}{c}\text { Drum Speed } \\
(\mathrm{RPM})\end{array}$ & Mean $\tau_{\text {circ }}(\mathrm{s})$ & $\begin{array}{c}\text { Standard } \\
\text { Deviation (s) }\end{array}$ & $\begin{array}{c} \pm 95 \% \text { Confidence } \\
\text { Interval (s) }\end{array}$ \\
\hline 6.3 & $1 / 8$ & 6 & 9.31 & 10.27 & 1.46 \\
\hline 6.3 & $1 / 8$ & 6 & 9.21 & 11.52 & 1.64 \\
\hline 6.3 & $1 / 8$ & 9 & 5.93 & 7.24 & 0.82 \\
\hline 6.3 & $1 / 8$ & 12 & 5.19 & 5.77 & 0.61 \\
\hline 6.3 & $1 / 8$ & 12 & 5.08 & 5.42 & 0.57 \\
\hline 6.3 & $1 / 4$ & 6 & 15.50 & 22.02 & 4.09 \\
\hline 6.3 & $1 / 4$ & 6 & 13.73 & 16.15 & 2.84 \\
\hline 6.3 & $1 / 4$ & 9 & 12.28 & 15.23 & 2.55 \\
\hline 6.3 & $1 / 4$ & 12 & 9.92 & 12.22 & 1.79 \\
\hline 6.3 & $1 / 4$ & 12 & 10.68 & 12.33 & 1.90 \\
\hline 7.9 & $1 / 8$ & 6 & 5.46 & 5.89 & 0.64 \\
\hline 7.9 & $1 / 8$ & 9 & 4.12 & 4.00 & 0.38 \\
\hline 7.9 & $1 / 8$ & 12 & 3.14 & 3.03 & 0.25 \\
\hline 7.9 & $1 / 4$ & 6 & 12.69 & 15.12 & 2.51 \\
\hline 7.9 & $1 / 4$ & 9 & 9.84 & 16.39 & 2.42 \\
\hline 7.9 & $1 / 4$ & 12 & 7.81 & 8.98 & 1.17 \\
\hline 10.4 & $1 / 8$ & 6 & 5.82 & 5.84 & 0.65 \\
\hline 10.4 & $1 / 8$ & 6 & 5.88 & 6.54 & 0.73 \\
\hline 10.4 & $1 / 8$ & 9 & 3.71 & 3.82 & 0.34 \\
\hline 10.4 & $1 / 8$ & 12 & 2.79 & 2.79 & 0.22 \\
\hline 10.4 & $1 / 8$ & 12 & 2.94 & 2.89 & 0.23 \\
\hline 10.4 & $1 / 4$ & 6 & 10.17 & 12.39 & 1.84 \\
\hline 10.4 & $1 / 4$ & 6 & 8.96 & 10.19 & 1.43 \\
\hline 10.4 & $1 / 4$ & 9 & 8.73 & 11.45 & 1.59 \\
\hline 10.4 & $1 / 4$ & 12 & 8.15 & 12.03 & 1.62 \\
\hline 10.4 & $1 / 4$ & 12 & 6.61 & 10.34 & 1.23 \\
\hline & 1 & & & & \\
\hline
\end{tabular}

Table 5.2: Mean circulation time $\left(\tau_{\text {circ }}\right)$ data for baffled system 


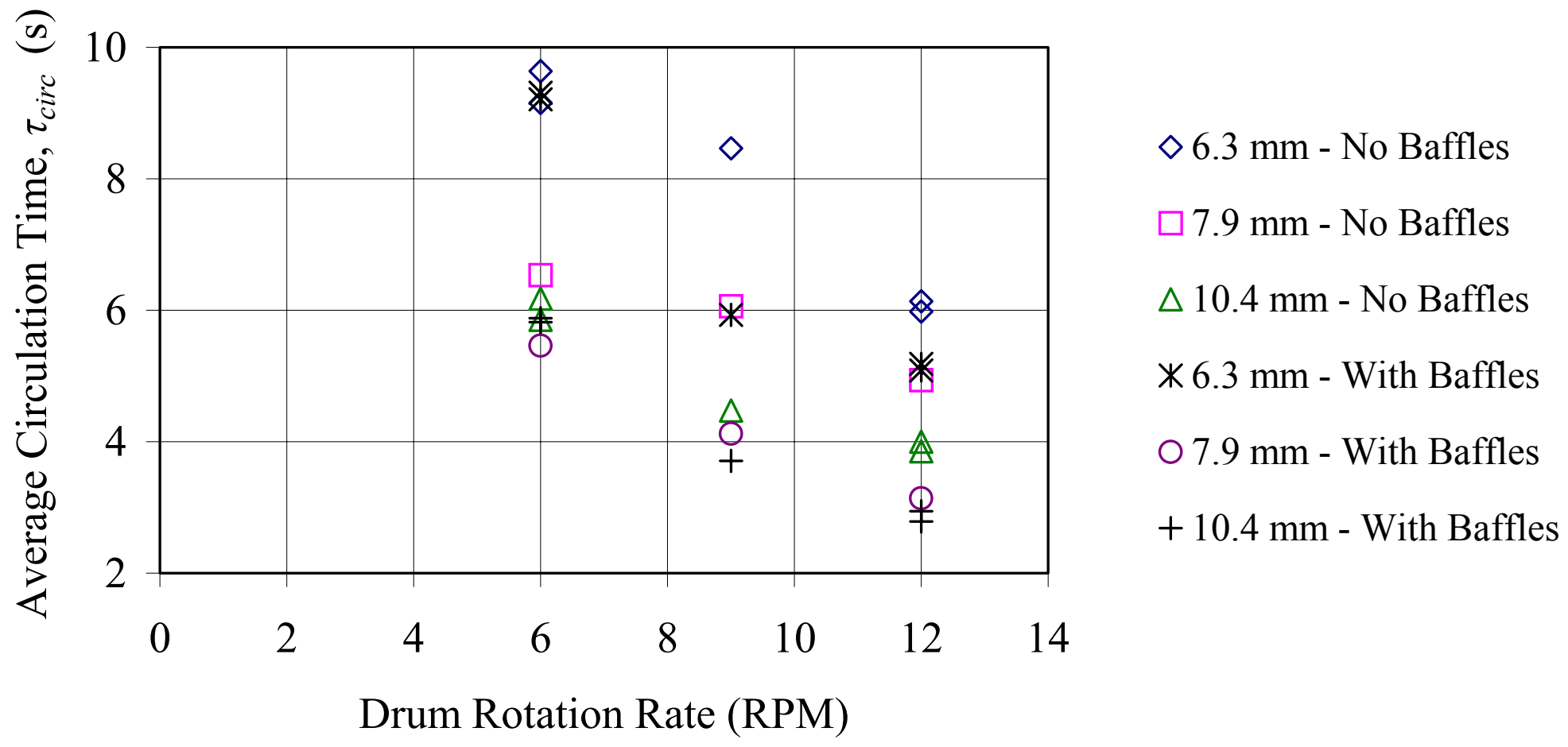

Figure 5.4: Comparison of average circulation time $\left(\tau_{\text {circ }}\right)$ as a function of drum rotation rate, for baffled and unbaffled systems, with $1 / 8$ drum loading 


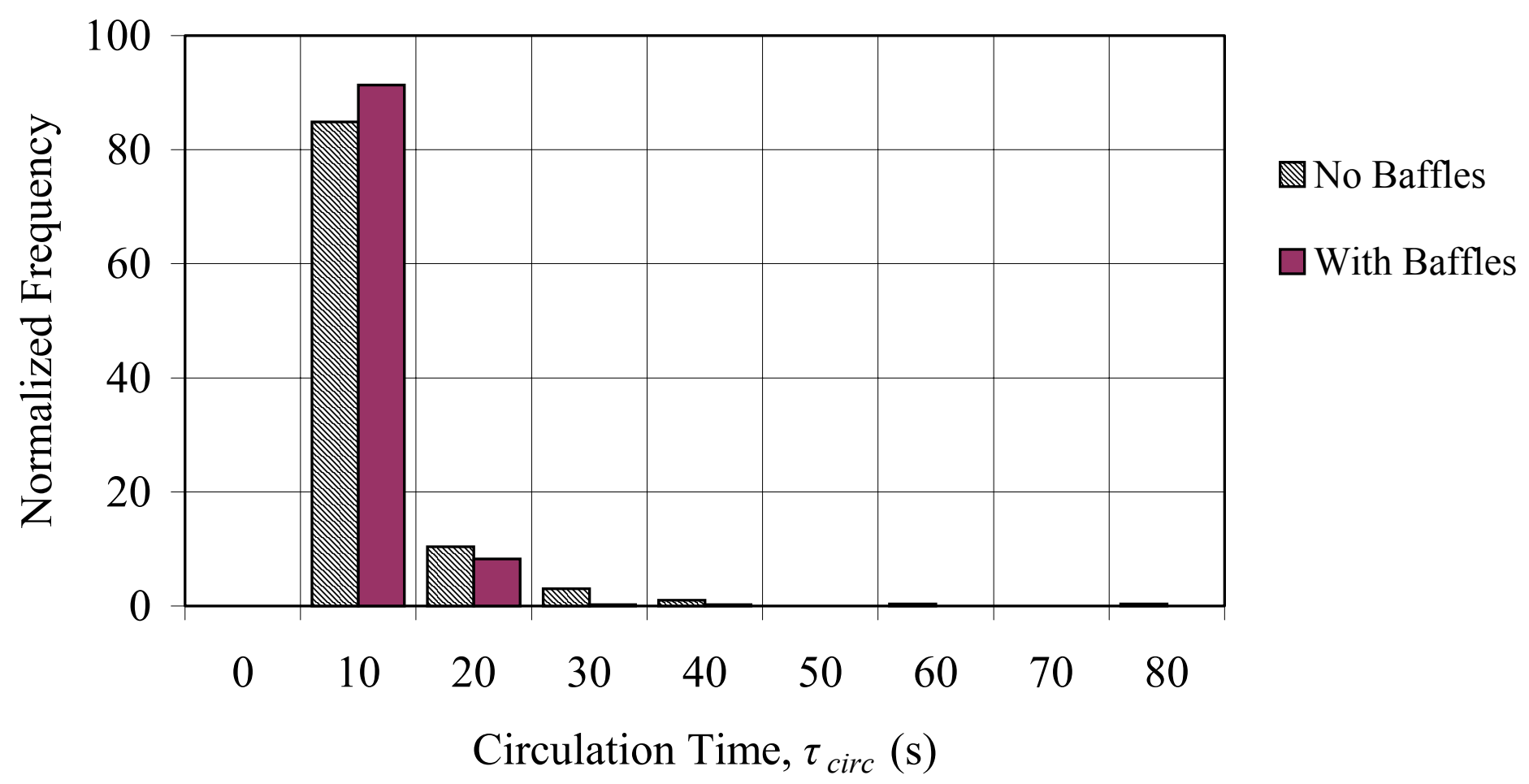

Figure 5.5: Distribution of circulation time $\left(\tau_{\text {circ }}\right)$ for $7.9 \mathrm{~mm}$ tablets, $1 / 8$ drum loading, 9 rpm drum speed 


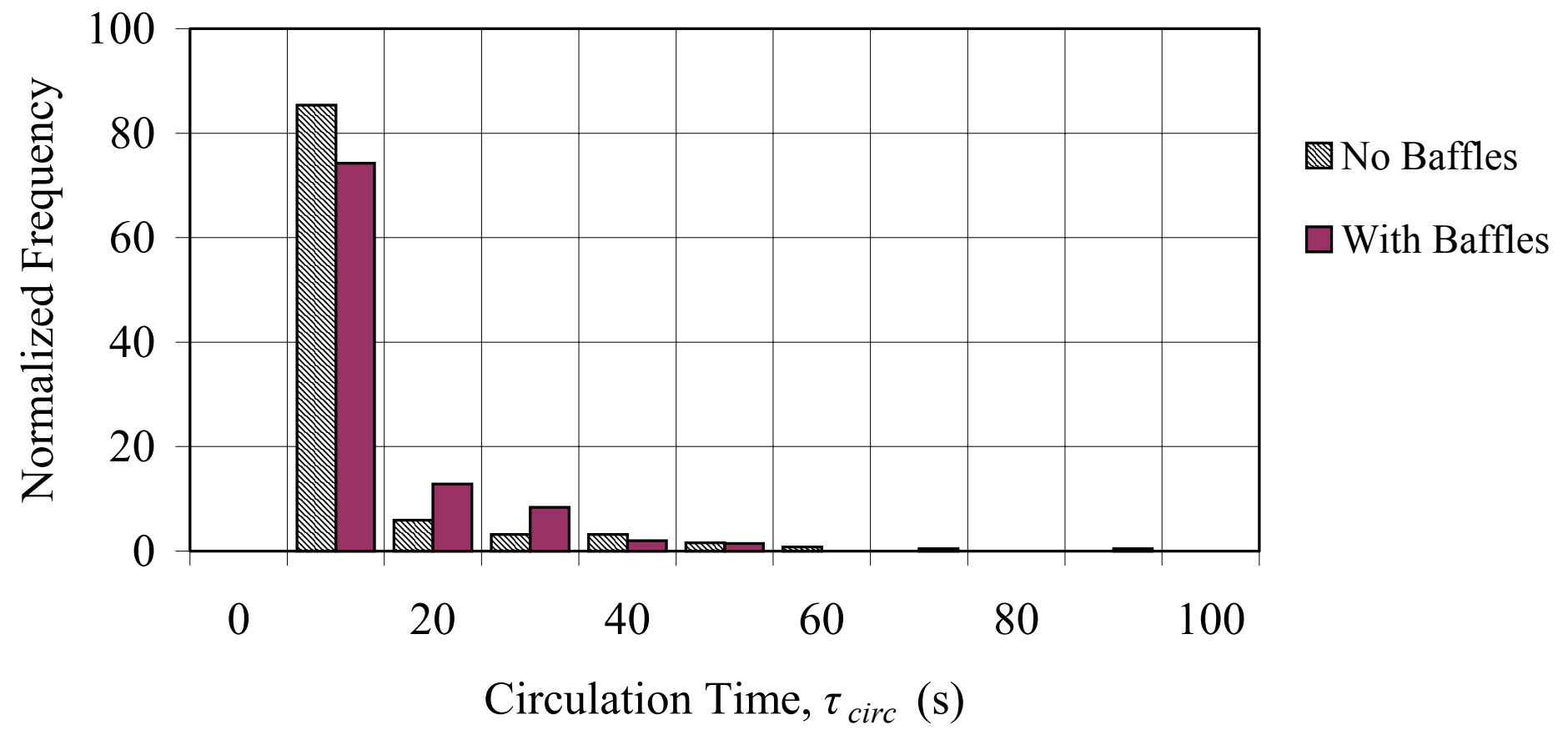

Figure 5.6: Distribution of circulation time $\left(\tau_{\text {circ }}\right)$ for $10.4 \mathrm{~mm}$ tablets, $1 / 4$ drum loading, $9 \mathrm{rpm}$ drum speed 


\subsection{Surface Time $\left(\tau_{\text {surface }}\right)$}

Surface Time $\left(\tau_{\text {surface }}\right)$ is defined as the time that a particle spends within the spray zone during each pass (explained in Section 4.3.2). An estimation of this time would help determine the amount of spray a tablet may receive, when it passes through the spray zone on the surface. As evident from Table 5.3, the average surface time decreases with increasing drum rotation rate and drum loading. This can be also observed in Figures 5.7 and 5.8, which show the relation of the average surface time of the tablets with increasing drum speeds for the two drum loadings, respectively. The surface times can be correlated with the surface velocities, which will be discussed in Section 5.4. According to the results obtained by Leaver et al. (1985), an increase in the tablet size results in increased surface times, due to the change in the force balance acting on the tablets. The effect of tablet size on the surface times is evident on comparison of the $95 \%$ confidence intervals about mean $\tau_{\text {surface }}$.

The average values of $\tau_{\text {surface }}$ with different drum speeds, and drum loadings for the different sizes of tablets, with baffles inside the rotating drum are given in Table 5.4. Figure 5.9 shows a comparison of the results obtained for $\tau_{\text {surface }}$ with the baffled and unbaffled systems for 1/8 loading. According to Leaver et al. (1985), baffles have an effect on the surface time of the tablets with considerably higher surface times recorded in the unbaffled system, due to the absence of induced turbulence within the bed. Different baffle designs might help in understanding the effect of baffles on the surface times of the tablets better. 


\begin{tabular}{|c|c|c|c|c|c|}
\hline $\begin{array}{l}\text { Tablet Size } \\
\quad(\mathrm{mm})\end{array}$ & \begin{tabular}{|} 
Drum Loading \\
(fill)
\end{tabular} & $\begin{array}{c}\text { Drum Speed } \\
\text { (RPM) }\end{array}$ & $\begin{array}{c}\text { Mean } \tau_{\text {surface }} \\
(\mathrm{s})\end{array}$ & $\begin{array}{c}\text { Standard } \\
\text { Deviation (s) }\end{array}$ & $\begin{array}{c} \pm 95 \% \text { Confidence } \\
\text { Interval (s) }\end{array}$ \\
\hline 6.3 & $1 / 8$ & 6 & 0.18 & 0.11 & 0.02 \\
\hline 6.3 & $1 / 8$ & 6 & 0.17 & 0.11 & 0.02 \\
\hline 6.3 & $1 / 8$ & 9 & 0.15 & 0.07 & 0.01 \\
\hline 6.3 & $1 / 8$ & 12 & 0.12 & 0.06 & 0.01 \\
\hline 6.3 & $1 / 8$ & 12 & 0.12 & 0.06 & 0.01 \\
\hline 6.3 & $1 / 4$ & 6 & 0.11 & 0.05 & 0.01 \\
\hline 6.3 & $1 / 4$ & 6 & 0.11 & 0.05 & 0.01 \\
\hline 6.3 & $1 / 4$ & 9 & 0.08 & 0.03 & 0.01 \\
\hline 6.3 & $1 / 4$ & 12 & 0.07 & 0.03 & 0.00 \\
\hline 6.3 & $1 / 4$ & 12 & 0.07 & 0.03 & 0.00 \\
\hline 7.9 & $1 / 8$ & 6 & 0.20 & 0.11 & 0.01 \\
\hline 7.9 & $1 / 8$ & 9 & 0.15 & 0.08 & 0.01 \\
\hline 7.9 & $1 / 8$ & 12 & 0.12 & 0.06 & 0.01 \\
\hline 7.9 & $1 / 4$ & 6 & 0.09 & 0.05 & 0.01 \\
\hline 7.9 & $1 / 4$ & 9 & 0.08 & 0.03 & 0.00 \\
\hline 7.9 & $1 / 4$ & 12 & 0.07 & 0.03 & 0.00 \\
\hline 10.4 & $1 / 8$ & 6 & 0.20 & 0.10 & 0.01 \\
\hline 10.4 & $1 / 8$ & 6 & 0.20 & 0.10 & 0.01 \\
\hline 10.4 & $1 / 8$ & 9 & 0.16 & 0.08 & 0.01 \\
\hline 10.4 & $1 / 8$ & 12 & 0.13 & 0.06 & 0.01 \\
\hline 10.4 & $1 / 8$ & 12 & 0.13 & 0.06 & 0.01 \\
\hline 10.4 & $1 / 4$ & 6 & 0.10 & 0.05 & 0.01 \\
\hline 10.4 & $1 / 4$ & 6 & 0.11 & 0.05 & 0.01 \\
\hline 10.4 & $1 / 4$ & 9 & 0.09 & 0.04 & 0.00 \\
\hline 10.4 & $1 / 4$ & 12 & 0.06 & 0.03 & 0.00 \\
\hline 10.4 & $1 / 4$ & 12 & 0.06 & 0.03 & 0.00 \\
\hline
\end{tabular}

Table 5.3: Mean surface time $\left(\tau_{\text {surface }}\right)$ values for unbaffled system 


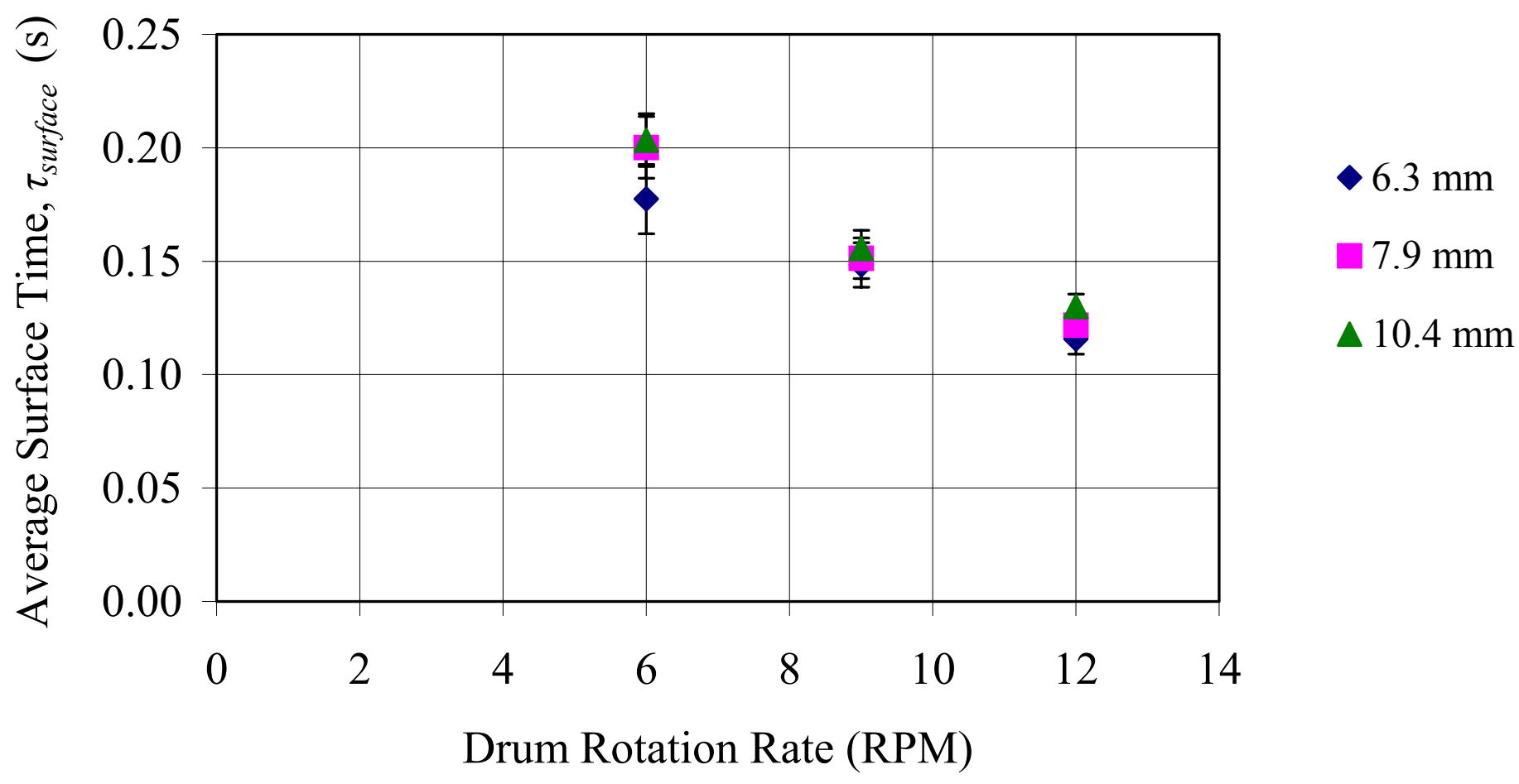

Figure 5.7: Change in average surface time $\left(\tau_{\text {surface }}\right)$ as a function of drum rotation rate, for unbaffled system with $1 / 8$ drum loading 


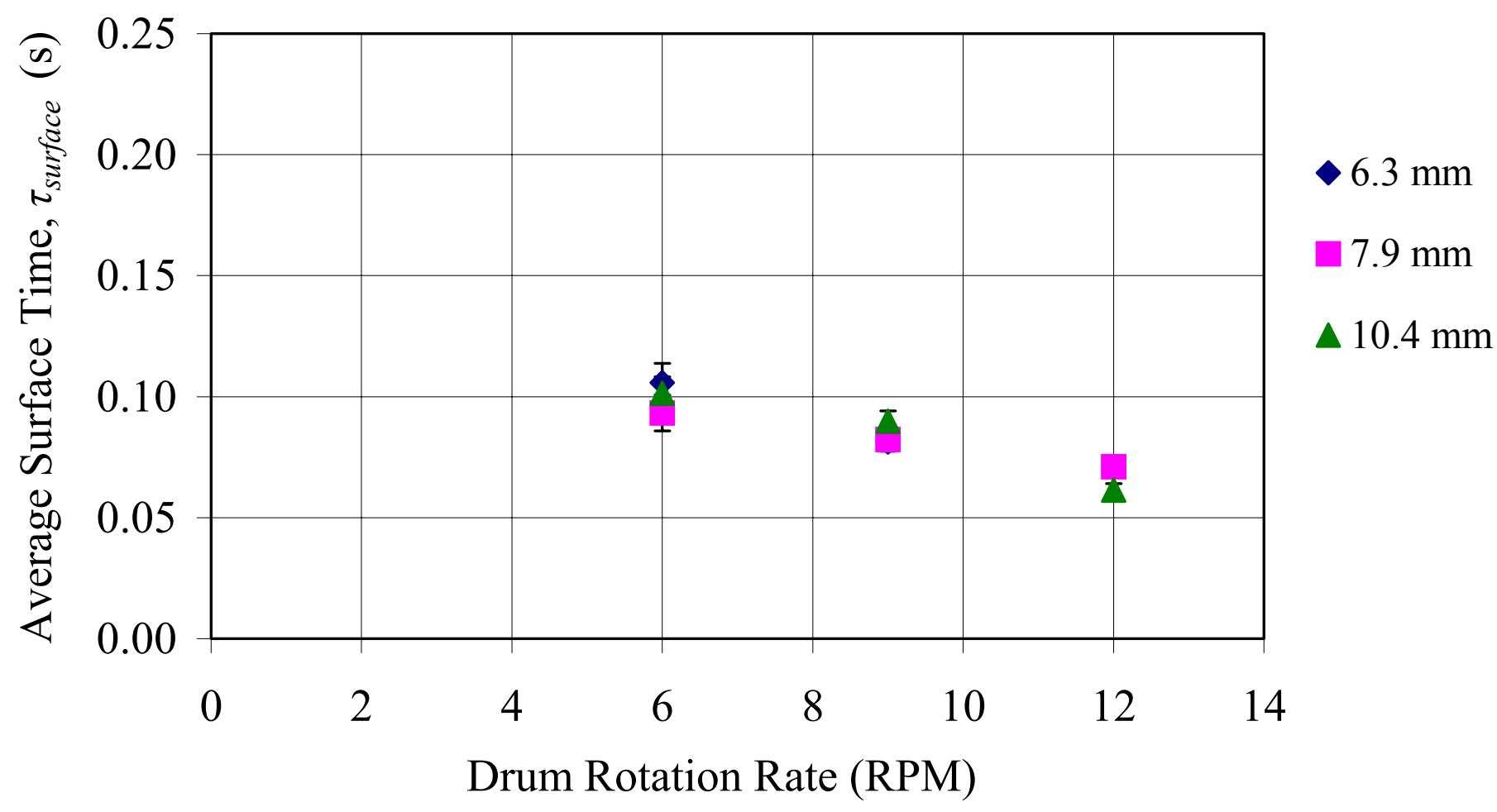

Figure 5.8: Change in average surface time $\left(\tau_{\text {surface }}\right)$ as a function of drum rotation rate, for unbaffled system with $1 / 4$ drum loading 


\begin{tabular}{|c|c|c|c|c|c|}
\hline $\begin{array}{c}\text { Tablet Size } \\
(\mathrm{mm})\end{array}$ & \begin{tabular}{|c} 
Drum Loading \\
(fill)
\end{tabular} & $\begin{array}{c}\text { Drum Speed } \\
(\mathrm{RPM})\end{array}$ & $\begin{array}{c}\text { Mean } \tau_{\text {surface }} \\
(\mathrm{s})\end{array}$ & $\begin{array}{c}\text { Standard } \\
\text { Deviation (s) }\end{array}$ & $\begin{array}{c} \pm 95 \% \text { Confidence } \\
\text { Interval (s) }\end{array}$ \\
\hline 6.3 & $1 / 8$ & 6 & 0.14 & 0.11 & 0.11 \\
\hline 6.3 & $1 / 8$ & 6 & 0.15 & 0.11 & 0.02 \\
\hline 6.3 & $1 / 8$ & 9 & 0.13 & 0.08 & 0.01 \\
\hline 6.3 & $1 / 8$ & 12 & 0.10 & 0.06 & 0.01 \\
\hline 6.3 & $1 / 8$ & 12 & 0.10 & 0.06 & 0.01 \\
\hline 6.3 & $1 / 4$ & 6 & 0.11 & 0.05 & 0.01 \\
\hline 6.3 & $1 / 4$ & 6 & 0.10 & 0.05 & 0.01 \\
\hline 6.3 & $1 / 4$ & 9 & 0.09 & 0.04 & 0.01 \\
\hline 6.3 & $1 / 4$ & 12 & 0.08 & 0.03 & 0.00 \\
\hline 6.3 & $1 / 4$ & 12 & 0.08 & 0.03 & 0.01 \\
\hline 7.9 & $1 / 8$ & 6 & 0.19 & 0.12 & 0.01 \\
\hline 7.9 & $1 / 8$ & 9 & 0.14 & 0.09 & 0.01 \\
\hline 7.9 & $1 / 8$ & 12 & 0.10 & 0.06 & 0.01 \\
\hline 7.9 & $1 / 4$ & 6 & 0.10 & 0.04 & 0.01 \\
\hline 7.9 & $1 / 4$ & 9 & 0.09 & 0.04 & 0.01 \\
\hline 7.9 & $1 / 4$ & 12 & 0.07 & 0.03 & 0.00 \\
\hline 10.4 & $1 / 8$ & 6 & 0.19 & 0.12 & 0.01 \\
\hline 10.4 & $1 / 8$ & 6 & 0.20 & 0.12 & 0.01 \\
\hline 10.4 & $1 / 8$ & 9 & 0.14 & 0.08 & 0.01 \\
\hline 10.4 & $1 / 8$ & 12 & 0.11 & 0.06 & 0.00 \\
\hline 10.4 & $1 / 8$ & 12 & 0.11 & 0.06 & 0.00 \\
\hline 10.4 & $1 / 4$ & 6 & 0.11 & 0.04 & 0.01 \\
\hline 10.4 & $1 / 4$ & 6 & 0.11 & 0.05 & 0.01 \\
\hline 10.4 & $1 / 4$ & 9 & 0.09 & 0.04 & 0.01 \\
\hline 10.4 & $1 / 4$ & 12 & 0.07 & 0.03 & 0.00 \\
\hline 10.4 & $1 / 4$ & 12 & 0.07 & 0.03 & 0.00 \\
\hline
\end{tabular}

Table 5.4: Mean surface time $\left(\tau_{\text {surface }}\right)$ data for baffled system 


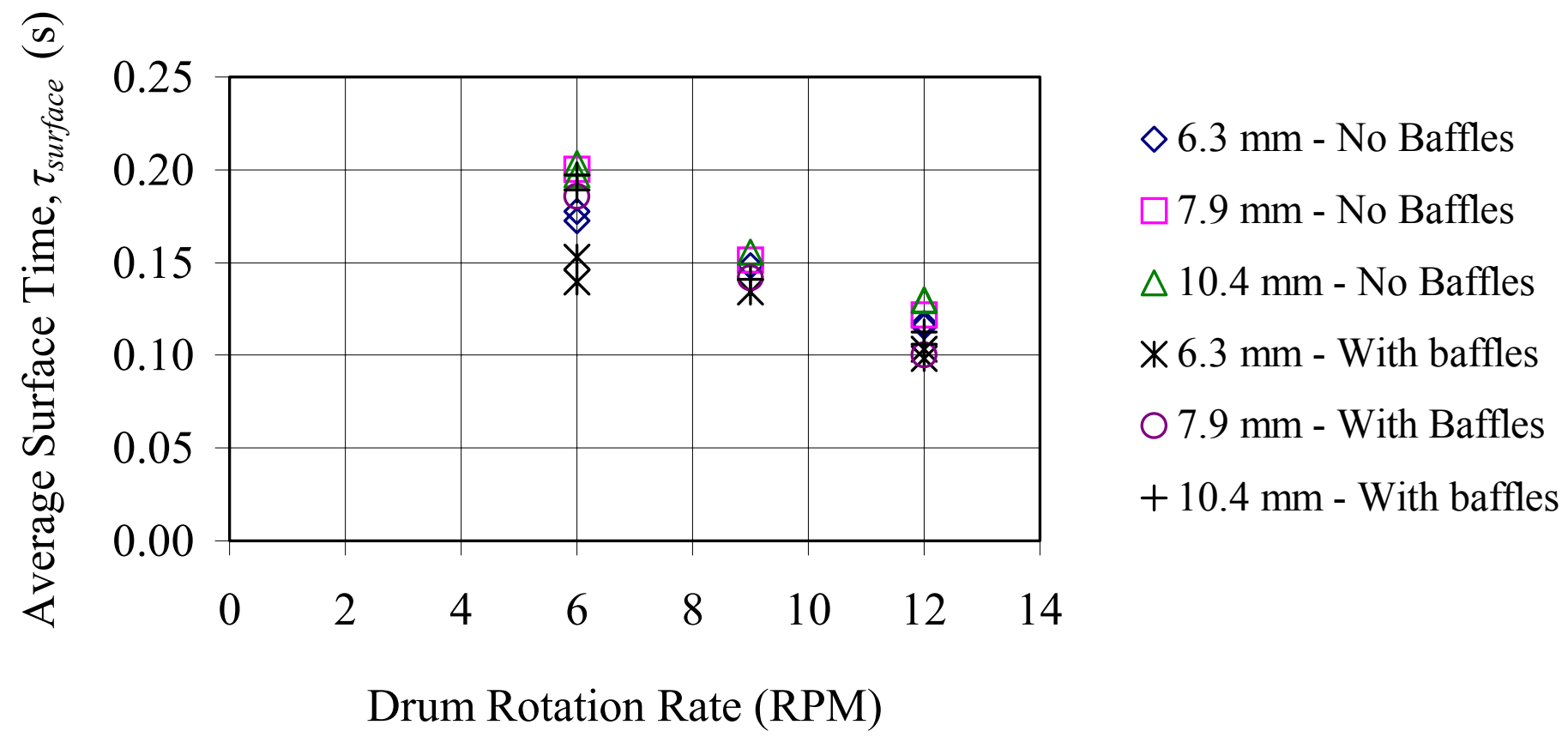

Figure 5.9: Change in average surface time $\left(\tau_{\text {surface }}\right)$ as a function of drum rotation rate, for baffled and unbaffled systems, with $1 / 8$ drum loading 


\subsection{Projected Surface Area $\left(A_{t a b}\right)$}

The surface area of the tablet projected towards the camera, during each pass through the ROI, is defined as $A_{t a b}$. The methods of calculation and validation of $A_{t a b}$ have been discussed in Sections 4.3.3 and 4.3.4. The mean projected surface area values are given in Table 5.5 and are plotted as functions of the drum rotation rate in Figures 5.10 and 5.11. The table also includes normalized area values for the different tablet sizes, drum loadings and drum speeds. Normalized area is calculated as $A_{t a b} / D^{2}(D=$ diameter of the tablets) and the distributions are shown in Figure 5.12. The values of $A_{t a b}$ reported are the average projected surface areas for one pass, which are again averaged for each experiment. The trends in $A_{t a b}$ are similar to those with the surface times. The mean values of $A_{t a b}$ decrease with increasing drum speed. The values are predictably higher for the larger tablets $10.4 \mathrm{~mm}$ (13/32 inch), in both $1 / 8$ and $1 / 4$ drum loadings. However the normalized surface area values (Figure 5.12) almost coincide at a particular drum speed and drum loading, which indicates that the surface area of the tablets projected towards the camera in the ROI is a function of both drum rotation rate and drum loading, but is not a strong function of tablet size. The mean $A_{t a b}$ values for the baffled system are given in Table 5.6 and their distributions in Figures 5.13 and 5.14 for $1 / 8$ and $1 / 4$ drum loading respectively. The results indicate that the presence of baffles show decreased projected surface area values. This is also evident in the normalized area values in Figure 5.17. The estimation of $A_{\text {tab }}$ and $\tau_{\text {surface }}$ will help to determine the share of the coating solution that the tablet may receive during a coating run. Figures 5.15 and 5.16 show the distributions of total surface area per pass at $1 / 8$ and $1 / 4$ drum loadings respectively, for the systems with and without baffles. 


\begin{tabular}{|c|c|c|c|c|c|c|}
\hline $\begin{array}{c}\text { Tablet } \\
\text { Size } \\
(\mathrm{mm})\end{array}$ & $\begin{array}{c}\text { Drum Loading } \\
\text { (Fill) }\end{array}$ & $\begin{array}{c}\text { Drum Speed } \\
(\mathrm{RPM})\end{array}$ & $\begin{array}{c}\text { Mean } A_{\text {tab }} \\
\left(\mathrm{mm}^{2}\right)\end{array}$ & $\begin{array}{c}\text { Standard } \\
\text { Deviation } \\
\left(\mathrm{mm}^{2}\right)\end{array}$ & $\begin{array}{c} \pm 95 \% \\
\text { Confidence } \\
\text { Interval }\left(\mathrm{mm}^{2}\right)\end{array}$ & $\begin{array}{c}\text { Normalized } \\
\text { Area } \\
\left(A_{\text {tab }} / D^{2}\right.\end{array}$ \\
\hline 6.3 & $1 / 8$ & 6 & 52.78 & 43.83 & 6.19 & 132.98 \\
\hline 6.3 & $1 / 8$ & 6 & 52.88 & 44.81 & 6.57 & 133.23 \\
\hline 6.3 & $1 / 8$ & 9 & 42.00 & 30.62 & 4.14 & 105.83 \\
\hline 6.3 & $1 / 8$ & 12 & 33.13 & 25.12 & 2.87 & 83.48 \\
\hline 6.3 & $1 / 8$ & 12 & 33.23 & 25.41 & 2.92 & 83.73 \\
\hline 6.3 & $1 / 4$ & 6 & 28.19 & 19.98 & 3.36 & 71.03 \\
\hline 6.3 & $1 / 4$ & 6 & 26.26 & 20.26 & 3.35 & 66.15 \\
\hline 6.3 & $1 / 4$ & 9 & 20.26 & 16.74 & 2.67 & 51.04 \\
\hline 6.3 & $1 / 4$ & 12 & 14.05 & 13.86 & 1.93 & 35.41 \\
\hline 6.3 & $1 / 4$ & 12 & 12.69 & 13.42 & 1.67 & 31.97 \\
\hline 7.9 & $1 / 8$ & 6 & 83.89 & 66.35 & 7.86 & 134.42 \\
\hline 7.9 & $1 / 8$ & 9 & 62.68 & 47.51 & 5.41 & 100.43 \\
\hline 7.9 & $1 / 8$ & 12 & 46.86 & 38.42 & 3.95 & 75.08 \\
\hline 7.9 & $1 / 4$ & 6 & 32.52 & 27.45 & 4.46 & 52.11 \\
\hline 7.9 & $1 / 4$ & 9 & 32.19 & 26.09 & 4.06 & 51.58 \\
\hline 7.9 & $1 / 4$ & 12 & 25.65 & 22.28 & 3.02 & 41.10 \\
\hline 10.4 & $1 / 8$ & 6 & 142.34 & 104.81 & 11.77 & 131.60 \\
\hline 10.4 & $1 / 8$ & 6 & 137.23 & 107.46 & 12.38 & 126.88 \\
\hline 10.4 & $1 / 8$ & 9 & 98.58 & 81.39 & 7.99 & 91.14 \\
\hline 10.4 & $1 / 8$ & 12 & 81.91 & 65.45 & 5.97 & 75.73 \\
\hline 10.4 & $1 / 8$ & 12 & 85.07 & 70.82 & 6.52 & 78.65 \\
\hline 10.4 & $1 / 4$ & 6 & 52.79 & 44.12 & 6.70 & 48.81 \\
\hline 10.4 & $1 / 4$ & 6 & 59.90 & 50.43 & 7.34 & 55.38 \\
\hline 10.4 & $1 / 4$ & 9 & 51.97 & 40.41 & 4.99 & 48.05 \\
\hline 10.4 & $1 / 4$ & 12 & 21.49 & 31.05 & 2.71 & 19.87 \\
\hline 10.4 & $1 / 4$ & 12 & 19.17 & 31.07 & 2.45 & 17.72 \\
\hline
\end{tabular}

Table 5.5: Mean projected surface area $\left(A_{t a b}\right)$ data for unbaffled system 


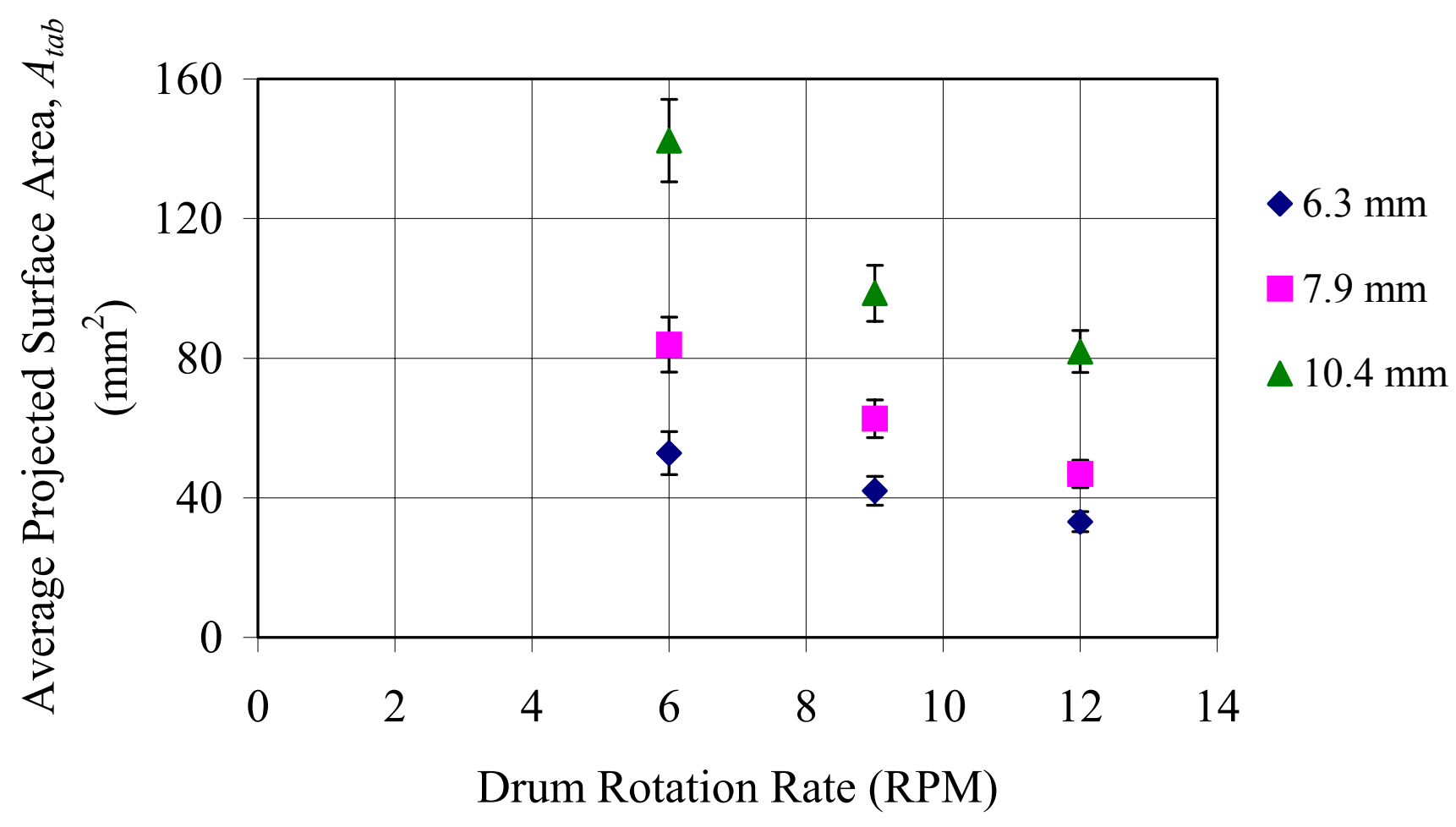

Figure 5.10: Change in average $A_{t a b}$ as a function of drum rotation rate for unbaffled system with 1/8 drum loading 


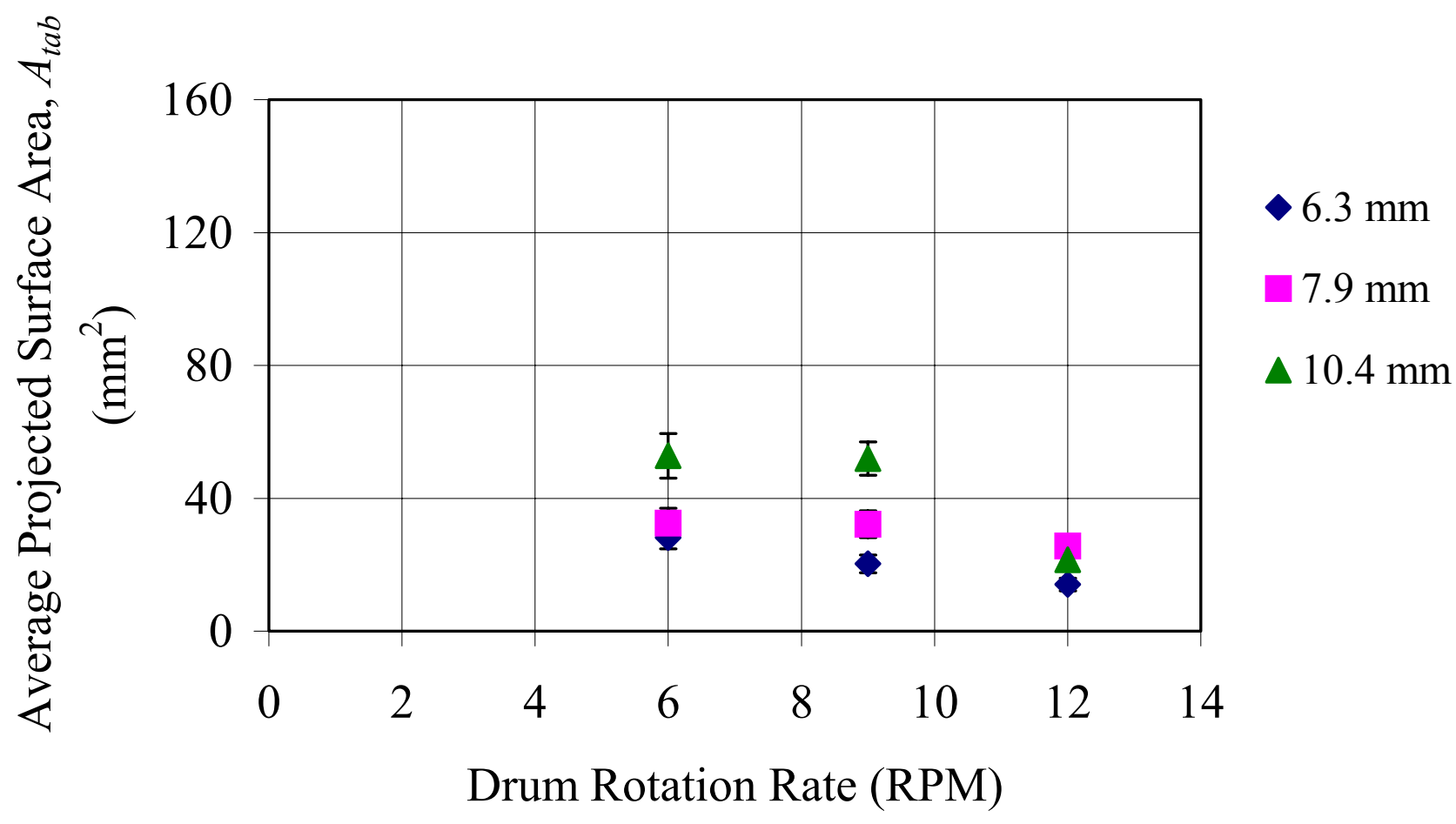

Figure 5.11: Change in average $A_{t a b}$ as a function of drum rotation rate for unbaffled system with 1/4 drum loading 


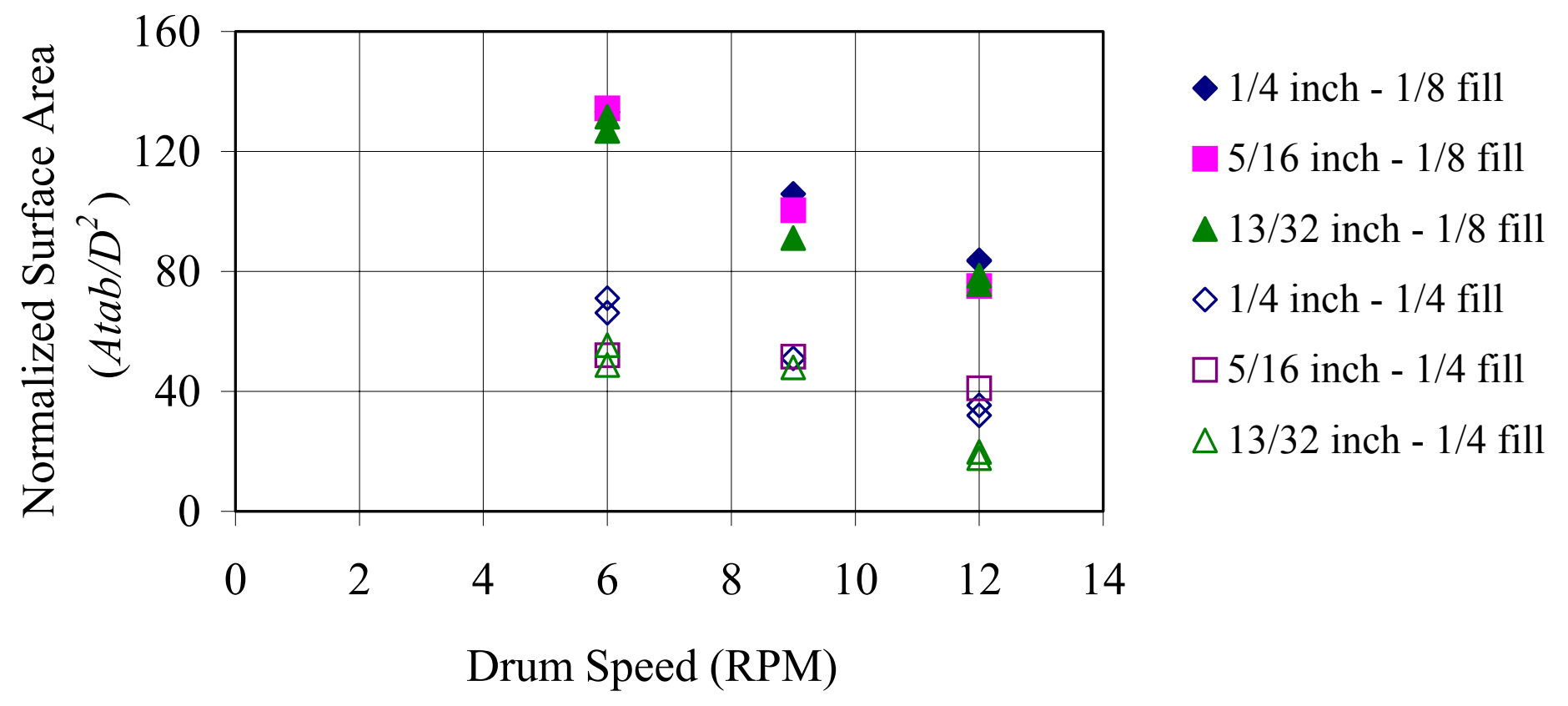

Figure 5.12: Change in normalized surface area $\left(A_{t a b} / D^{2}\right)$ as a function of drum rotation rate for unbaffled system 


\begin{tabular}{|c|c|c|c|c|c|c|}
\hline $\begin{array}{l}\text { Tablet } \\
\text { Size } \\
(\mathrm{mm}) \\
\end{array}$ & $\begin{array}{c}\text { Drum Loading } \\
\text { (fill) }\end{array}$ & $\begin{array}{c}\text { Drum Speed } \\
\text { (RPM) }\end{array}$ & $\begin{array}{l}\text { Mean } A_{t a b} \\
\quad\left(\mathrm{~mm}^{2}\right)\end{array}$ & $\begin{array}{c}\text { Standard } \\
\text { Deviation } \\
\left(\mathrm{mm}^{2}\right) \\
\end{array}$ & $\begin{array}{c} \pm 95 \% \text { Confidence } \\
\text { Interval }\left(\mathrm{mm}^{2}\right)\end{array}$ & $\begin{array}{l}\text { Normalized Area } \\
\quad\left(A_{t a b} / D^{2}\right)\end{array}$ \\
\hline 6.3 & $1 / 8$ & 6 & 19.23 & 17.20 & 2.44 & 48.45 \\
\hline 6.3 & $1 / 8$ & 6 & 21.12 & 17.90 & 2.53 & 53.22 \\
\hline 6.3 & $1 / 8$ & 9 & 16.15 & 11.35 & 1.29 & 40.70 \\
\hline 6.3 & $1 / 8$ & 12 & 14.28 & 11.08 & 1.17 & 35.98 \\
\hline 6.3 & $1 / 8$ & 12 & 12.44 & 9.52 & 1.00 & 31.35 \\
\hline 6.3 & $1 / 4$ & 6 & 30.01 & 22.96 & 4.24 & 75.60 \\
\hline 6.3 & $1 / 4$ & 6 & 27.33 & 21.95 & 3.84 & 68.86 \\
\hline 6.3 & $1 / 4$ & 9 & 23.46 & 18.58 & 3.09 & 59.12 \\
\hline 6.3 & $1 / 4$ & 12 & 17.53 & 13.77 & 2.01 & 44.17 \\
\hline 6.3 & $1 / 4$ & 12 & 17.88 & 14.13 & 2.17 & 45.05 \\
\hline 7.9 & $1 / 8$ & 6 & 48.25 & 40.15 & 4.34 & 77.32 \\
\hline 7.9 & $1 / 8$ & 9 & 28.57 & 22.86 & 2.14 & 45.77 \\
\hline 7.9 & $1 / 8$ & 12 & 19.31 & 16.93 & 1.39 & 30.94 \\
\hline 7.9 & $1 / 4$ & 6 & 37.41 & 30.36 & 5.02 & 59.94 \\
\hline 7.9 & $1 / 4$ & 9 & 32.72 & 26.53 & 3.90 & 52.42 \\
\hline 7.9 & $1 / 4$ & 12 & 28.09 & 22.30 & 2.90 & 45.00 \\
\hline 10.4 & $1 / 8$ & 6 & 126.82 & 107.01 & 11.92 & 117.25 \\
\hline 10.4 & $1 / 8$ & 6 & 129.01 & 109.01 & 12.22 & 119.28 \\
\hline 10.4 & $1 / 8$ & 9 & 73.97 & 60.18 & 5.37 & 68.39 \\
\hline 10.4 & $1 / 8$ & 12 & 41.39 & 32.88 & 2.54 & 38.27 \\
\hline 10.4 & $1 / 8$ & 12 & 34.83 & 29.48 & 2.34 & 32.20 \\
\hline 10.4 & $1 / 4$ & 6 & 68.10 & 55.06 & 8.14 & 62.96 \\
\hline 10.4 & $1 / 4$ & 6 & 63.24 & 53.43 & 7.47 & 58.47 \\
\hline 10.4 & $1 / 4$ & 9 & 50.40 & 43.76 & 6.06 & 46.60 \\
\hline 10.4 & $1 / 4$ & 12 & 41.53 & 35.92 & 4.83 & 38.40 \\
\hline 10.4 & $1 / 4$ & 12 & 42.47 & 36.56 & 4.36 & 39.27 \\
\hline
\end{tabular}

Table 5.6: Mean projected surface area $\left(A_{t a b}\right)$ data for baffled system 


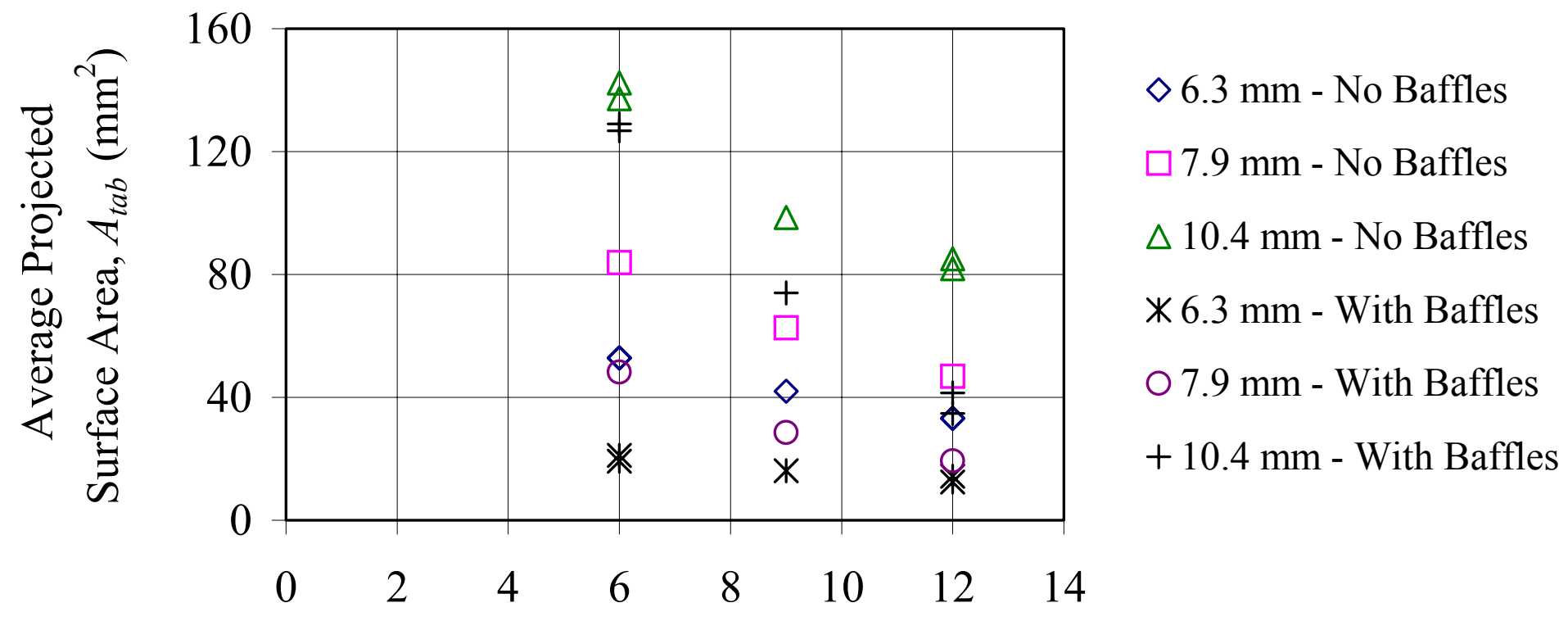

Drum Rotation Rate (RPM)

Figure 5.13: Comparison of average $A_{t a b}$ as a function of drum rotation rate for baffled and unbaffled systems, $1 / 8$ drum loading 


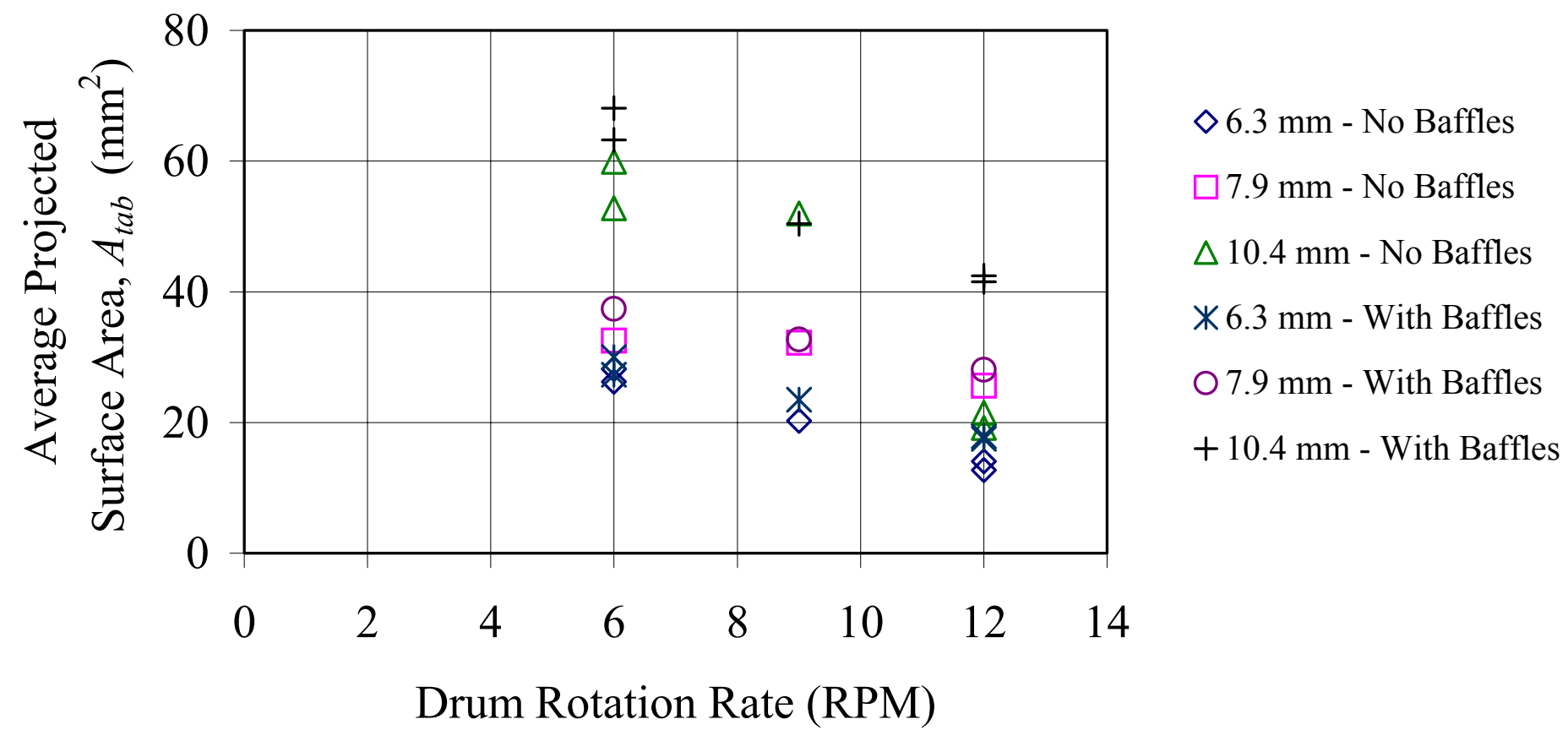

Figure 5.14: Comparison of average $A_{t a b}$ as a function of drum rotation rate for baffled and unbaffled systems, $1 / 4$ drum loading 


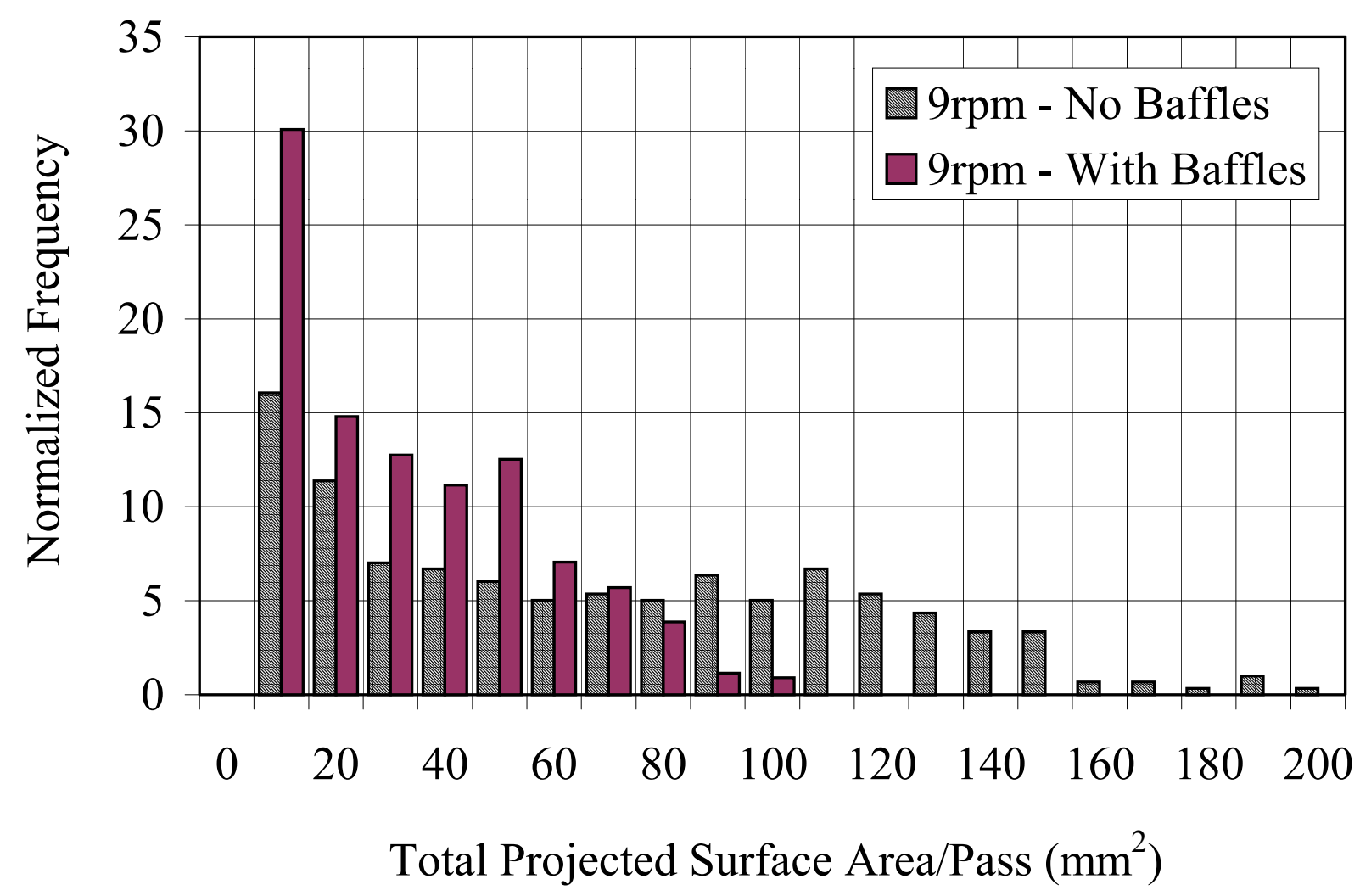

Figure 5.15: Distribution of total projected surface area per pass for $7.9 \mathrm{~mm}$ tablets, 1/8 drum loading, $9 \mathrm{rpm}$ drum speed 


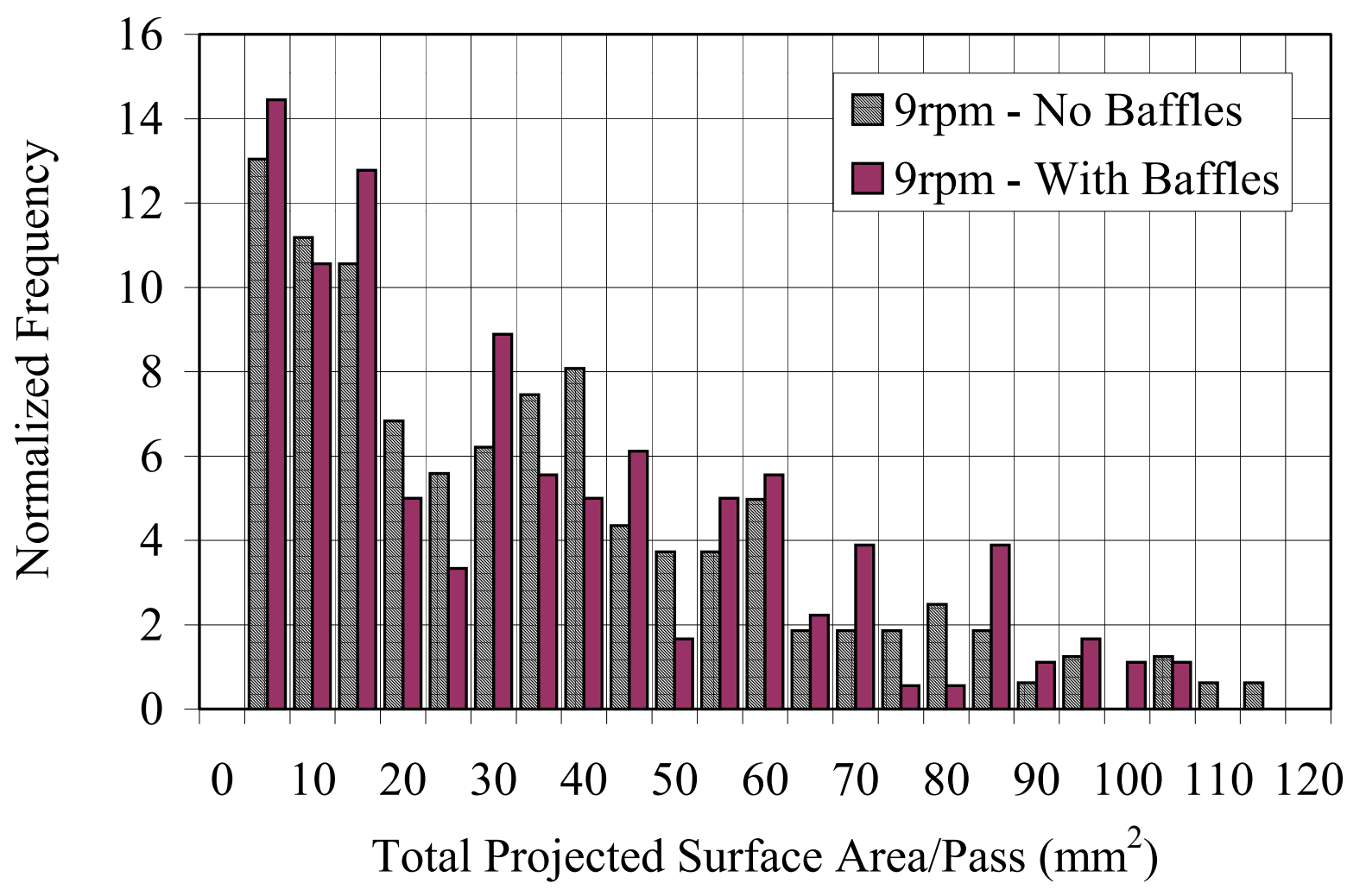

Figure 5.16: Distribution of total projected surface area per pass for $7.9 \mathrm{~mm}$ tablets, $1 / 4$ drum loading, $9 \mathrm{rpm}$ drum speed 


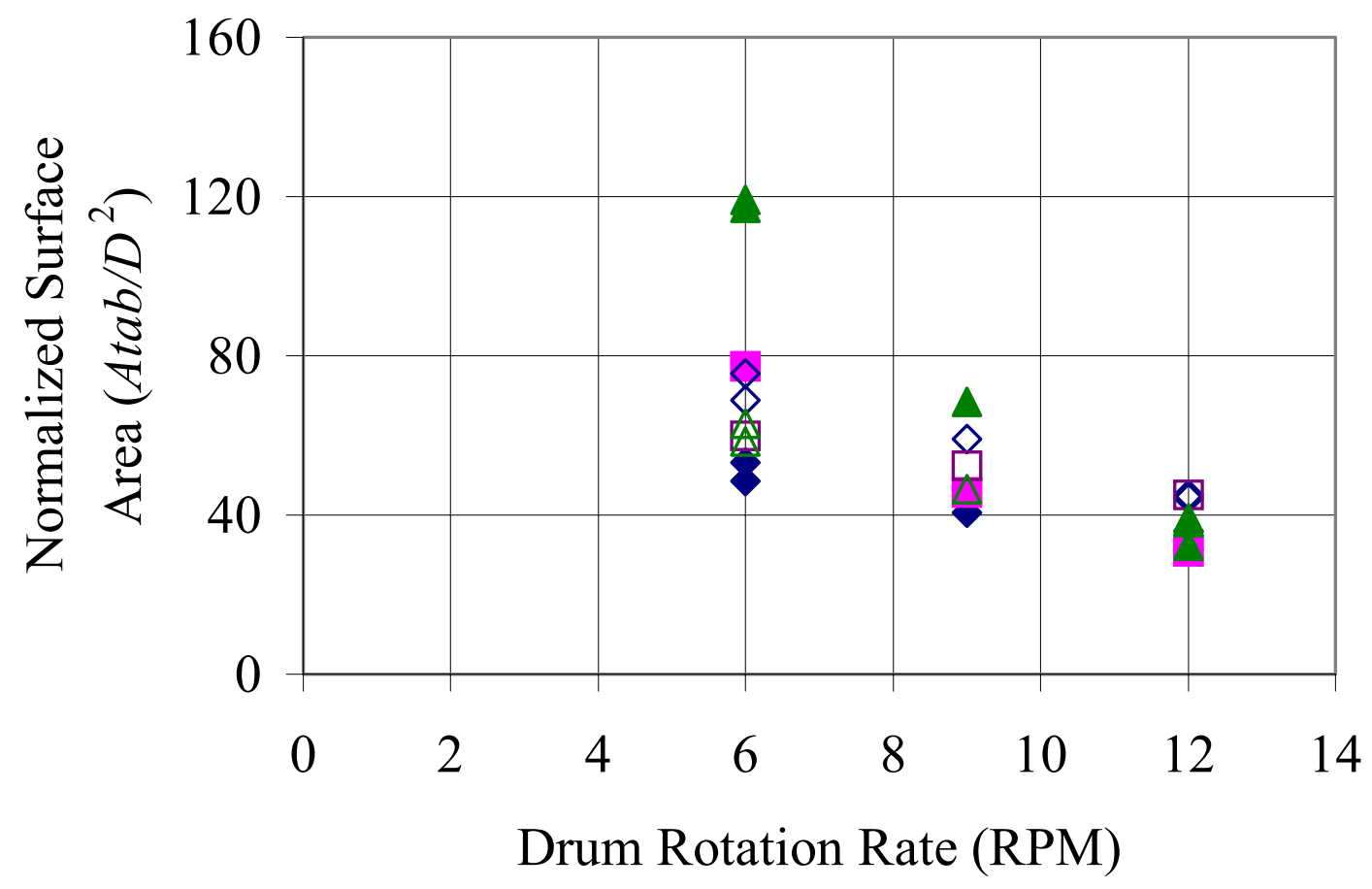

$\diamond 6.3 \mathrm{~mm}-1 / 8$ fill $7.9 \mathrm{~mm}-1 / 8$ fill $\triangle 10.4 \mathrm{~mm}-1 / 8$ fill $\diamond 6.3 \mathrm{~mm}-1 / 4$ fill $\square 7.9 \mathrm{~mm}-1 / 4$ fill $\triangle 10.4 \mathrm{~mm}-1 / 4$ fill

Figure 5.17: Comparison of normalized surface area $\left(A_{t a b} / D^{2}\right)$ as a function of drum rotation rate for baffled system 


\subsection{Surface Velocities $\left(V_{x}, V_{y}\right)$}

The calculation of surface velocities has been explained in detail in Section 4.3.5. The mean $x$-velocity $\left(V_{x}\right)$ and $y$-velocity $\left(V_{y}\right)$ values have been summarized in Tables 5.7 and 5.8 for unbaffled and baffled systems respectively. Also given are their standard deviation and 95\% confidence interval values. The $V_{y}$ values show an increase with increasing drum rotation rate, drum loading, and tablet size. There is a slight increase in the surface velocities of the tablets with the use of baffles. Predictably, the values of $V_{x}$ have an average around zero, which means that there is no net axial movement of the tablets in the present set-up. This result is expected for movement perpendicular to the rotation of the drum, so long as the bed is level. This can be seen in the Figures 5.18 and 5.19, which show the distributions for $V_{x}$ and $V_{y}$ respectively. In Figure 5.20, the changes in average $V_{x}$ values as a function of drum rotation rate, for $1 / 8$ drum loading for the systems with and without baffles have been shown. 


\begin{tabular}{|c|c|c|c|c|c|c|c|c|}
\hline $\begin{array}{l}\text { Tablet Size } \\
(\mathrm{mm})\end{array}$ & $\begin{array}{c}\text { Drum } \\
\text { Loading (fill) }\end{array}$ & $\begin{array}{c}\text { Drum Speed } \\
\text { (RPM) }\end{array}$ & $\begin{array}{l}\text { Average } V_{x} \\
(\mathrm{~mm} / \mathrm{s})\end{array}$ & $\begin{array}{c}\text { Standard } \\
\text { Deviation } V_{x} \\
(\mathrm{~mm} / \mathrm{s})\end{array}$ & $\begin{array}{l} \pm 95 \% \text { Confidence } \\
\text { Interval } V_{x}(\mathrm{~mm} / \mathrm{s})\end{array}$ & $\begin{array}{c}\text { Average } V_{y} \\
(\mathrm{~mm} / \mathrm{s})\end{array}$ & $\begin{array}{c}\text { Standard } \\
\text { Deviation } V_{y} \\
(\mathrm{~mm} / \mathrm{s})\end{array}$ & $\begin{array}{l} \pm 95 \% \text { Confidence } \\
\text { Interval } V_{y}(\mathrm{~mm} / \mathrm{s})\end{array}$ \\
\hline 6.3 & $1 / 8$ & 6 & 2.75 & 29.78 & 2.34 & 249.48 & 103.92 & 8.17 \\
\hline 6.3 & $1 / 8$ & 6 & 10.35 & 30.99 & 2.57 & 255.09 & 108.55 & 9.01 \\
\hline 6.3 & $1 / 8$ & 9 & 6.25 & 33.28 & 2.83 & 321.83 & 106.66 & 9.06 \\
\hline 6.3 & $1 / 8$ & 12 & -0.24 & 33.81 & 2.87 & 406.20 & 90.37 & 7.66 \\
\hline 6.3 & $1 / 4$ & 6 & -0.88 & 34.21 & 4.55 & 395.23 & 63.57 & 8.45 \\
\hline 6.3 & $1 / 4$ & 6 & 6.78 & 29.72 & 3.83 & 376.73 & 68.22 & 8.79 \\
\hline 6.3 & $1 / 4$ & 9 & 7.18 & 36.96 & 5.86 & 480.82 & 59.64 & 9.46 \\
\hline 7.9 & $1 / 8$ & 6 & -1.00 & 37.25 & 2.29 & 232.04 & 102.04 & 6.26 \\
\hline 7.9 & $1 / 8$ & 9 & 3.04 & 38.39 & 2.69 & 316.55 & 103.74 & 7.26 \\
\hline 7.9 & $1 / 8$ & 12 & 3.94 & 42.37 & 3.17 & 372.94 & 102.16 & 7.65 \\
\hline 7.9 & $1 / 4$ & 6 & 5.07 & 39.42 & 5.61 & 412.87 & 81.20 & 11.56 \\
\hline 7.9 & $1 / 4$ & 9 & 7.07 & 41.54 & 6.41 & 509.23 & 68.65 & 10.58 \\
\hline 7.9 & $1 / 4$ & 12 & 11.86 & 42.08 & 6.57 & 558.94 & 63.80 & 9.96 \\
\hline
\end{tabular}

Table 5.7: Mean surface velocities for unbaffled system 


\begin{tabular}{|c|c|c|c|c|c|c|c|c|}
\hline $\begin{array}{l}\text { Tablet Size } \\
\text { (mm) }\end{array}$ & $\begin{array}{c}\text { Drum } \\
\text { Loading (fill) }\end{array}$ & $\begin{array}{c}\text { Drum Speed } \\
(\mathrm{RPM})\end{array}$ & $\begin{array}{l}\text { Average } V_{x} \\
(\mathrm{~mm} / \mathrm{s})\end{array}$ & $\begin{array}{c}\text { Standard } \\
\text { Deviation } V_{x} \\
(\mathrm{~mm} / \mathrm{s})\end{array}$ & \begin{tabular}{|l} 
$\pm 95 \%$ Confidence \\
Interval $V_{x}(\mathrm{~mm} / \mathrm{s})$
\end{tabular} & $\begin{array}{l}\text { Average } V_{y} \\
(\mathrm{~mm} / \mathrm{s})\end{array}$ & \begin{tabular}{|c|} 
Standard \\
Deviation $V_{y}$ \\
$(\mathrm{~mm} / \mathrm{s})$
\end{tabular} & $\begin{array}{l} \pm 95 \% \text { Confidence } \\
\text { Interval } V_{y}(\mathrm{~mm} / \mathrm{s})\end{array}$ \\
\hline 10.4 & $1 / 8$ & 6 & 6.08 & 45.67 & 2.65 & 261.75 & \begin{tabular}{|l|}
111.38 \\
\end{tabular} & 6.45 \\
\hline 10.4 & $1 / 8$ & 6 & 2.36 & 46.29 & 2.82 & 270.91 & 115.17 & 7.02 \\
\hline 10.4 & $1 / 8$ & 9 & 5.37 & 51.67 & 3.10 & 329.21 & 119.20 & 7.15 \\
\hline 10.4 & $1 / 8$ & 12 & 2.12 & 51.73 & 3.27 & 403.00 & 117.89 & 7.46 \\
\hline 10.4 & $1 / 8$ & 12 & 7.60 & 58.20 & 3.71 & 397.16 & 141.05 & 8.98 \\
\hline 10.4 & $1 / 4$ & 6 & -0.72 & 49.90 & 6.28 & 400.95 & 97.73 & 12.30 \\
\hline 10.4 & $1 / 4$ & 6 & 1.43 & 48.40 & 5.56 & 404.36 & 90.46 & 10.40 \\
\hline 10.4 & $1 / 4$ & 9 & 13.68 & 47.45 & 5.30 & 474.08 & 82.47 & 9.22 \\
\hline 10.4 & $1 / 4$ & 12 & 6.44 & 66.00 & 8.94 & 546.99 & 130.22 & 17.63 \\
\hline 10.4 & $1 / 4$ & 12 & 10.87 & 75.98 & 9.76 & 488.66 & 174.06 & 22.37 \\
\hline
\end{tabular}

Table 5.7: Mean surface velocities for unbaffled system (continued) 


\begin{tabular}{|c|c|c|c|c|c|c|c|c|}
\hline $\begin{array}{l}\text { Tablet Size } \\
\quad(\mathrm{mm})\end{array}$ & $\begin{array}{c}\text { Drum } \\
\text { Loading (fill) }\end{array}$ & $\begin{array}{c}\text { Drum Speed } \\
\text { (RPM) }\end{array}$ & $\begin{array}{l}\text { Average } V_{x} \\
(\mathrm{~mm} / \mathrm{s})\end{array}$ & $\begin{array}{c}\text { Standard } \\
\text { Deviation } V_{x} \\
(\mathrm{~mm} / \mathrm{s}) \\
\end{array}$ & $\begin{array}{l} \pm 95 \% \text { Confidence } \\
\text { Interval } V_{x}(\mathrm{~mm} / \mathrm{s})\end{array}$ & $\begin{array}{c}\text { Average } V_{y} \\
(\mathrm{~mm} / \mathrm{s})\end{array}$ & $\begin{array}{c}\text { Standard } \\
\text { Deviation } V_{y} \\
(\mathrm{~mm} / \mathrm{s})\end{array}$ & $\begin{array}{l} \pm 95 \% \text { Confidence } \\
\text { Interval } V_{y}(\mathrm{~mm} / \mathrm{s})\end{array}$ \\
\hline 6.3 & $1 / 8$ & 6 & -2.81 & 29.22 & 2.77 & 174.94 & 82.05 & 7.77 \\
\hline 6.3 & $1 / 8$ & 6 & -5.61 & 50.58 & 4.53 & 180.34 & 96.69 & 8.65 \\
\hline 6.3 & $1 / 8$ & 9 & -1.05 & 39.70 & 3.09 & 221.65 & 80.30 & 6.25 \\
\hline 6.3 & $1 / 8$ & 12 & -8.13 & 69.52 & 6.38 & 308.33 & 96.22 & 8.84 \\
\hline 6.3 & $1 / 8$ & 12 & -3.22 & 43.15 & 3.79 & 277.34 & 90.02 & 7.90 \\
\hline 6.3 & $1 / 4$ & 6 & -5.09 & 33.70 & 4.92 & 433.33 & 76.55 & 11.17 \\
\hline 6.3 & $1 / 4$ & 6 & 0.57 & 33.81 & 4.85 & 426.60 & 83.10 & 11.92 \\
\hline 6.3 & $1 / 4$ & 9 & -5.20 & 29.69 & 4.62 & 494.82 & 71.58 & 11.14 \\
\hline 6.3 & $1 / 4$ & 12 & -6.06 & 36.65 & 5.74 & 535.68 & 59.39 & 9.30 \\
\hline 6.3 & $1 / 4$ & 12 & -2.19 & 32.42 & 5.38 & 544.99 & 56.62 & 9.39 \\
\hline 7.9 & $1 / 8$ & 6 & -0.46 & 45.39 & 2.69 & 199.35 & 115.64 & 6.86 \\
\hline 7.9 & $1 / 8$ & 9 & -0.05 & 45.75 & 2.83 & 231.41 & 101.92 & 6.30 \\
\hline 7.9 & $1 / 8$ & 12 & 1.78 & 70.42 & 5.13 & 286.16 & 131.90 & 9.60 \\
\hline 7.9 & $1 / 4$ & 6 & 0.19 & 41.50 & 5.91 & 452.96 & 90.49 & 12.88 \\
\hline 7.9 & $1 / 4$ & 9 & -2.89 & 41.64 & 5.71 & 513.29 & 81.62 & 11.18 \\
\hline 7.9 & $1 / 4$ & 12 & -4.70 & 49.93 & 7.03 & 606.89 & 81.20 & 11.44 \\
\hline
\end{tabular}

Table 5.8: Mean surface velocities for baffled system 


\begin{tabular}{|c|c|c|c|c|c|c|c|c|}
\hline $\begin{array}{l}\text { Tablet Size } \\
\qquad(\mathrm{mm})\end{array}$ & $\begin{array}{c}\text { Drum } \\
\text { Loading (fill) }\end{array}$ & $\begin{array}{c}\text { Drum Speed } \\
\text { (RPM) }\end{array}$ & $\begin{array}{l}\text { Average } V_{x} \\
(\mathrm{~mm} / \mathrm{s})\end{array}$ & $\begin{array}{c}\text { Standard } \\
\text { Deviation } V_{x} \\
(\mathrm{~mm} / \mathrm{s}) \\
\end{array}$ & $\begin{array}{l} \pm 95 \% \text { Confidence } \\
\text { Interval } V_{x}(\mathrm{~mm} / \mathrm{s})\end{array}$ & $\begin{array}{l}\text { Average } V_{y} \\
(\mathrm{~mm} / \mathrm{s})\end{array}$ & $\begin{array}{c}\text { Standard } \\
\text { Deviation } V_{y} \\
(\mathrm{~mm} / \mathrm{s}) \\
\end{array}$ & $\begin{array}{l} \pm 95 \% \text { Confidence } \\
\text { Interval } V_{y}(\mathrm{~mm} / \mathrm{s})\end{array}$ \\
\hline 10.4 & $1 / 8$ & 6 & 1.30 & 81.25 & 4.90 & 267.06 & 139.23 & 8.39 \\
\hline 10.4 & $1 / 8$ & 6 & -0.94 & 60.26 & 3.58 & 254.40 & 128.76 & 7.64 \\
\hline 10.4 & $1 / 8$ & 9 & -3.70 & 89.09 & 5.31 & 335.42 & 151.97 & 9.05 \\
\hline 10.4 & $1 / 8$ & 12 & -4.49 & 90.62 & 6.05 & 336.19 & 128.87 & 8.61 \\
\hline 10.4 & $1 / 4$ & 6 & -4.93 & 50.59 & 5.82 & 437.30 & 99.60 & 11.45 \\
\hline 10.4 & $1 / 4$ & 6 & 1.65 & 48.29 & 5.22 & 426.14 & 94.46 & 10.21 \\
\hline 10.4 & $1 / 4$ & 9 & -4.11 & 53.68 & 6.97 & 527.59 & 95.77 & 12.44 \\
\hline
\end{tabular}

Table 5.8: Mean surface velocities for baffled system (continued) 


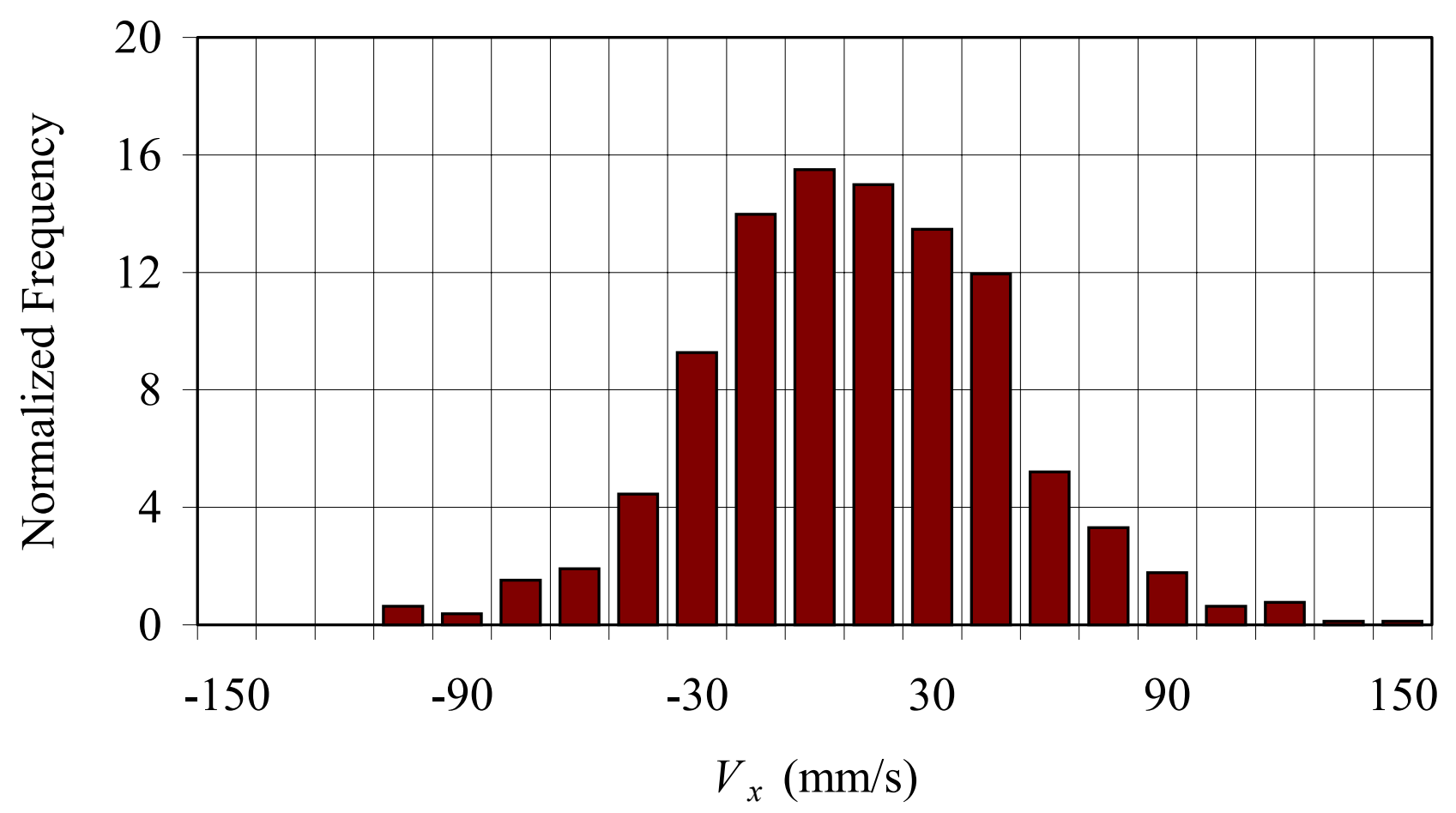

Figure 5.18: Distribution of $V_{x}$ for $7.9 \mathrm{~mm}$ tablets, $1 / 8$ drum loading, 9 rpm drum speed, unbaffled system 


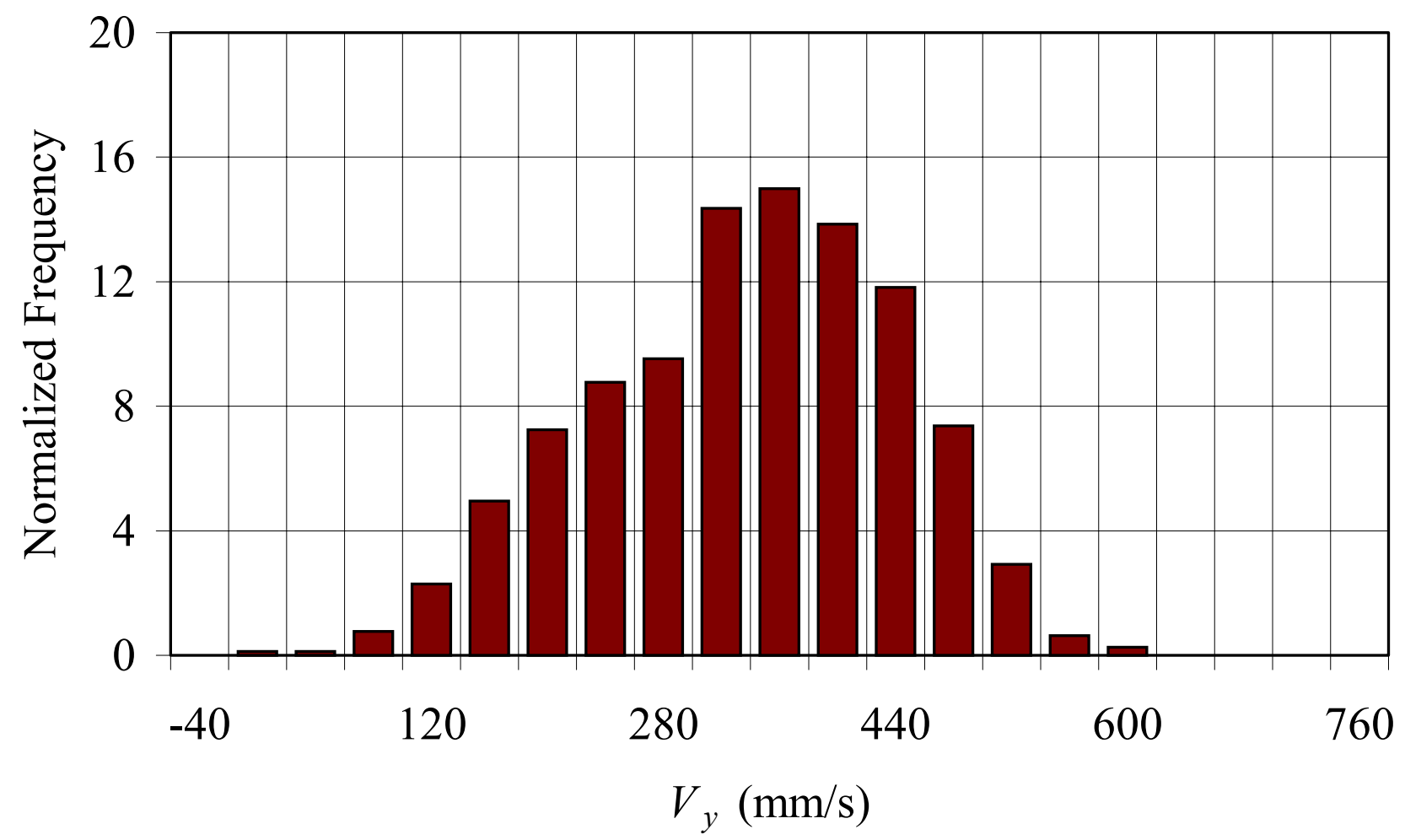

Figure 5.19: Distribution of $V_{y}$ for $7.9 \mathrm{~mm}$ tablets, $1 / 8$ drum loading, $9 \mathrm{rpm}$ drum speed, unbaffled system 


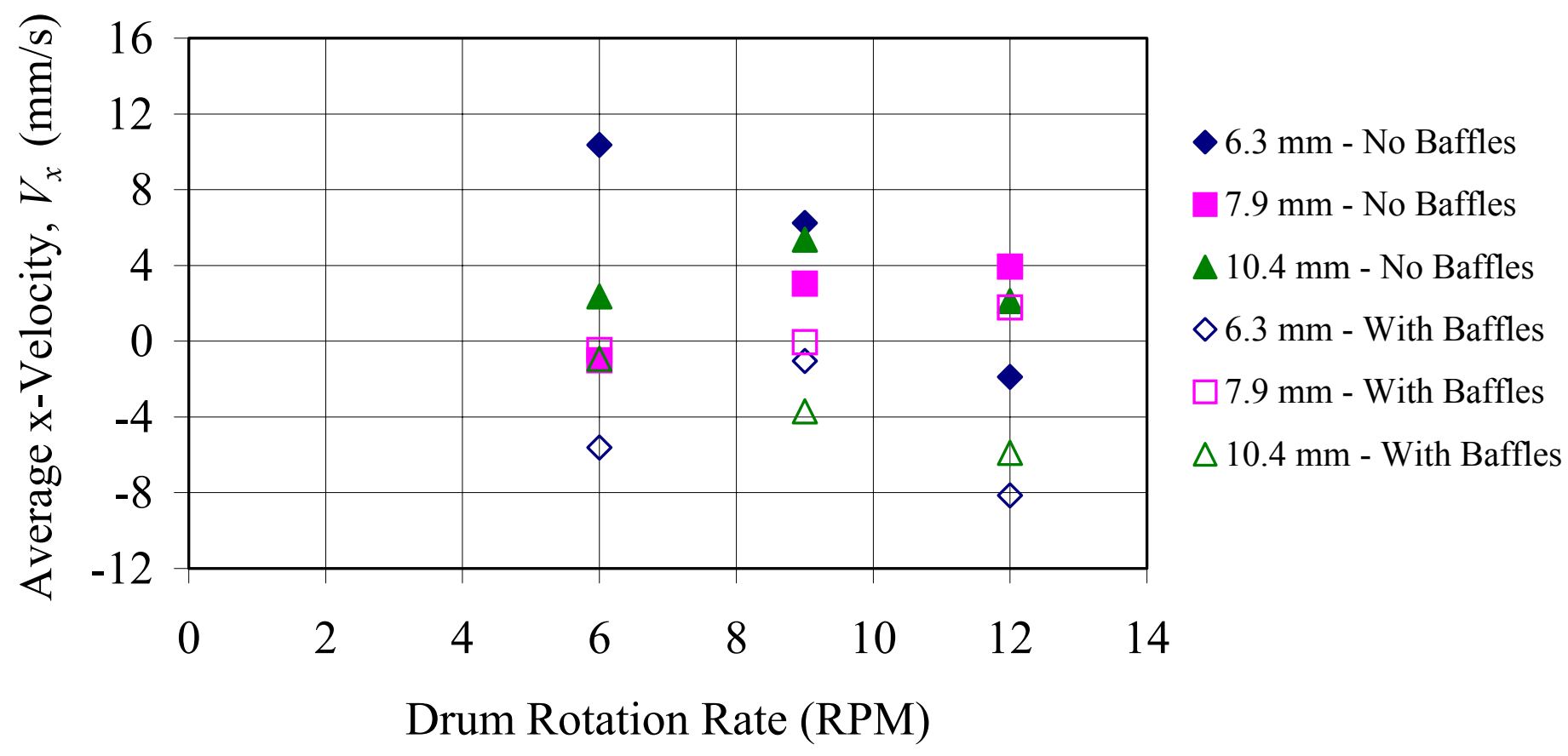

Figure 5.20: Change in average surface velocity $\left(V_{x}\right)$ as a function of drum rotation rate for baffled and unbaffled systems with $1 / 8$ drum loading 


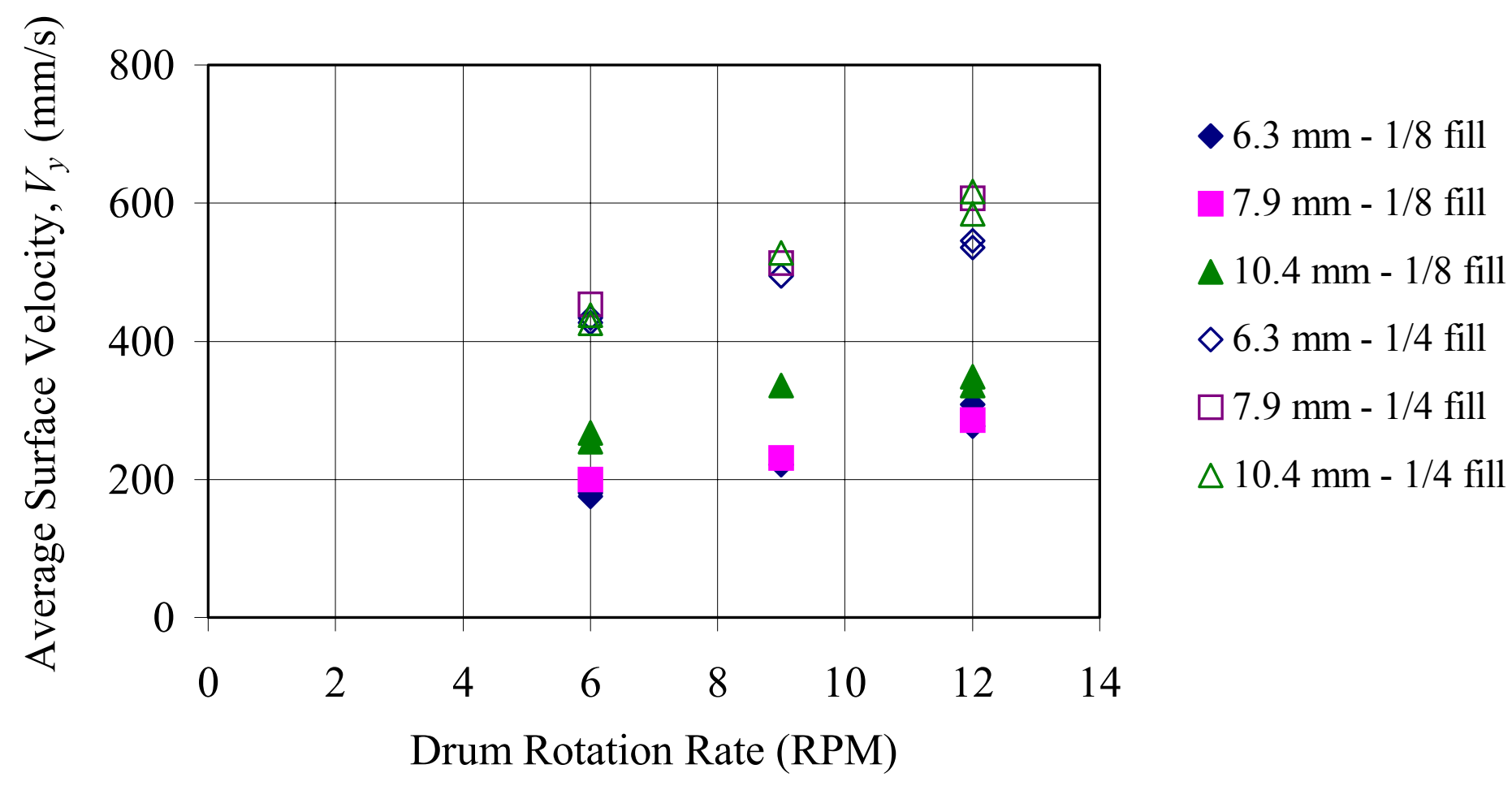

Figure 5.21: Change in average surface velocity $\left(V_{y}\right)$ as a function of drum rotation rate for unbaffled system 
The values of $V_{y}$ can be correlated with the surface times, i.e. when the surface times are lower, the particles move with higher velocities (Figure 5.21). However the values of $V_{y}$ are much lower than the average velocities predicted using the average surface times, knowing the dimensions of the ROI (Average Velocity $=$ Length of ROI / $\tau_{\text {surface }) .}$

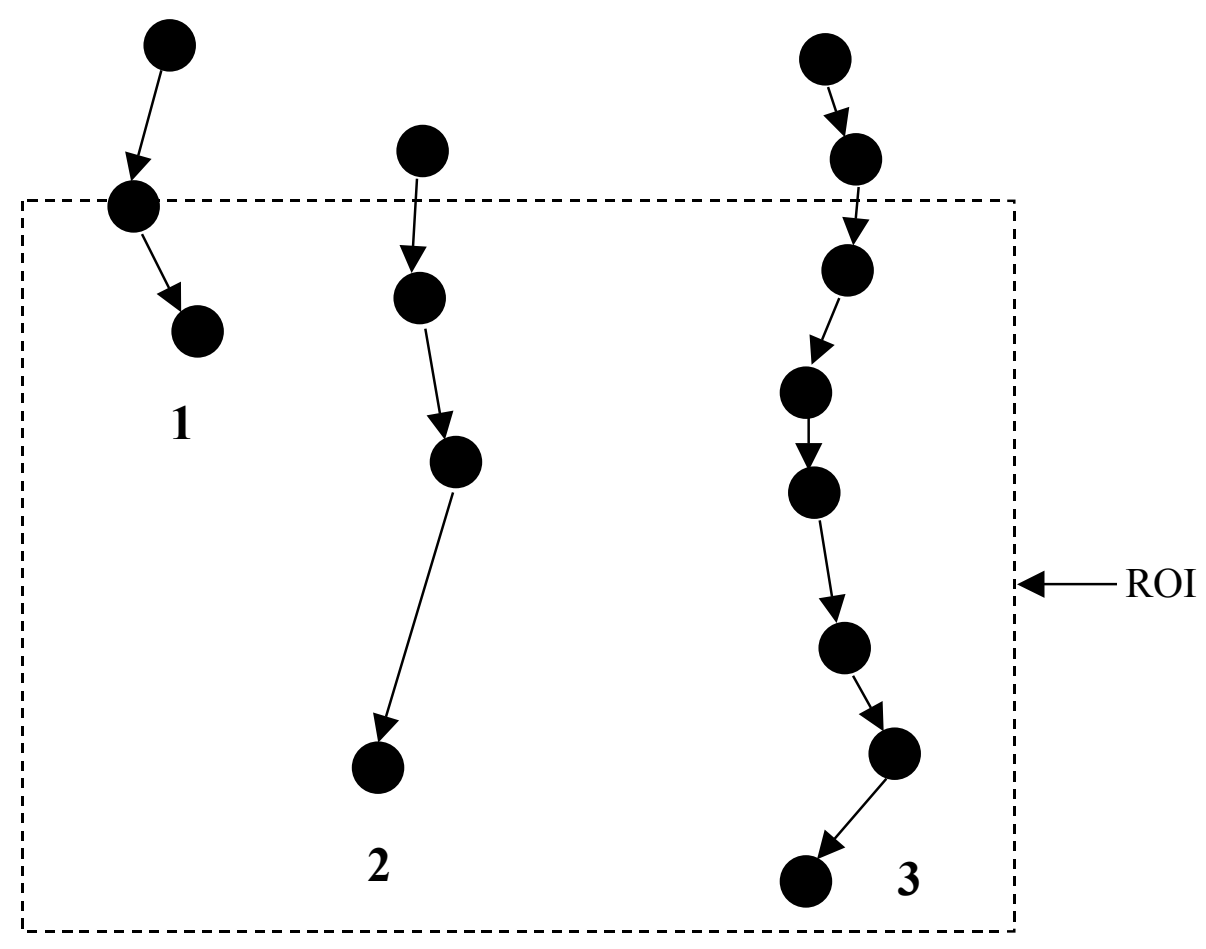

Figure 5.22: Movement of tracer particle through ROI

This can be explained with Figure 5.22, which depicts three different paths taken by the tablet, each time it enters the ROI. In each of the three cases, the tablet is on the surface for different amounts of time. The tablet may also disappear into the bed once it appears on the surface and reappear in one pass. The average surface time calculated based on the average velocity of the particle in the ROI, is different in each case. 
Therefore the surface time calculated in case 1 will be considerably lower than cases 2 or 3 , since the time of exposure of this tablet on the surface is much shorter than the other two cases for a given length of ROI. However if the maximum time spent by the tracer tablet on the surface in the ROI ( $\left.\tau_{\text {surface,max }}\right)$ is considered to estimate the average velocity, the values obtained are comparable with the average $V_{y}$ values. The fraction of time that the tracer tablet is exposed towards the camera was calculated using the average $\tau_{\text {surface }}$ and $V_{y}$ values for a given length of the ROI $\left(f_{\text {exp }}=\right.$ exposure fraction $=\tau_{\text {sufface, avg }} /($ Length of $\left.R O I / V_{y, a v g}\right)$ ). The results for exposure fraction, with both the unbaffled and baffled systems are shown in Tables 5.9 and 5.10 respectively. The value of $f_{\text {exp }}$ indicates the fraction of the time that the particle spends on the surface of the tablet bed in the ROI. 


\begin{tabular}{|c|c|c|c|c|}
\hline Baffles & Tablet Size $(\mathrm{mm})$ & Drum Loading (fill) & Drum Speed (RPM) & $\begin{array}{c}\text { Exposure Fraction } \\
\left(f_{\text {exp }}\right)\end{array}$ \\
\hline No & 6.3 & $1 / 8$ & 6 & 0.44 \\
\hline No & 6.3 & $1 / 8$ & 6 & 0.44 \\
\hline No & 6.3 & $1 / 8$ & 9 & 0.48 \\
\hline No & 6.3 & $1 / 8$ & 12 & 0.46 \\
\hline No & 6.3 & $1 / 8$ & 12 & 0.48 \\
\hline No & 6.3 & $1 / 4$ & 6 & 0.42 \\
\hline No & 6.3 & $1 / 4$ & 6 & 0.41 \\
\hline No & 6.3 & $1 / 4$ & 9 & 0.39 \\
\hline No & 6.3 & $1 / 4$ & 12 & 0.36 \\
\hline No & 6.3 & $1 / 4$ & 12 & 0.35 \\
\hline No & 7.9 & $1 / 8$ & 6 & 0.46 \\
\hline No & 7.9 & $1 / 8$ & 9 & 0.48 \\
\hline No & 7.9 & $1 / 8$ & 12 & 0.45 \\
\hline No & 7.9 & $1 / 4$ & 6 & 0.38 \\
\hline No & 7.9 & $1 / 4$ & 9 & 0.42 \\
\hline No & 7.9 & $1 / 4$ & 12 & 0.40 \\
\hline No & 10.4 & $1 / 8$ & 6 & 0.53 \\
\hline No & 10.4 & $1 / 8$ & 6 & 0.53 \\
\hline No & 10.4 & $1 / 8$ & 9 & 0.51 \\
\hline No & 10.4 & $1 / 8$ & 12 & 0.52 \\
\hline No & 10.4 & $1 / 8$ & 12 & 0.51 \\
\hline No & 10.4 & $1 / 4$ & 6 & 0.41 \\
\hline No & 10.4 & $1 / 4$ & 6 & 0.43 \\
\hline No & 10.4 & $1 / 4$ & 9 & 0.43 \\
\hline No & 10.4 & $1 / 4$ & 12 & 0.34 \\
\hline No & 10.4 & $1 / 4$ & 12 & 0.30 \\
\hline
\end{tabular}

Table 5.9: Exposure Fraction $\left(f_{e x p}\right)$ for unbaffled system 


\begin{tabular}{|c|c|c|c|c|}
\hline Baffles & Tablet Size (mm) & Drum Loading (fill) & Drum Speed (RPM) & $\begin{array}{c}\text { Exposure Fraction } \\
\left(f_{\text {exp }}\right)\end{array}$ \\
\hline Yes & 6.3 & $1 / 8$ & 6 & 0.24 \\
\hline Yes & 6.3 & $1 / 8$ & 6 & 0.28 \\
\hline Yes & 6.3 & $1 / 8$ & 9 & 0.30 \\
\hline Yes & 6.3 & $1 / 8$ & 12 & 0.30 \\
\hline Yes & 6.3 & $1 / 8$ & 12 & 0.29 \\
\hline Yes & 6.3 & $1 / 4$ & 6 & 0.46 \\
\hline Yes & 6.3 & $1 / 4$ & 6 & 0.43 \\
\hline Yes & 6.3 & $1 / 4$ & 9 & 0.43 \\
\hline Yes & 6.3 & $1 / 4$ & 12 & 0.40 \\
\hline Yes & 6.3 & $1 / 4$ & 12 & 0.42 \\
\hline Yes & 7.9 & $1 / 8$ & 6 & 0.37 \\
\hline Yes & 7.9 & $1 / 8$ & 9 & 0.33 \\
\hline Yes & 7.9 & $1 / 8$ & 12 & 0.29 \\
\hline Yes & 7.9 & $1 / 4$ & 6 & 0.44 \\
\hline Yes & 7.9 & $1 / 4$ & 9 & 0.44 \\
\hline Yes & 7.9 & $1 / 4$ & 12 & 0.45 \\
\hline Yes & 10.4 & $1 / 8$ & 6 & 0.50 \\
\hline Yes & 10.4 & $1 / 8$ & 6 & 0.50 \\
\hline Yes & 10.4 & $1 / 8$ & 9 & 0.47 \\
\hline Yes & 10.4 & $1 / 8$ & 12 & 0.39 \\
\hline Yes & 10.4 & $1 / 8$ & 12 & 0.36 \\
\hline Yes & 10.4 & $1 / 4$ & 6 & 0.48 \\
\hline Yes & 10.4 & $1 / 4$ & 6 & 0.47 \\
\hline Yes & 10.4 & $1 / 4$ & 9 & 0.46 \\
\hline Yes & 10.4 & $1 / 4$ & 12 & 0.45 \\
\hline Yes & 10.4 & $1 / 4$ & 12 & 0.44 \\
\hline
\end{tabular}

Table 5.10: Exposure Fraction $\left(f_{\text {exp }}\right)$ for baffled system 


\subsection{Statistical Analysis}

Standard Analysis of Variance (ANOVA) tests were conducted using the results obtained for all the parameters, to study the effect of the process variables. The independent variables considered in a full factorial design were drum rotation rate, drum loading, tablet size and baffles. The dependent variables were $\tau_{\text {circ }}, \tau_{\text {surface }}, A_{\text {tab }}$ and $V_{y}$. The effect due to interactions between the variables was also studied. The detailed results for each of the parameters have been included as Appendix VI.

The ANOVA for $\tau_{\text {circ }}$ predictably showed significant effect $(\mathrm{p}<0.05)$ of drum speed, drum loading and tablet size on the circulation time values. The effect of baffles in this case was found to be insignificant. The value of $\mathrm{R}^{2}$ for the regression model developed was 0.988 . In the case of $\tau_{\text {surface }}$, all the variables showed significant effects $(p<0.05)$, with the drum fill exhibiting the strongest effect $\left(R^{2}=0.997\right)$, followed by the drum speed. Baffles and tablet size although not as significant as compared to the other two variables, still had an effect on the surface times. The tests for $A_{t a b}$ indicated a strong influence $(\mathrm{p}<0.05)$ of tablet size, followed by the drum loading and drum speed. The baffles also had a significant effect on the projected surface areas $\left(\mathrm{R}^{2}=0.998\right)$. Normalized areas were considered and predictably the results indicated no effect of the tablet size, but significant effects of drum speed, drum loading and baffles $\left(\mathrm{R}^{2}=0.997\right)$. In the case of $V_{y}$, as seen with the surface times, there is a strong effect of drum loading followed by the drum speed, tablet size and baffles $\left(\mathrm{R}^{2}=0.995\right)$. The effect due to interactions between the independent variables on each of the dependent variables was also studied in a full factorial design. These effects were statistically significant in some cases, which are indicated in the results for all the dependent parameters. The results of 
the ANOVA tests for the interactions have been included in Appendix VI. However for simplicity, only the main effects were taken into consideration to calculate linear regression models for all the parameters of interest.

A linear regression model can be calculated assuming linear effects of all the independent variables on the parameters considered, based on the statistical results for significance. This model can be used to estimate the optimum conditions for the coating operation in similar equipment. In linear regression, the statistics for a line are estimated by using the "least squares" method to calculate a straight line that best fits the data, which returns an array that describes the line. Based on the results obtained from the ANOVA tests, multiple regression analysis was conducted for each of the parameters of interest using Microsoft Excel. The equations calculated by the analysis are shown below. Using these equations the values of each of the dependent parameters can be predicted at known values of the independent variables. Figures 5.23, 5.24, 5.25, and 5.26 show the comparisons of the experimental and predicted values for each of the dependent parameters.

$$
\begin{aligned}
& \tau_{\text {circ }}=14.0-0.810 \mathrm{TS}+31.9 \mathrm{DL}-0.615 \mathrm{DR} \\
& \tau_{\text {surface }}=0.266-0.006 \mathrm{~B}+0.002 \mathrm{TS}-0.480 \mathrm{DL}-0.008 \mathrm{DR} \\
& A_{\text {tab }}=42.8-10.9 \mathrm{~B}+11.2 \mathrm{TS}-203.3 \mathrm{DL}-5.0 \mathrm{DR} \\
& V_{y}=-145.4-9.8 \mathrm{~B}+7.4 \mathrm{TS}+1549.2 \mathrm{DL}+21.0 \mathrm{DR} \\
& \text { where } B=\text { Baffles }(0=\text { No Baffles, } 1=\text { With Baffles }) \\
& T S=\text { Tablet Size (mm) } \\
& D L=\text { Drum Loading (fill level) } \\
& D R=\text { Drum Rotation Rate (rpm) }
\end{aligned}
$$




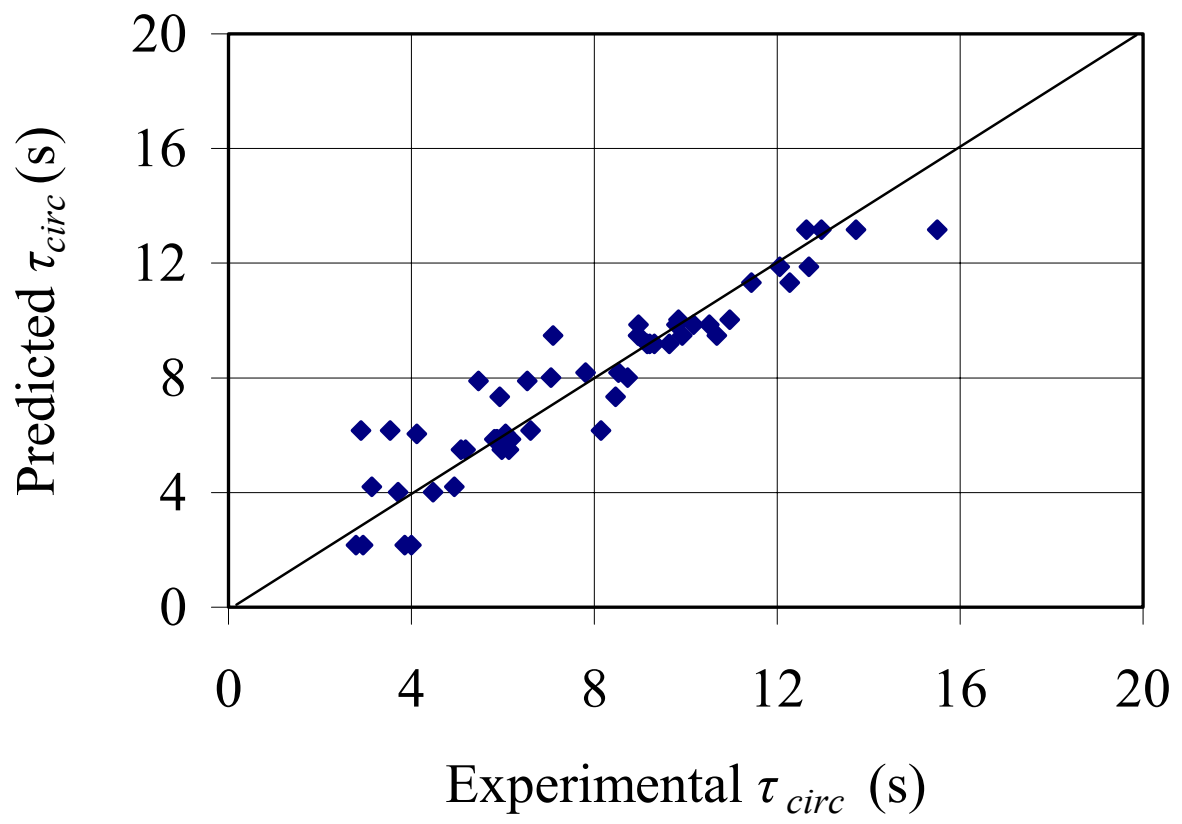

Figure 5.23: Comparison of experimental and predicted $\tau_{\text {circ }}$ values

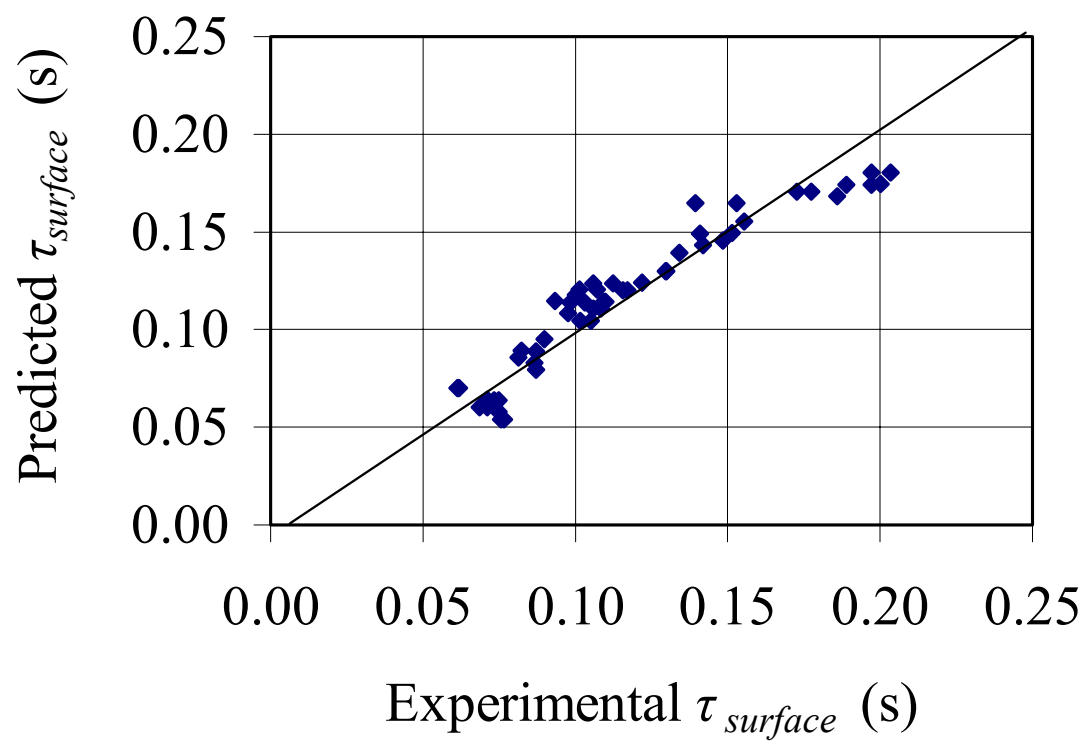

Figure 5.24: Comparison of experimental and predicted $\tau_{\text {surface }}$ values 


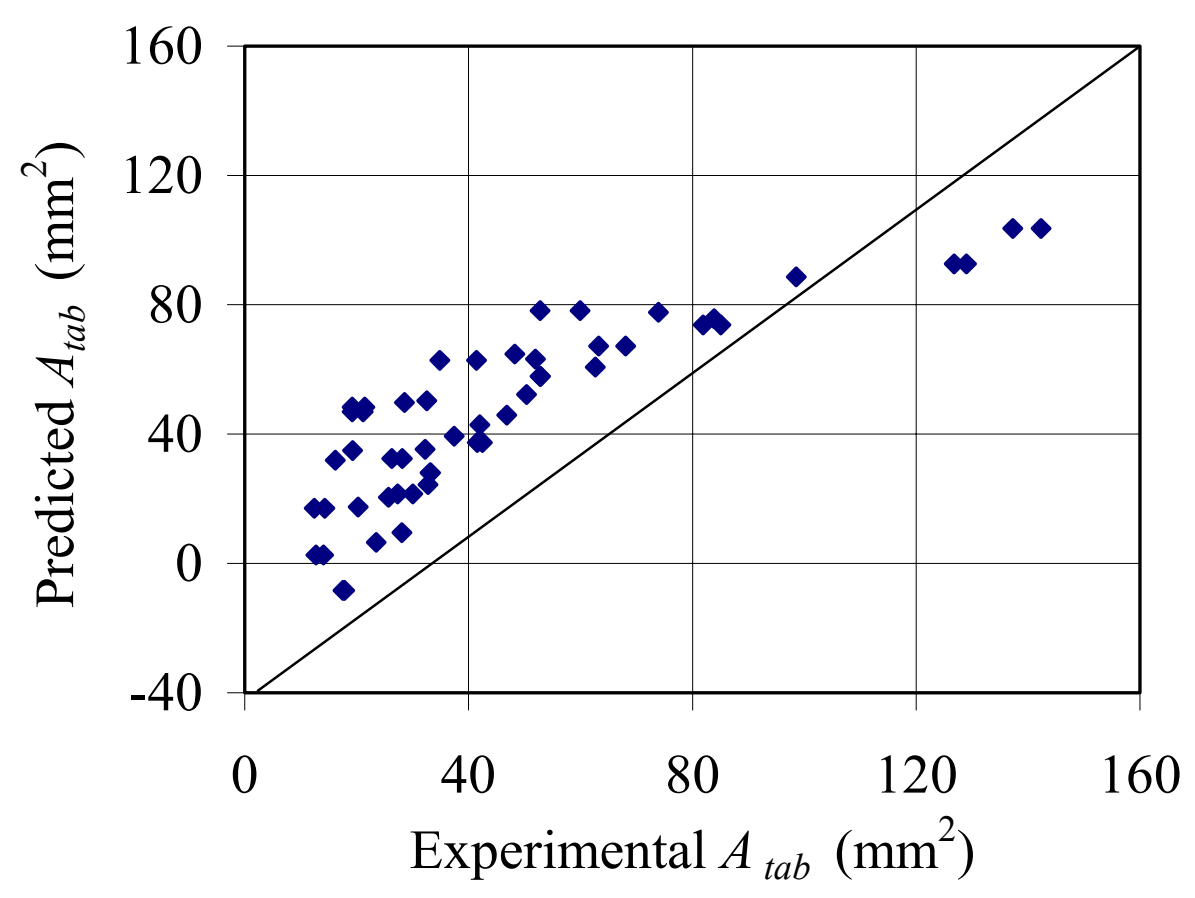

Figure 5.25: Comparison of experimental and predicted $A_{t a b}$ values

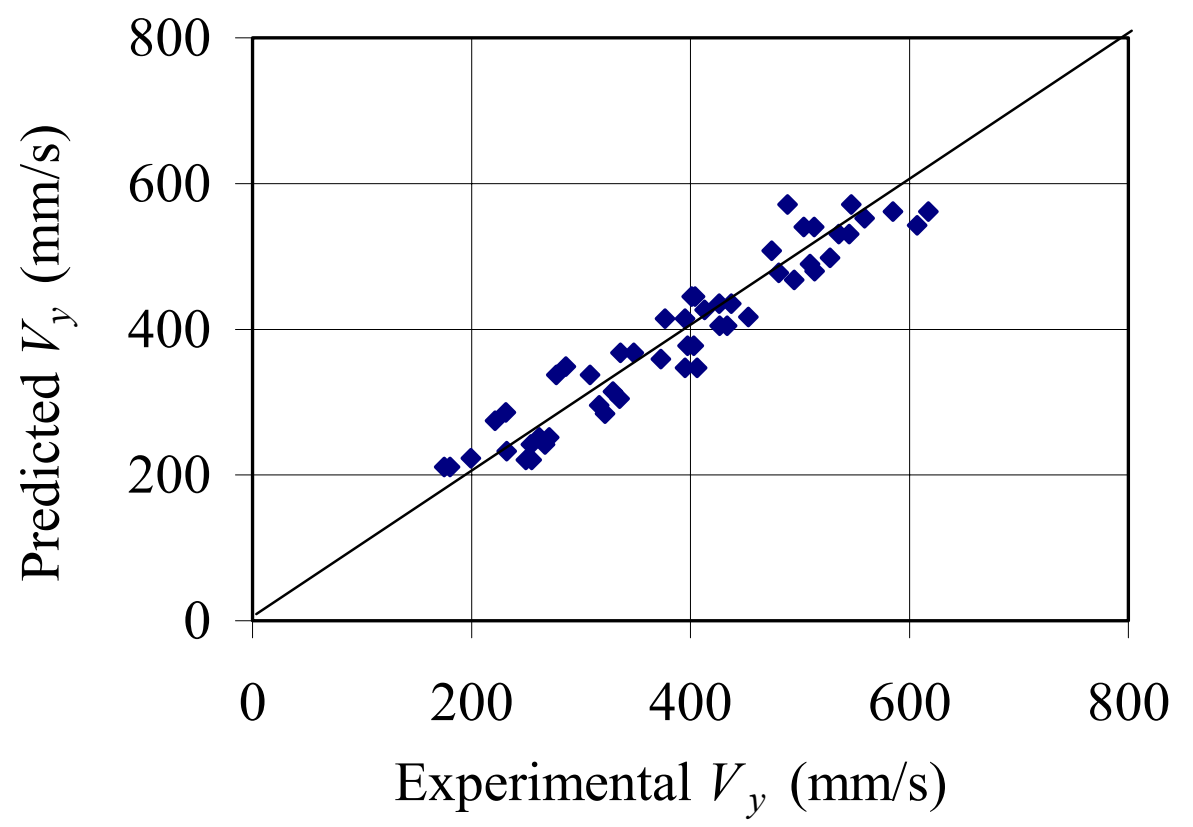

Figure 5.26: Comparison of experimental and predicted $V_{y}$ values 


\section{Conclusions}

The present study investigated the dependence of the movement of particles on the process variables i.e. drum speed, drum loading and the presence/absence of mixing elements, using a two-dimensional rotating drum and particle tracking techniques. This was achieved by quantifying the three parameters $\tau_{c i r c}, \tau_{\text {surface, }}$, and $A_{\text {tab }}$ using digital imaging and machine-vision software. The results obtained in this study indicate that the use of machine vision software and digital imaging can be applied successfully to the acquisition of tablet movement on the surface of moving beds in drum coating equipment. The potential advantage of this technique is that the acquisition of particle movement is conducted in real-time, which gives a good estimation of the parameters of interest.

The trends in circulation time $\left(\tau_{\text {circ }}\right)$, surface time $\left(\tau_{\text {surface }}\right)$ and projected surface area $\left(A_{t a b}\right)$ compare well with the results obtained by Leaver et al. (1985). The results from this study show the same decreasing trends in $\tau_{\text {circ }}$ and $\tau_{\text {surface }}$ with increasing drum rotation rates. However the results can only be compared qualitatively since the data given by Leaver et al. do not contain any information about the tablet shape. The studies done by Leaver et al. do not include the projected surface area calculations, which can be a useful tool to estimate the coating uniformity and the efficiency of the coating process.

The results for circulation time indicate that the larger particles move with higher velocities through the tablet bed and hence show lower $\tau_{\text {circ }}$ values. With increase in the drum rotation rate, the $\tau_{\text {circ }}$ values show a decreasing trend. Thus by increasing the drum speed, the frequency of appearance of the tablets on the surface can by accelerated, which may reduce the coating thickness variation to a certain extent. The use of baffles inside 
the drum did not affect the values of $\tau_{\text {circ }}$ for the different drum speeds and loadings when compared with the results for the system with no baffles. However with the use of baffles, the distribution of $\tau_{\text {circ }}$ was more uniform and narrow at lower drum loading. The changes in $\tau_{\text {circ }}$ were also more uniform with the use of baffles. This indicates that the use of mixing elements in a coating device may be beneficial to the coating uniformity since it promotes uniform tablet appearances on the surface of the tablet bed. The effect of baffles on $\tau_{\text {circ }}$ with respect to drum loadings is significant for the lower loadings. However, studies with different drum loadings can help to understand the effect of baffles better.

The values of surface times and projected surface areas indicate that $\tau_{\text {surface }}$ and $A_{t a b}$ are functions of drum rotation rate and drum loading. The results for normalized areas of the tablets also show that the amount of surface area exposed is a function of drum loading and drum speed, but not a strong function of tablet size. Hence the amount of spray received by a particular particle can be controlled to achieve minimum coat thickness variation between the tablets in a coating operation. This can be achieved by using optimum values of both the drum speed and the drum loading. However, experimenting with different baffle designs may help to determine the optimum values of the variables of interest in a coating operation.

In addition to the three parameters mentioned above, the present study also included the evaluation of tablet velocity on the surface, both parallel and perpendicular to the flow, and the location of the tablets in the ROI at any given point of time. This information can be used to understand the mixing dynamics and correlate the coefficient of dispersion for the movement of particles in the rotating drum. The results obtained for 
the surface velocities for both $V_{x}$ and $V_{y}$ (velocities perpendicular and parallel to the direction of flow of tablets in the drum), indicate a significant effect of drum speed, drum loading, tablet size, and use of baffles. The average $V_{x}$ values are close to zero, which implies that there is negligible net axial movement in the rotating drum. The values of $V_{y}$ can be correlated with the surface times of the tablets i.e. with increasing drum speeds, the surface velocities increase and thus the surface time decreases. With an increase in the bed weight, the surface velocities also increase and hence the surface times decrease. The values of average $V_{y}$ were estimated theoretically from the surface time, knowing the dimensions of the ROI. However, the values of experimental $V_{y}$ obtained were lower than the theoretical values, which can be attributed to the different path taken by the tracer tablet each time it enters the ROI, and the amount of time spent on the surface of the ROI.

The independent variables drum speed, drum loading, and tablet size (ANOVA) had statistically significant effects $(\mathrm{p}<0.05)$ on the $\tau_{\text {circ }}, \tau_{\text {surface }}, A_{\text {tab }}$, and $V_{y}$. The influence of baffles was found to be significant for $\tau_{\text {surface }}, A_{\text {tab }}$, and $V_{y}$, but not $\tau_{\text {circ }}$. The interactions between the independent variables showed statistically significant effects on the dependent parameters in some cases. However, for simplicity only the main effects were taken into consideration to calculate linear models for the variables. Thus a linear regression model was calculated assuming linear effects of all the independent variables on the parameters considered $\left(\mathrm{R}^{2} \sim 0.85\right)$. This model can be used to estimate the optimum conditions for the coating operation in similar equipment. 


\section{Recommendation for Future Work}

The parameters calculated in this study can be used to simulate the particle movement in a rotating drum coating device. In addition, this data can also be used for scale-up and the optimum conditions determined for industrial scale equipment. These experiments will give useful results to improve the coating process efficiency and the coating uniformity on the tablets in a coating pan in industrial scale equipment.

Inherent dead zones are formed in a pan coater at the center region of the tablet bed, which leads to very high circulation times for the particles entrapped in these dead zones. This leads to non-uniformity of coating deposited on the tablets. This problem may be solved with the use of small particles, such as glass beads, to fill the dead zone in the coating pan. The utility of using glass beads is based on predictions by Dury and Ristow (1999), that a core of dense particles can be created in a bed of less dense particles and this segregation may be beneficial to the circulation of tablets in the drum, i.e., a more uniform circulation of tablets may be obtained in the drum. Different amounts of glass beads may be used to determine significant changes in the circulation time or coating uniformity of the tablets.

The use of liquid spray along with the imaging technique developed in this research will give better representative data for the actual coating operation. However, several difficulties may be encountered during the experiments using a spray. The use of heated air to promote drying in the present experimental set-up will not be possible, and the spraying solution will most likely consist of an organic solvent. In addition, the effect of an atomized binder on the CCD camera is unknown, although, any deposition on the lens will be highly detrimental to the quality of the captured images. Therefore the 
spraying runs with the present set-up may be limited to the use of only solvents. Also the effect of cohesive forces (due to binder) on the movement of tablets in the bed may be investigated by adding small amounts of non-volatile oil in the drum, to simulate a viscous liquid coating.

The two variables, glass beads and liquid spray were not attempted during the course of this research due to limitations with the equipment and time. However the equipment can be modified slightly and used for further studies, the data from which can be used to simulate particle movement in the pan coater and thus determine optimum levels for all the variables in the rotating drum coating device. The use of a threedimensional pan may also give representative data for simulation. In addition, the use of different baffle designs may help to understand better the effect of baffles on the parameters of interest. 


\section{Nomenclature}

\begin{tabular}{|c|c|}
\hline$\tau_{\text {circ }}$ & Circulation time (s) \\
\hline$\tau_{\text {surface }}$ & Surface time (s) \\
\hline$A_{\text {tab }}$ & Projected surface area $\left(\mathrm{mm}^{2}\right)$ \\
\hline$n$ & Number of frames the tracer tablet is exposed per pass \\
\hline$(x, y)$ & Centroid Position (pixels) \\
\hline$x$ & Direction perpendicular to flow of tablets \\
\hline$y$ & Direction of flow of tablets \\
\hline$V_{x}$ & Surface velocity in $x$-direction $(\mathrm{mm} / \mathrm{s})$ \\
\hline$V_{y}$ & Surface velocity in $y$-direction $(\mathrm{mm} / \mathrm{s})$ \\
\hline$t_{1}, t_{n}, t_{n+1}$ & Time (ms) \\
\hline$\Delta t$ & Change in Time (ms) \\
\hline Length of ROI & $10 \mathrm{~cm}$ \\
\hline$\Delta x$ & Change in $x$ (pixels) \\
\hline$\Delta y$ & Change in $y$ (pixels) \\
\hline$\tau_{\text {surface, avg }}$ & Average surface time (s) \\
\hline$V_{y, a v g}$ & Average surface velocity in $y$-direction $(\mathrm{mm} / \mathrm{s})$ \\
\hline$A_{\text {actual }}$ & Actual area of tablets $\left(\mathrm{mm}^{2}\right)$ \\
\hline$A_{\max }$ & Maximum area of tablet exposed (pixels) \\
\hline$d_{\text {pixel }}$ & Diameter estimated from $A_{\max }$ (pixels) \\
\hline$d_{\text {actual }}$ & Actual diameter of tablets (mm) \\
\hline Area Factor & Area conversion factor from pixel to SI units \\
\hline Velocity factor & Velocity conversion factor from pixel to SI units \\
\hline
\end{tabular}




$\begin{array}{ll}f_{\text {exp }} & \text { Exposure fraction } \\ B & \text { Baffles (0=No Baffles, 1= With Baffles) } \\ T S & \text { Tablet Size (mm) } \\ D L & \text { Drum Loading (fill level) } \\ D R & \text { Drum Rotation Rate (rpm) } \\ \mathrm{H} & \text { Height of Tablets in Bed } \\ \mathrm{D} & \text { Internal Diameter of Rotating Drum } \\ \mathrm{f} & \text { Fractional Fill Level } \\ \mathrm{p} & \text { Probability } \\ \text { "blob" } & \text { Tracer Tablet } \\ \text { ID } & \text { Internal Diameter } \\ \text { OD } & \text { Outer Diameter } \\ \text { CCD } & \text { Charged Coupled Device } \\ \text { ROI } & \text { Region of Interest } \\ \text { VCR } & \text { Video Cassette Recorder } \\ \text { ANOVA } & \text { Analysis of Variances }\end{array}$




\section{Bibliography}

- Cheng X X and Turton R, The Prediction of Variability occurring in Fluidized Bed Coating Equipment, Pharmaceutical Development and Technology, 5(3), pp 311-322 (2000).

- Dury Christian M and Ristow Gerald H, Competition of Mixing and Segregation in Rotating Cylinders, Physics of Fluids, 11(6), pp 1387-1394(June 1999).

- Heinamaki Jyrki, Ruotsalainen Mirja, Lehtola Veli-Matti, Antikainen Osmo and Yliruusi Jouko, Optimization of Aqueous-Based Film Coating of Tablets Performed by a Side-Vented Pan-Coating System, Pharmaceutical Development and Technology, 2(4), pp 357-364 (1997).

- Kennedy J P and Niebergall P J, Preliminary Assessment of an Image Analysis Method for the Evaluation of Pharmaceutical Coatings, Pharmaceutical Development and Technology, 2(3), pp 205-212 (1997).

- Khakhar D V, McCarthy J J, Shinbrot Troy and Ottino J M, Transverse Flow and Mixing of Granular Materials in a Rotating Cylinder, Physics of Fluids, 9(1), pp 31-43 (January 1997 a).

- Khakhar D V, McCarthy J J and Ottino J M, Radial Segregation of Granular Materials in Rotating Cylinders, Physics of Fluids, 9(12), pp 3600-3614 (December 1997 b).

- Leaver T M, Shannon H D and Rowe R C, A Photometric Analysis of Tablet Movement in a Side-Vented Perforated Drum (Accela-Cota), J. Pharm. Pharmacol., 37, pp 17-21 (1985). 
- Mann U, Analysis of Spouted-Bed Coating and Granulation. 1. Batch Operation, Ind. Eng. Chem. Proc. Des. Dev., 22, pp 288-292 (1983).

- Mann U and Crosby E J, Cycle Time Distribution Measurements in Spouted Beds, Can. J. Chem. Eng., 53, pp 579-581 (1975)

- Mann U, Coating of Particulate Solids by Air Suspension, Ph.D. Thesis, University of Wisconsin (1972).

- Mehta Atul M, Aqueous Polymeric Coatings for Pharmaceutical Dosage Forms, Chapter8, Marcel Dekker, New York (1997).

- Mendenhall William, Beaver Robert J, Beaver Barbara M, Introduction to Probability and Statistics, Duxbury Press, Tenth Edition.

- Parker D J, Dijkstra A E, Martin T W and Seville J P K, Positron Emission Particle Tracking Studies of Spherical Particle Motion in Rotating Drums, Chemical Engineering Science, 52(13), pp 2011-2022 (1997).

- Prater D A, Wilde J S and Meakin B J, A Model System for the Production of Aqueous Tablet Film Coating for Laboratory Evaluation, J. Pharm. Pharmacol., 32, Suppl. 90P (1980).

- Porter Stuart C, Coating of Pharmaceutical Dosage Forms, Chapter 91, Remingtons Pharmaceutical Sciences, $17^{\text {th }}$ Edition, pp 1633-1643, 1985.

- Rodriguez L, Grecchi R, Cini M, Passerini N, Caputo O, and Vecchio C, Variation of Operational Parameters and Process Optimization in Aqueous Film Coating, Pharmaceutical Technology, April, pp 76-86 (1996). 
- Rowe R C and Forse S F, The Effect of Film Thickness on the Incidence of the Defect Bridging of Intagliations on Film Coated Tablets, J. Pharm. Pharmacol., 32, pp 647-648 (1980).

- Saadevandi Bram A and Turton R, The Application of Computer-Based Imaging to the Measurements of Particle Velocity and Voidage Profiles in a Fluidized Bed, Powder Technology, 98, pp 183-189 (1998).

- Shelukar Suhas, Ho Jennifer, Zega James, Roland Ed, Yeh Norman, Quiram David, Nole Anthony, Katdare Ashok, Reynolds Scott, Identification and Characterization of Factors Controlling Tablet Coating Uniformity in a Wurster Coating Process, Powder Technology, 110, pp 29-36 (2000).

- Yamane Y, Sata T, Tanaka T, Tsuji Y, Computer Simulation of Tablet Motion in Coating Drum, Pharmaceutical Research, 12, pp 1264-1268 (1995).

- Wilson Kirk E and Crossman Eli, The Influence of Tablet Shape and Pan Speed on Intra-tablet Film Coating Uniformity, Drug Dev. Ind. Pharm., 23(12), pp 1239-1243 (1997). 


\section{Appendix I: Comparison of Distributions of Surface Areas}

The method of validation of projected surface areas $\left(A_{t a b}\right)$ using three different tracer tablets has been discussed in Section 4.3.4. Experiments were conducted using each of the three tracer tablets at two different drum speeds of $6 \mathrm{rpm}$ and $9 \mathrm{rpm}$. The distributions for $A_{t a b}$ using each of the tracer tablets are shown in Figures A.1 and A.2. 


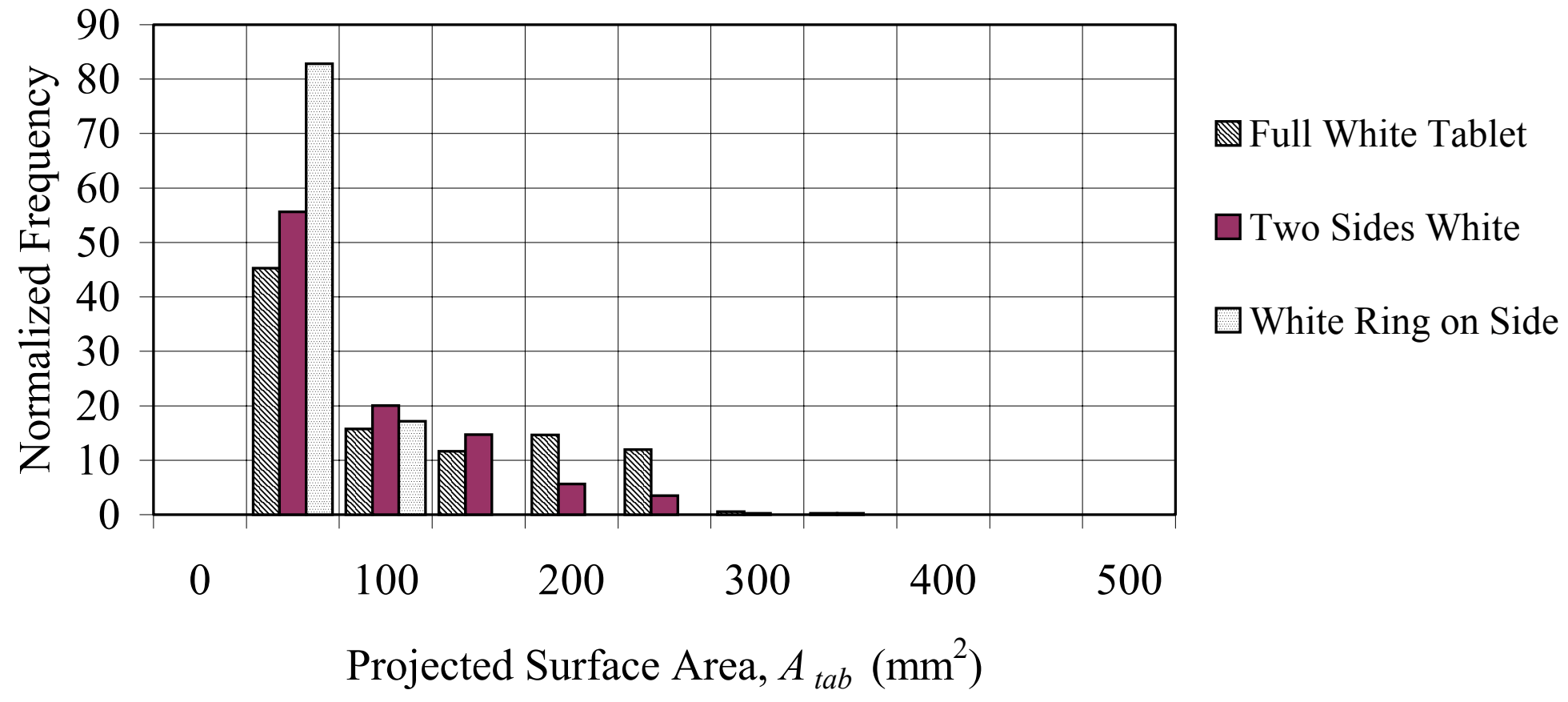

Figure A.1: Comparison of distributions of projected surface area $\left(A_{t a b}\right)$ for validation of surface area (6rpm drum speed) 


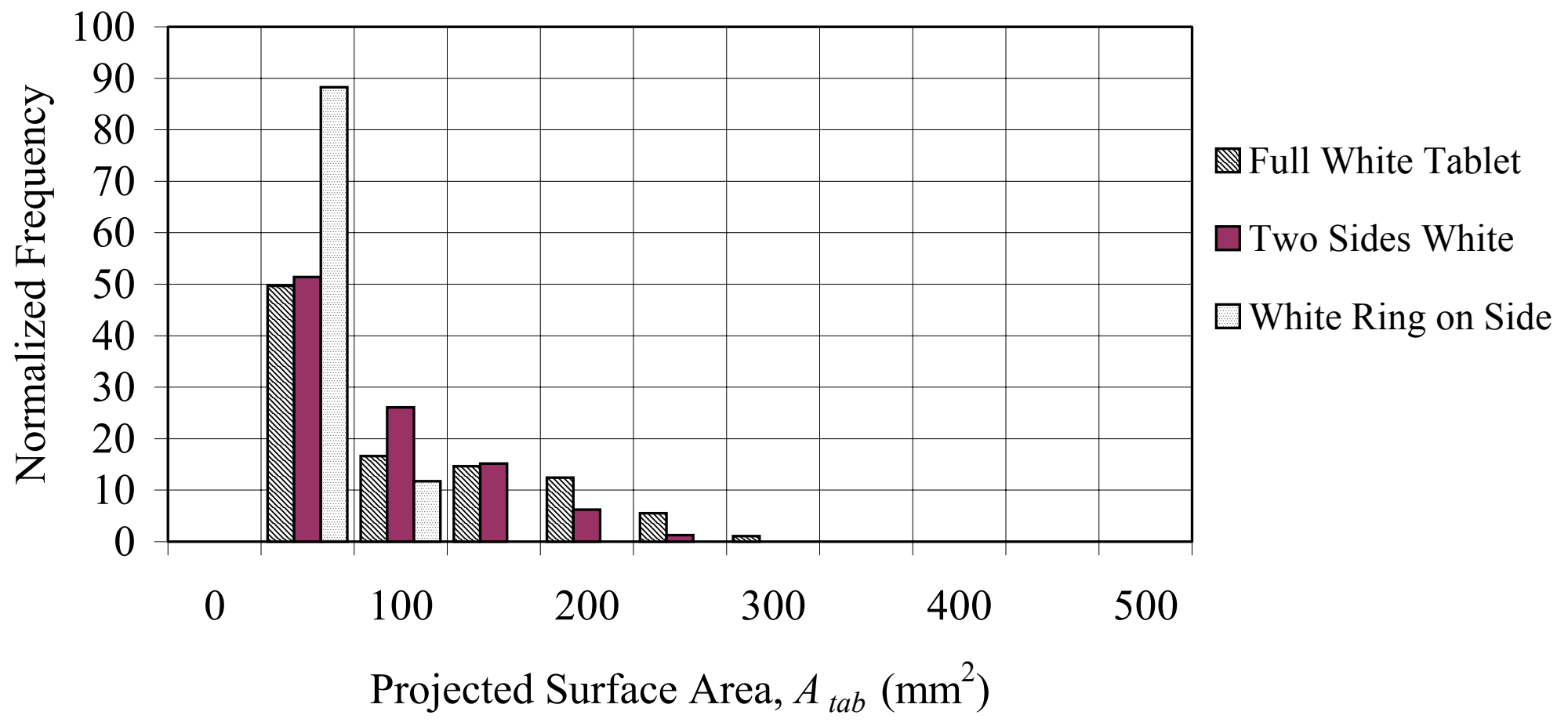

Figure A.2: Comparison of distributions of projected surface area $\left(A_{t a b}\right)$ for validation of surface area (9rpm drum speed) 


\section{Appendix II: Sherlock-32 ${ }^{\mathrm{TM}}$ Program}

The tracer particle is identified using Sherlock-32 software. A sample program used for identification and analysis of the tracer particle is given in this section. The flow instruction also saves the data obtained to a text file, which can be used for offline analysis. The program is written using Sherlock software and the flow instructions can be documented to a text file, which are shown below. Comments have been added in the program and are shown in italics.

Investigation: $\mathrm{C}:\lfloor$ Sherlock $\backslash$ Programs $\backslash$ sample code.txt

Sherlock32 Version: 6.0.0.0

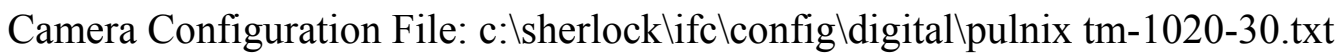

'The user can select a configuration file for the camera, which will be used for the investigation.

\section{Report Options}

Generate Reporting: 0

Standard heading: 0

Clear report screen each investigation: 0

Report SPC: 1

Auto SPC summary: 0

Serial port enable: 0

Parallel port enable: 0

Major alert message disabled 
'Declare variables used in the program during the investigation

\section{Variables}

GetCaptureTime type: Number. Init before investigate with: 0.000

PreservedTime type: Number. Init before investigate with: 0.000

blobarea type: Number Array

blobheight type: Number Array. Init before investigate with: $0.0 \ldots$

blobwidth type: Number Array. Init before investigate with: $0.0 \ldots$

occratio type: Number Array. Init before investigate with: $0.0 \ldots$

\#blobs type: Number

centx,centy type: Point. Init before investigate with: $(0.00,0.00)$

Actual distance type: Number

ActualWidth type: Number

ActualHeight type: Number

ActualArea type: Number

'The program strategy is to analyze images specified within a peek (ROI); the program runs a "connectivity" algorithm on the image and if a "blob" is found, a subroutine "Mark Time" is called to save the data needed. Otherwise all the variables are set to zero and the program is re-initiated.

\section{Strategy}

main

Blobstakeout

Get Time

MSec time 


rectA
\# Blobs
Tol Pass
call MarkTime
Tol Fail
ioctrlC
ok
return
area
cent[0]
ok
height
warktridth
occ ratio

Instruction Details

main

instruction type $=$ subroutine 
execute when called

Blobstakeout

instruction type $=$ stakeout

video source $=$ camera: 1 trigger enable $=0$

live $=0$

use Landmarks $=1$

incremental Landmarking $=1$

grid type $=$ none

grid spacing: $\mathrm{x}=100.00, \mathrm{y}=100.00$

window zoom $=1: 1$

window scroll: hor $=17$, ver $=184$

window position: left=-7,right $=1012$,top $=-4$, bottom $=906$

window state $=$ minimized

'Use "Get Time" function to save the time for the frame if the "blob" is found in ms

\section{Get Time}

instruction type $=$ formula

function:

type $=$ Get MSec time

inputs:

output readings:

MSec time

type: Number

survey: 1 
SPC: 0

store to variable: GetCaptureTime

rectA

instruction type $=$ rect peek

coordinates $=$

165,279

846,824

rotation $=0$

interpolate $=0$

leave unwrapped $=0$

display outine $=0$

display preprocess $=0$

display annotations $=0$

display readings $=0$

preprocess 0:

type $=$ Threshold

paramters:

$$
\begin{aligned}
& \text { perform? }(1=\text { yes } 0=\text { no })=1 \\
& \text { threshold }=160
\end{aligned}
$$

algorithm:

type $=$ Connectivity

paramters:

blob qty $=1$ 


$$
\begin{aligned}
& \text { blob color }=255 \\
& \text { high area }=10000 \\
& \text { low area }=75 \\
& \text { high height }=100 \\
& \text { low height }=10 \\
& \text { high width }=100 \\
& \text { low width }=10 \\
& \text { edge blobs }=1 \\
& \text { sort by }=0 \\
& \text { sort dir }=1 \\
& \text { torus split wrap }=0
\end{aligned}
$$

readings:

$$
\text { \# Blobs }
$$

type: Number

tolerence: high $=3.00$ low $=1.00$

survey: 1

SPC: 0

store to variable: \#blobs

area

type: Number Array

survey: 1

SPC: 0

store to variable: blobarea 
$\operatorname{cent}[0]$

type: Point

survey: 0

display in stakeout: 1

landmark: 0

SPC: 0

store to variable: centx,centy

height

type: Number Array

survey: 1

SPC: 0

store to variable: blobheight

width

type: Number Array

survey: 1

SPC: 0

store to variable: blobwidth

occ ratio

type: Number Array

survey: 1

SPC: 0

store to variable: occratio

ioctrlC 


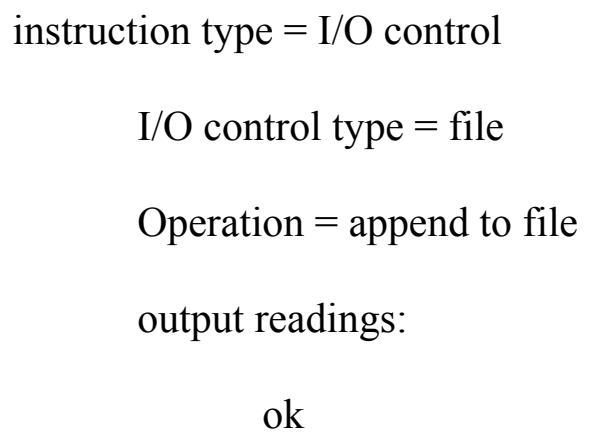

\section{MarkTime}

instruction type $=$ subroutine

execute when called

\section{CopyTime}

instruction type $=$ formula

function:

$$
\begin{aligned}
& \text { type = Copy - N } \\
& \text { inputs: }
\end{aligned}
$$

\section{GetCaptureTime}

output readings:

copy

type: Number

survey: 1

SPC: 1

store to variable: PreservedTime 
ioctrlB

instruction type $=\mathrm{I} / \mathrm{O}$ control

$\mathrm{I} / \mathrm{O}$ control type $=$ file

Operation $=$ append to file

output readings:

ok

type: Bool

survey: 0

SPC: 0 


\section{Appendix III: Calculation of Parameters}

In order to calculate the values of circulation time, surface time and projected surface area, a Microsoft Visual Basic program was used that is given in this section. The data obtained from the Sherlock software as a text file, is filtered and sorted using Microsoft Excel. This data file is then input to the Visual Basic program below (Figure A.3). This program also writes the resultant values of the parameters to a text file that can be retrieved for further analysis.

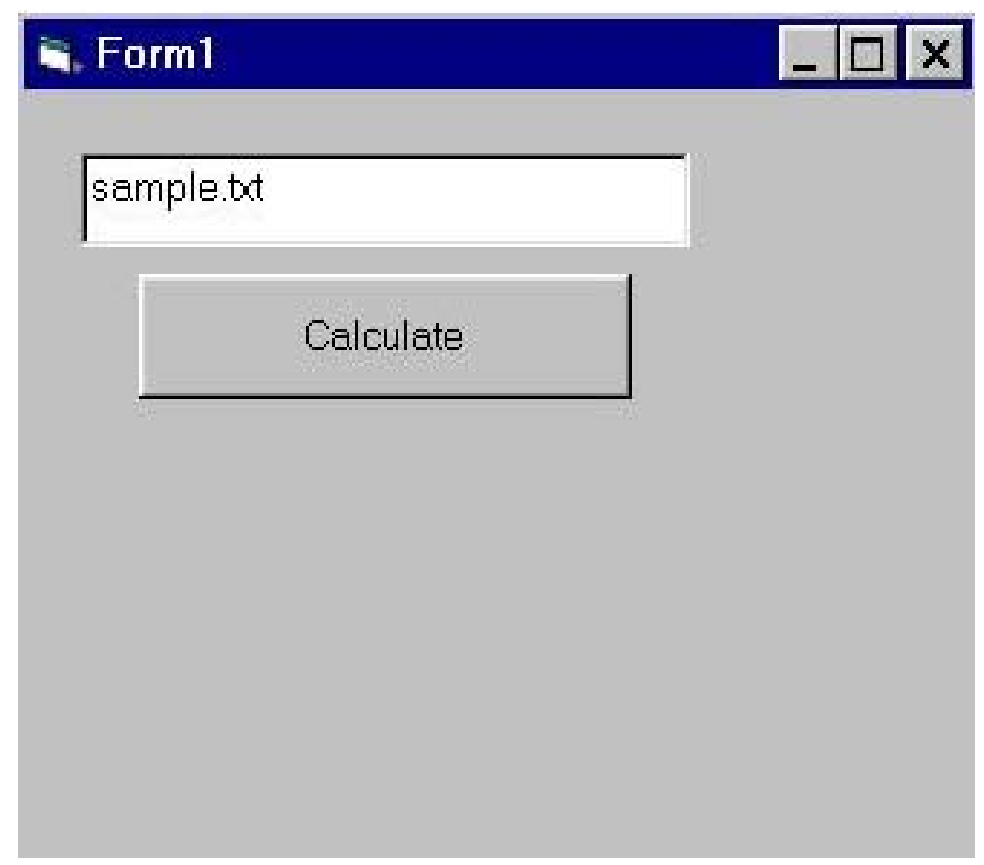

Figure A.3: Sample visual basic program used for calculation of parameters

Private Sub cmdCalc_Click()

Open App.Path \& "।" \& txtFilename For Input As \#1

Open App.Path \& "।" \& "calc" \& txtFilename For Output As \#2 
'Open the input file as \#1 and save the output as \#2

'Declare variables

Dim blob, height, width, area, cx, cy, occratio As Integer

Dim time As Double

Dim i As Integer

Dim temp1 As Double

Dim temp2 As Double

Dim circulationtime As Double

Dim surfacetime As Double

Dim recordcount As Integer

Dim flag As Integer

Dim cumarea As Integer

Const frametime $=0.04$

flag $=0$

$\mathrm{i}=0$

temp $1=0$

recordcount $=0$

cumarea $=0$

'Scan until end of file

Do While Not EOF(1)

'Read record parameters into appropriate variables

Input \#1, blob, height, width, area, cx, cy, occratio, time

'Check for a "blob" of 1 
If blob $>0$ Then

If (flag $=0)$ Then

Store the time for first record with "blob" $=1$, to calculate circulation time temp $1=$ time

flag $=1$

End If

'Calculate circulation time by specifying a window $>=500 \mathrm{~ms}$. Count the number of records per pass and calculate surface time.

If (time - temp1) >= 500 Then

circulationtime $=($ time - temp 1$) / 1000$

surfacetime $=$ recordcount $*$ frametime

'Write output to file \#2

Write \#2, blob, height, width, area, cx, cy, occratio, time, circulationtime, recordcount, surfacetime, cumarea

'Initialize for next segment

temp $1=$ time

recordcount $=1$

cumarea $=$ area

Else

'Calculate the record count and cumulative area per pass

recordcount $=$ recordcount +1

cumarea $=$ cumarea + area

End If 


$$
\mathrm{i}=\mathrm{i}+1
$$

End If

Loop

'Output values for the last record

surfacetime $=$ recordcount $*$ frametime

circulationtime $=9999999$

Write \#2, blob, height, width, area, cx, cy, occratio, time, circulationtime, recordcount, surfacetime, cumarea

lblCount.Caption $=$ "Found " \& i \& " records with blob 1"

lblCount. Visible $=$ True

Close \#1

Close \#2

End Sub 


\section{Appendix IV: Calculation of Velocity}

To calculate the surface velocities of the particles, a Microsoft Visual Basic program was used. The data obtained from the Sherlock software as a text file, is filtered and sorted using Microsoft Excel. This data file is again input to the Visual Basic program below (Figure A.4). The input parameters necessary for this program are the name of the data file (text file) and the size of the tablets used. This program also writes the resultant values of the parameters to a text file, which can be used for further analysis.

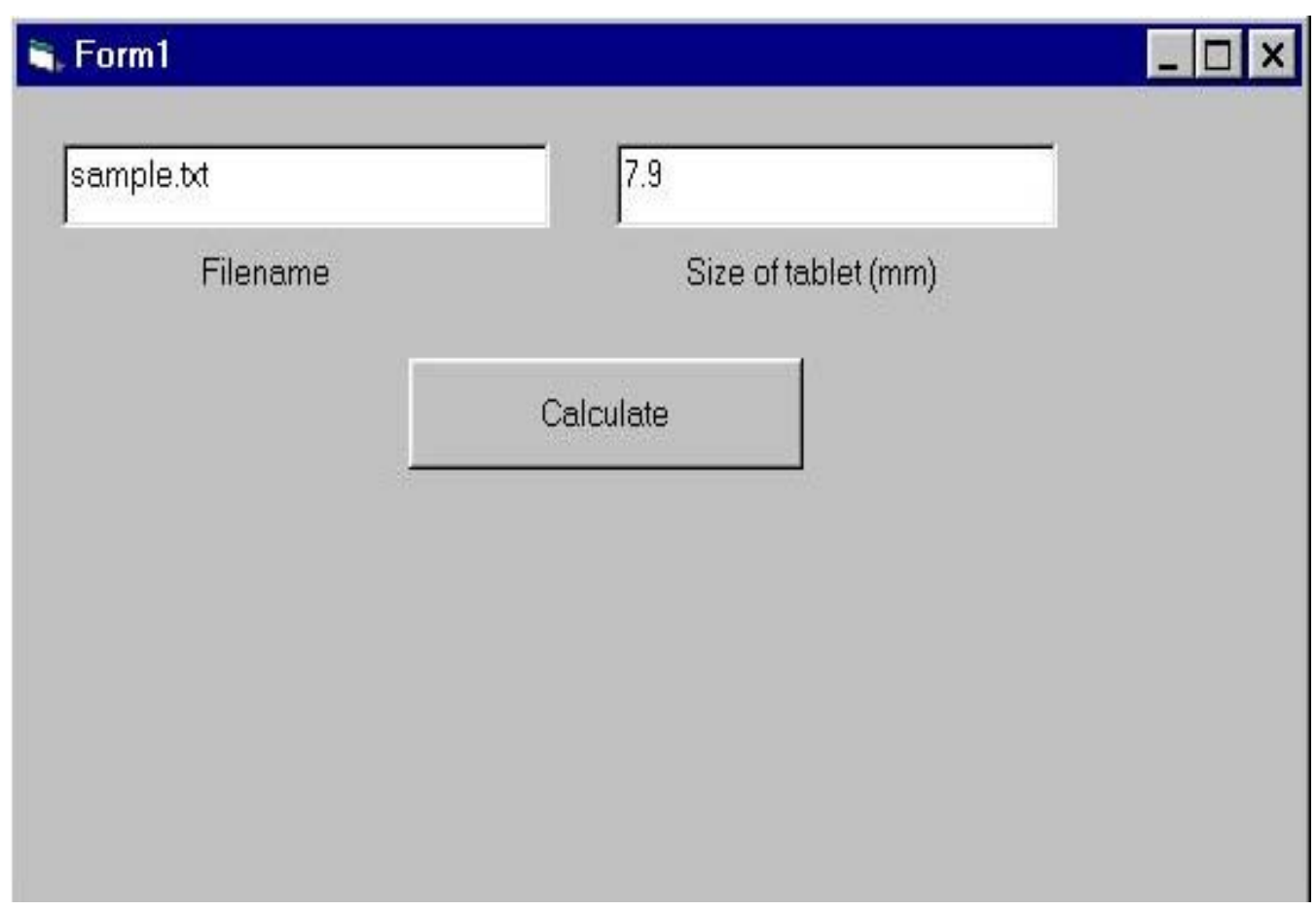

Figure A.4: Sample visual basic program to calculate surface velocity

Private Sub cmdCalc_Click()

Open App.Path \& "।" \& txtFilename For Input As \#1

Open App.Path \& "\" \& "vel" \& txtFilename For Output As \#2 
'Open the input file as \#1 and save the output as \#2 and declare variables

Dim blob, height, width, area, cx, cy, occratio As Integer

Dim time As Double

Dim Amax As Integer

Dim Dpixel As Double

Dim factor As Double

Dim vx As Double

Dim vy As Double

Dim prevx, prevy As Double

Dim prevflag As Integer

Dim prevt As Double

velflag $=0$

$\operatorname{Amax}=0$

'Calculate maximum area from the input file and save as Amax

Do While Not EOF(1)

Input \#1, blob, height, width, area, cx, cy, occratio, time

If Amax < area Then

$\operatorname{Amax}=$ area

End If

Loop

Close \#1

MsgBox ("amax " \& Amax)

'Calculate dpixel from Amax 
Dpixel $=\operatorname{Sqr}(4 * A \max / 3.1428)$

'Calculate factor for conversion of values from pixel to SI units

factor $=$ txtSize $/$ Dpixel

Open App.Path \& "।" \& txtFilename For Input As \#1

'Scan until end of file

Do While Not EOF(1)

'Read record parameters into appropriate variables

Input \#1, blob, height, width, area, cx, cy, occratio, time

If $(\mathrm{blob}=0)$ Then

prevflag $=0$

End If

'Calculate velocities from $(x, y)$ position and time data

$$
\begin{aligned}
& \text { If }(\text { prevflag }=1) \text { Then } \\
& \mathrm{vx}=(\mathrm{cx} * \text { factor }- \text { prevx }) * 1000 /(\text { time }- \text { prevt }) \\
& \mathrm{vy}=(\mathrm{cy} * \text { factor }- \text { prevy }) * 1000 /(\text { time }- \text { prevt })
\end{aligned}
$$

'Save data to file \#2

Write \#2, blob, cx * factor, cy * factor, time, vx, vy

\section{End If}

'Convert from pixels to SI units

$$
\begin{aligned}
& \text { If blob }>0 \text { Then } \\
& \text { prevx }=c x * \text { factor } \\
& \text { prevy }=c y * \text { factor } \\
& \text { prevt }=\text { time }
\end{aligned}
$$




$$
\text { prevflag }=1
$$

Else

$$
\text { prevflag }=0
$$

End If

Loop

Close \#1

Close \#2

End Sub 


\section{Appendix V: Method of Calculation of Statistical Parameters}

\section{Standard Deviation:}

The standard deviation $(\sigma)$ of a sample is a measure of how widely values are dispersed from the average value. It is calculated using equation A1. If a set of numbers (in this case, $\tau_{\text {circ }}, \tau_{\text {surface }}, A_{\text {tab }}$, and $V_{y}$ ) is close to the average of those values, then the standard deviation is expected to be low. In contrast, if the set of numbers is spread across a greater range, it may present a high standard deviation. It is desirable to have a sample population with low standard deviation.

$$
\sigma=\sqrt{\frac{n \sum x^{2}-\left(\sum x\right)^{2}}{n(n-1)}}
$$

where $x=$ sample value

$n=$ sample size of the population

\section{Confidence Intervals:}

Another measure of variability is the confidence interval, which is a range on either side of a sample mean, within which the population value is likely to fall. $\alpha$ is the significance level used to compute the confidence level. The confidence level equals $100 *(1-\alpha) \%$, or in other words, an $\alpha$ value equal to 0.05 indicates a 95 percent confidence level. Thus it is expected that $95 \%$ of the data would be within 1.96 standard deviations of the mean. This is called a $95 \%$ confidence interval for the sample and is calculated using equation A2.

$$
x_{a v g} \pm 1.96\left(\frac{\sigma}{\sqrt{n}}\right)
$$


where $x_{a v g}=$ mean of the sample population

$\sigma=$ standard deviation of the population

$n=$ sample size of the population

\section{Student's t-test:}

In order to correlate between two samples and determine if the mean from the two samples are statistically different from each other, a student's t-test is used. The formula used for the t-test is a ratio. The numerator is the difference between the two means and the denominator is a measure of the variability or dispersion of the scores. The statistical value of $\mathrm{t}$ (t-statistic) is calculated using Equation A.3. The degrees of freedom $(d f)$ are calculated using Equation A.4.

$$
\begin{gathered}
t-\text { statistic }=\frac{x_{1}-x_{2}-\Delta}{\sqrt{\frac{S_{1}^{2}}{n_{1}}+\frac{S_{2}^{2}}{n_{2}}}} \\
d f=\frac{\left(\frac{S_{1}^{2}}{n_{1}}+\frac{S_{2}^{2}}{n_{2}}\right)^{2}}{\frac{\left(S_{1}^{2} / n_{1}\right)^{2}}{\left(n_{1}-1\right)}+\frac{\left(S_{2}^{2} / n_{2}\right)^{2}}{\left(n_{2}-1\right)}}
\end{gathered}
$$

where $x_{\text {lavg }}=$ mean of sample 1

$$
\begin{aligned}
& x_{2 a v g}=\text { mean of sample } 2 \\
& S_{1}=\text { standard deviation of sample } 1 \\
& S_{2}=\text { standard deviation of sample } 2 \\
& n_{1}=\text { size of sample } 1
\end{aligned}
$$


$n_{2}=$ size of sample 2

$\Delta=$ hypothesized mean difference ( 0 for null hypothesis)

The values of the t-statistic are then compared with the critical value of $t(t-$ critical) based on the degrees of freedom $(d f)$ and $95 \%$ confidence interval, from the tabulated values for a standard t-distribution. The rejection of the hypothesis for a onetailed test is $t$-statistic $>t$-critical. For a two-tailed test, the rejection region is $t$-statistic $>t$-critical or $t$-statistic $<-t$-critical (or p-value $<0.05$ ). If the hypothesis is rejected, then there is significant difference in the variances or means between the two sample populations; else it can be assumed that the means or variances from the two samples are statistically equal. 


\section{Appendix VI: Statistical Analysis Results}

The responses that are generated in an experimental situation always exhibit a certain amount of variability. In an Analysis of Variance (ANOVA), the total variation in the response measurements is divided into portions that may be attributed to the various factors of interest. If the experiment has been properly designed, these portions can be used to answer questions about the effects of various factors on the response on interest. Standard Analysis of Variance (ANOVA) tests as mentioned in Section 5.5, were conducted using the results obtained for all the parameters, to study the effect of the process variables. The independent variables considered in a full factorial design were drum rotation rate $(D R)$, drum loading $(D L)$, tablet size $(T S)$ and baffles $(B)$. The dependent variables were $\tau_{\text {circ }}, \tau_{\text {surface }}, A_{t a b}$ and $V_{y}$. The effect due to interactions between the variables was also studied. The results obtained for each of the parameters are detailed in this section. The effect of any variable is considered significant when $\mathrm{p}<0.05$, where $\mathrm{p}$ is the probability. JMP ${ }^{\circledR}$ software (SAS Institute Inc., Cary, NC) was used for the statistical analysis. 


\section{Circulation Time $\left(\tau_{c i r c}\right)$}

\begin{tabular}{|c|c|c|c|c|}
\hline Source & $\begin{array}{c}\text { Degrees of } \\
\text { Freedom }\end{array}$ & Sum of Squares & F Ratio & Probability>F \\
\hline$B$ & 1 & 0.07 & 0.19 & 0.67 \\
\hline$T S$ & 2 & 103.92 & 133.18 & 0.00 \\
\hline$D L$ & 1 & 206.95 & 530.47 & 0.00 \\
\hline$D R$ & 2 & 116.01 & 148.68 & 0.00 \\
\hline$B^{*} T S$ & 2 & 4.55 & 5.83 & 0.01 \\
\hline$B^{*} D L$ & 1 & 13.39 & 34.33 & 0.00 \\
\hline$T S^{*} D L$ & 2 & 7.73 & 9.91 & 0.00 \\
\hline$B^{*} D R$ & 2 & 1.72 & 2.21 & 0.14 \\
\hline$T S^{*} D R$ & 4 & 1.72 & 1.10 & 0.14 \\
\hline$D L^{*} D R$ & 2 & 7.12 & 9.13 & 0.00 \\
\hline$B^{*} T S^{*} D L$ & 2 & 1.24 & 1.59 & 0.23 \\
\hline$B^{*} T S^{*} D R$ & 4 & 4.54 & 2.91 & 0.06 \\
\hline$B^{*} D L^{*} D R$ & 2 & 2.45 & 3.14 & 0.07 \\
\hline$T S^{*} D L^{*} D R$ & 4 & 1.28 & 0.82 & 0.53 \\
\hline$B^{*} T S^{*} D L^{*} D R$ & 4 & 4.24 & 2.72 & 0.07 \\
\hline
\end{tabular}

Table A.1: ANOVA results for $\tau_{\text {circ }}$ 
2. Surface Time ( $\left.\tau_{\text {surface }}\right)$

\begin{tabular}{|c|c|c|c|c|}
\hline Source & $\begin{array}{c}\text { Degrees of } \\
\text { Freedom }\end{array}$ & Sum of Squares & F Ratio & Probability $>$ F \\
\hline$B$ & 1 & 0.00043 & 31.45 & 0.00 \\
\hline$T S$ & 2 & 0.00075 & 27.21 & 0.00 \\
\hline$D L$ & 2 & 0.04273 & 3088.16 & 0.00 \\
\hline$D R$ & 2 & 0.02331 & 842.41 & 0.00 \\
\hline$B^{*} T S$ & 1 & 0.00003 & 1.27 & 0.31 \\
\hline$B^{*} D L$ & 2 & 0.00119 & 85.86 & 0.00 \\
\hline$T S^{*} D L$ & 2 & 0.00084 & 30.25 & 0.00 \\
\hline$B^{*} D R$ & 4 & 0.00001 & 0.36 & 0.70 \\
\hline$T S^{*} D R$ & 2 & 0.00057 & 10.28 & 0.00 \\
\hline$D L * D R$ & 2 & 0.00347 & 125.47 & 0.00 \\
\hline$B^{*} T S^{*} D L$ & 4 & 0.00000 & 0.24 & 0.79 \\
\hline$B^{*} T S^{*} D R$ & 2 & 0.00021 & 3.73 & 0.02 \\
\hline$B^{*} D L * D R$ & 4 & 0.00007 & 2.45 & 0.12 \\
\hline$T S^{*} D L * D R$ & 0.00076 & 13.81 & 0.00 \\
\hline$B^{*} T S^{*} D L * D R$ & & 0.00007 & 1.40 & 0.28 \\
\hline
\end{tabular}

Table A.2: ANOVA results for $\tau_{\text {surface }}$ 


\section{Projected Surface Area $\left(A_{t a b}\right)$}

\begin{tabular}{|c|c|r|r|c|}
\hline Source & $\begin{array}{c}\text { Degrees of } \\
\text { Freedom }\end{array}$ & Sum of Squares & F Ratio & Probability $>\mathrm{F}$ \\
\hline$B$ & 1 & 1593.40 & 276.73 & 0.00 \\
\hline$T S$ & 2 & 188865.73 & 1638.22 & 0.00 \\
\hline$D L$ & 1 & 6394.28 & 1110.50 & 0.00 \\
\hline$D R$ & 2 & 7213.32 & 626.37 & 0.00 \\
\hline$B^{*} T S$ & 2 & 68.83 & 5.98 & 0.01 \\
\hline$B^{*} D L$ & 1 & 3295.06 & 572.26 & 0.00 \\
\hline$T S^{*} D L$ & 2 & 3478.08 & 302.02 & 0.00 \\
\hline$B^{*} D R$ & 2 & 20.27 & 1.76 & 0.20 \\
\hline$T S^{*} D R$ & 4 & 3210.41 & 139.39 & 0.00 \\
\hline$D L^{*} D R$ & 2 & 1315.00 & 114.19 & 0.00 \\
\hline$B^{*} T S^{*} D L$ & 2 & 38.09 & 3.31 & 0.06 \\
\hline$B^{*} T S^{*} D R$ & 4 & 196.04 & 8.51 & 0.00 \\
\hline$B^{*} D L^{*} D R$ & 2 & 69.86 & 6.07 & 0.01 \\
\hline$T S^{*} D L^{*} D R$ & 4 & 998.75 & 43.36 & 0.00 \\
\hline$B^{*} T S^{*} D L^{*} D R$ & 4 & 526.20 & 22.85 & 0.00 \\
\hline
\end{tabular}

Table A.3: ANOVA results for $A_{t a b}$ 
4. Normalized Area $\left(A_{t a b} / D^{2}\right)$

\begin{tabular}{|c|c|r|r|c|}
\hline Source & $\begin{array}{c}\text { Degrees of } \\
\text { Freedom }\end{array}$ & Sum of Squares & F Ratio & Probability $>$ F \\
\hline$B$ & 1 & 4796.25 & 575.46 & 0.00 \\
\hline$T S$ & 2 & 16.99 & 1.02 & 0.38 \\
\hline$D L$ & 1 & 10208.57 & 1224.57 & 0.00 \\
\hline$D R$ & 2 & 12750.80 & 764.76 & 0.00 \\
\hline$B^{*} T S$ & 2 & 1058.55 & 63.49 & 0.00 \\
\hline$B^{*} D L$ & 1 & 8622.231 & 1034.28 & 0.00 \\
\hline$T S^{*} D L$ & 2 & 1192.38 & 71.52 & 0.00 \\
\hline$B^{*} D R$ & 2 & 76.29 & 4.58 & 0.03 \\
\hline$T S^{*} D R$ & 4 & 550.52 & 16.51 & 0.00 \\
\hline$D L^{*} D R$ & 2 & 1847.07 & 110.78 & 0.00 \\
\hline$B^{*} T S^{*} D L$ & 2 & 859.84 & 51.57 & 0.00 \\
\hline$B^{*} T S^{*} D R$ & 4 & 458.92 & 13.76 & 0.00 \\
\hline$B^{*} D L^{*} D R$ & 2 & 26.69 & 1.60 & 0.23 \\
\hline$T S^{*} D L^{*} D R$ & 4 & 923.37 & 27.69 & 0.00 \\
\hline$B^{*} T S^{*} D L^{*} D R$ & 4 & 680.54 & 20.41 & 0.00 \\
\hline
\end{tabular}

Table A.4: ANOVA results for $A_{t a b} / D^{2}$ 
5. Surface Velocity $\left(V_{y}\right)$

\begin{tabular}{|c|c|c|c|c|}
\hline Source & $\begin{array}{c}\text { Degrees of } \\
\text { Freedom }\end{array}$ & Sum of Squares & F Ratio & Probability $>$ F \\
\hline$B$ & 1 & 1377.19 & 6.57 & 0.02 \\
\hline$T S$ & 2 & 9121.76 & 21.75 & 0.00 \\
\hline$D L$ & 1 & 465421.44 & 2219.56 & 0.00 \\
\hline$D R$ & 2 & 145593.30 & 347.16 & 0.00 \\
\hline$B^{*} T S$ & 2 & 5977.75 & 14.25 & 0.00 \\
\hline$B^{*} D L$ & 1 & 28456.81 & 135.71 & 0.00 \\
\hline$T S^{*} D L$ & 2 & 7792.65 & 18.58 & 0.00 \\
\hline$B^{*} D R$ & 2 & 746.64 & 1.78 & 0.20 \\
\hline$T S^{*} D R$ & 4 & 289.67 & 0.35 & 0.84 \\
\hline$D L^{*} D R$ & 2 & 995.31 & 2.37 & 0.12 \\
\hline$B^{*} T S^{*} D L$ & 2 & 1399.40 & 3.34 & 0.06 \\
\hline$B^{*} T S^{*} D R$ & 4 & 1323.72 & 1.58 & 0.22 \\
\hline$B^{*} D L^{*} D R$ & 2 & 2560.36 & 6.11 & 0.01 \\
\hline$T S^{*} D L^{*} D R$ & 4 & 2054.02 & 2.45 & 0.08 \\
\hline$B^{*} T S^{*} D L^{*} D R$ & 4 & 993.06 & 1.18 & 0.35 \\
\hline
\end{tabular}

Table A.5: ANOVA results for $V_{y}$ 


\section{Appendix VII: Effect of Process Variables on Tablet Bed}

\section{Surface Angle}

The effect of process variables specifically drum speed and drum loading on the angle formed at the surface of the tablet bed were investigated using $7.9 \mathrm{~mm}(5 / 16 \mathrm{inch})$ tablets. The results (shown in Table A.6) indicate that with an increase in tablet bed loading, the angle formed at the bed surface $(\theta)$ is steeper which may be a result of increased friction between the tablet bed and the drum at higher drum loadings. Thus the tablets move through the spray zone at higher velocities and hence record lower surface times. With an increase in the drum speed, there is an increase in the bed angle formed which may result in lower surface times. The force due to gravity acting in the direction of flow of tablets is a factor of cosine $(90-\theta)$.

\begin{tabular}{|c|c|c|c|}
\hline $\begin{array}{c}\text { Drum Speed } \\
(\mathrm{RPM})\end{array}$ & $\begin{array}{c}\text { Drum Loading } \\
\text { (Fill) }\end{array}$ & Angle $\left(\theta^{0}\right)$ & cosine (90- $\theta)$ \\
\hline 4.3 & $1 / 8$ & 28 & 0.47 \\
\hline 4.3 & $1 / 4$ & 35 & 0.57 \\
\hline 7.5 & $1 / 8$ & 34 & 0.56 \\
\hline 7.5 & $1 / 4$ & 38 & 0.61 \\
\hline
\end{tabular}

Table A.6: Effect of process variables on the angle formed at the surface of tablet bed 


\section{Appendix VIII: Comparison of Tablet Weights}

A random sample of the black tablets used in the study was weighed and compared with the tracer tablets for the three different sizes of tablets used. A standard ttest assuming equal variances was used to compare the weights of the tablets used in this work. The results are given in Tables A.7, A.8, and A.9. All the results show that there are no statistical differences in the means or variances of the black tablets when compared with the tracer tablets. These results support the assumption that the tracer tablets used have similar properties as the black bed of tablets. 


\section{$6.3 \mathrm{~mm}$ Tablets}

\begin{tabular}{|c|c|c|}
\hline Description & Black Tablet & Tracer Tablet \\
\hline Tablet Weight 1 (mg) & 104.1 & 105.0 \\
\hline Tablet Weight 2 (mg) & 105.0 & 106.0 \\
\hline Tablet Weight 3 (mg) & 105.3 & 104.9 \\
\hline Tablet Weight 4 (mg) & 105.5 & 105.4 \\
\hline Tablet Weight 5 (mg) & 105.7 & 106.0 \\
\hline Tablet Weight 6 (mg) & 105.2 & 106.0 \\
\hline Tablet Weight 7 (mg) & 106.3 & 106.2 \\
\hline Tablet Weight 8 (mg) & 106.2 & 105.6 \\
\hline Tablet Weight 9 (mg) & 106.0 & 104.2 \\
\hline Tablet Weight $10(\mathrm{mg})$ & 105.7 & 104.0 \\
\hline Mean Weight (mg) & 105.5 & 105.3 \\
\hline Standard Deviation (mg) & 0.65 & 0.78 \\
\hline $\pm 95 \%$ Confidence Interval (mg) & 0.46 & 0.56 \\
\hline Degrees of Freedom & \multicolumn{2}{|c|}{18} \\
\hline t-statistic & \multicolumn{2}{|c|}{0.53} \\
\hline $\mathrm{P}(\mathrm{T} \leq \mathrm{t})$ two-tail & \multicolumn{2}{|c|}{0.60} \\
\hline t-critical two-tail & \multicolumn{2}{|c|}{2.10} \\
\hline Summary & \multicolumn{2}{|c|}{ means are statistically equal } \\
\hline
\end{tabular}

Table A.7: Comparison of tablet weights for $6.3 \mathrm{~mm}$ tablets 
$7.9 \mathrm{~mm}$ Tablets

\begin{tabular}{|c|c|c|}
\hline Description & Black Tablet & Tracer Tablet \\
\hline Tablet Weight 1 (mg) & 208.3 & 207.3 \\
\hline Tablet Weight 2 (mg) & 210.2 & 207.0 \\
\hline Tablet Weight 3 (mg) & 208.8 & 207.3 \\
\hline Tablet Weight 4 (mg) & 209.5 & 207.3 \\
\hline Tablet Weight 5 (mg) & 206.7 & 208.6 \\
\hline Tablet Weight 6 (mg) & 207.2 & 205.5 \\
\hline Tablet Weight 7 (mg) & 208.5 & 206.8 \\
\hline Tablet Weight 8 (mg) & 208.6 & 208.5 \\
\hline Tablet Weight 9 (mg) & 211.1 & 210.6 \\
\hline Tablet Weight 10 (mg) & 209.3 & 207.2 \\
\hline Mean Weight (mg) & 208.8 & 207.6 \\
\hline Standard Deviation (mg) & 1.31 & 1.36 \\
\hline $\pm 95 \%$ Confidence Interval (mg) & 0.93 & 0.97 \\
\hline Degrees of Freedom & \multicolumn{2}{|c|}{18} \\
\hline t-statistic & \multicolumn{2}{|c|}{2.03} \\
\hline $\mathrm{P}(\mathrm{T} \leq \mathrm{t})$ two-tail & \multicolumn{2}{|c|}{0.06} \\
\hline t-critical two-tail & \multicolumn{2}{|c|}{2.10} \\
\hline Summary & \multicolumn{2}{|c|}{ means are statistically equal } \\
\hline
\end{tabular}

Table A.8: Comparison of tablet weights for $7.9 \mathrm{~mm}$ tablets 


\section{$10.4 \mathrm{~mm}$ Tablets}

\begin{tabular}{|c|c|c|}
\hline Description & Black Tablet & Tracer Tablet \\
\hline Tablet Weight 1 (mg) & 412.3 & 415.5 \\
\hline Tablet Weight 2 (mg) & 426.1 & 413.7 \\
\hline Tablet Weight 3 (mg) & 418.8 & 416.2 \\
\hline Tablet Weight 4 (mg) & 410.2 & 412.1 \\
\hline Tablet Weight 5 (mg) & 424.9 & 415.8 \\
\hline Tablet Weight 6 (mg) & 417.3 & 409.5 \\
\hline Tablet Weight 7 (mg) & 411.1 & 409.3 \\
\hline Tablet Weight 8 (mg) & 418.6 & 415.3 \\
\hline Tablet Weight 9 (mg) & 417.6 & 417.3 \\
\hline Tablet Weight 10 (mg) & 416.3 & 417.0 \\
\hline Mean Weight (mg) & 417.3 & 414.2 \\
\hline Standard Deviation (mg) & 5.31 & 2.93 \\
\hline $\pm 95 \%$ Confidence Interval (mg) & 3.80 & 2.10 \\
\hline Degrees of Freedom & \multicolumn{2}{|c|}{18} \\
\hline t-statistic & \multicolumn{2}{|c|}{1.64} \\
\hline $\mathrm{P}(\mathrm{T} \leq \mathrm{t})$ two-tail & \multicolumn{2}{|c|}{0.12} \\
\hline t-critical two-tail & \multicolumn{2}{|c|}{2.10} \\
\hline Summary & \multicolumn{2}{|c|}{ means are statistically equal } \\
\hline
\end{tabular}

Table A.9: Comparison of tablet weights for $10.4 \mathrm{~mm}$ tablets 